\title{
Future Potential of Hybrid and Diesel Powertrains in the U.S. Light-Duty Vehicle Market
}

\section{August 2004}

David L. Greene

Oak Ridge National Laboratory

K. G. Duleep

Energy \& Environmental Analysis, Inc.

Walter McManus

J. D. Power and Associates 


\title{
DOCUMENT AVAILABILITY
}

Reports produced after January 1,1996, are generally available free via the U.S. Department of Energy (DOE) Information Bridge:

Web site: http://www.osti.gov/bridge

Reports produced before January 1, 1996, may be purchased by members of the public from the following source:

\author{
National Technical Information Service \\ 5285 Port Royal Road \\ Springfield, VA 22161 \\ Telephone: 703-605-6000 (1-800-553-6847) \\ TDD: 703-487-4639 \\ Fax: $703-605-6900$ \\ E-mail: info@ ntis.fedworld.gov \\ Web site: http://www.ntis.gov/support/ordernowabout.htm
}

Reports are available to DOE employees, DOE contractors, Energy Technology Data Exchange (ETDE) representatives, and International Nuclear Information System (INIS) representatives from the following source:

Office of Scientific and Technical Information

P.O. Box 62

Oak Ridge, TN 37831

Telephone: 865-576-8401

Fax: 865-576-5728

E-mail: reports@adonis.osti.gov

Web site: http://www.osti.gov/contact.html

This report was prepared as an account of work sponsored by an agency of the United States Government. Neither the United States government nor any agency thereof, nor any of their employees, makes any warranty, express or implied, or assumes any legal liability or responsibility for the accuracy, completeness, or usefulness of any information, apparatus, product, or process disclosed, or represents that its use would not infringe privately owned rights. Reference herein to any specific commercial product, process, or service by trade name, trademark, manufacturer, or otherwise, does not necessarily constitute or imply its endorsement, recommendation, or favoring by the United States Government or any agency thereof. The views and opinions of authors expressed herein do not necessarily state or reflect those of the United States Government or any agency thereof. 


\title{
FUTURE POTENTIAL OF HYBRID AND DIESEL POWERTRAINS IN THE U.S. LIGHT-DUTY VEHICLE MARKET
}

\author{
David L. Greene \\ Oak Ridge National Laboratory \\ National Transportation Research Center \\ 2360 Cherahala Boulevard \\ Knoxville, TN 37932 \\ K.G. Duleep \\ Energy \& Environmental Analysis, Inc. \\ 1655 North Fort Meyer Drive, Suite 600 \\ Arlington, VA 22209 \\ Walter McManus \\ J.D. Power and Associates \\ 5435 Corp Drive, Suite 300 \\ Troy, MI 48098
}

August 20, 2004

Prepared by the

OAK RIDGE NATIONAL LABORATORY

P.O. BOX 2008

Oak Ridge, Tennessee 37830

managed by

UT-Battelle, LLC

for the

U.S. DEPARTMENT OF ENERGY

under contract No. DE-AC0500OR22725 



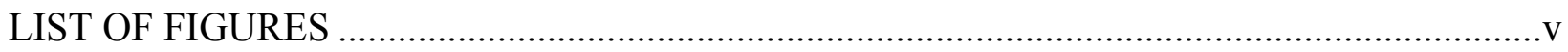

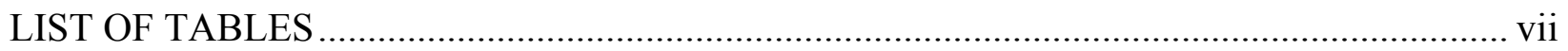

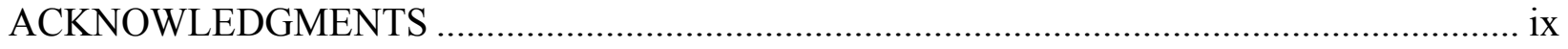

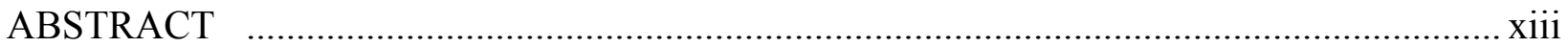

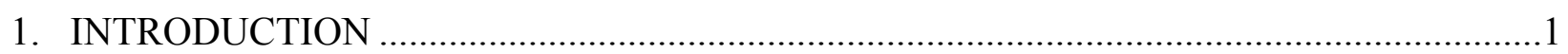

2. HYBRID AND DIESEL TECHNOLOGY STATUS AND PROSPECTS .................................

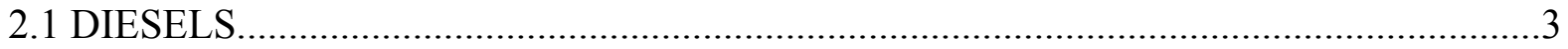

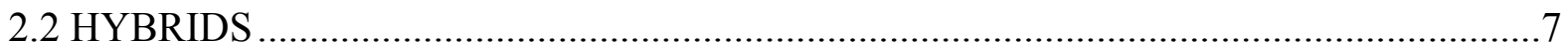

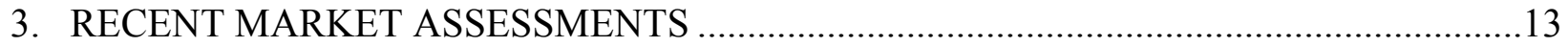

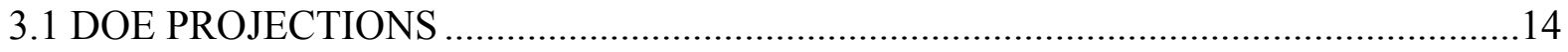

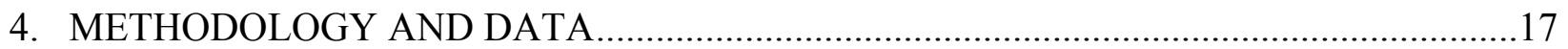

4.1 SCENARIOS OF DIESEL AND HYBRID INTRODUCTIONS ……............................17

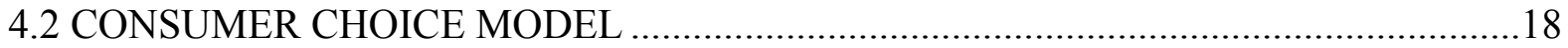

4.3 MARKET SEGMENTATION AND CHOICE MODEL STRUCTURE ………...............20

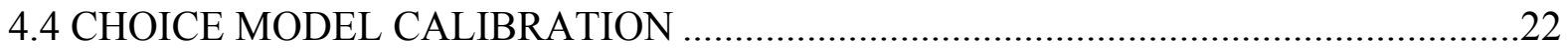

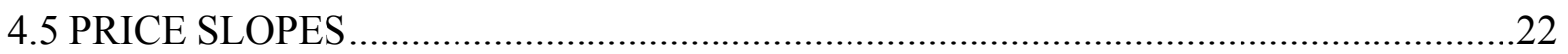

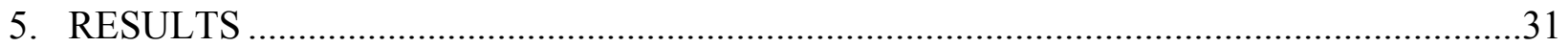

5.1 THE LONG-RUN POTENTIAL MARKET SHARES OF DIESEL AND HYBRID

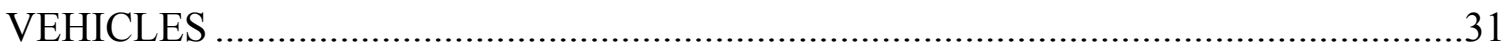

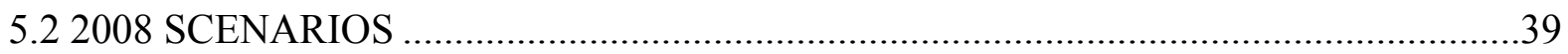

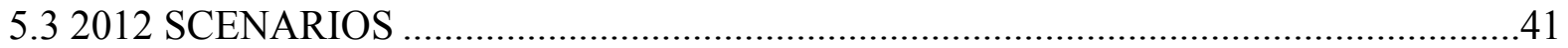

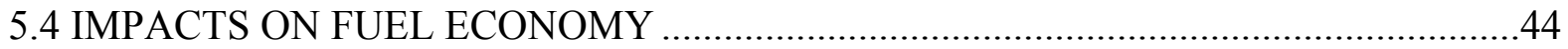

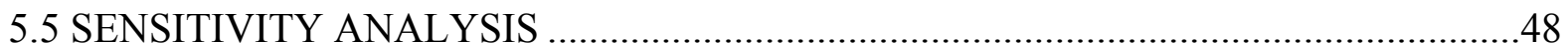

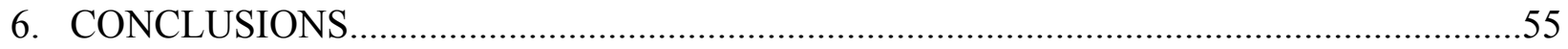

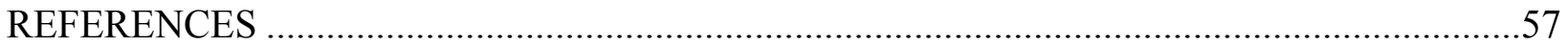

APPENDIX A: CALCULATION OF CONFIGURATION AND CLASS CONSTANTS..........63

APPENDIX B: ASSUMED PRODUCT INTRODUCTIONS ……………………….................67

APPENDIX C: CHARACTERISTICS OF DIESEL AND HYBRID PRODUCT LINES

FOR WHICH THRE IS NO MODEL YEAR 2002 COUNTERPART …...............................77 



\section{LIST OF FIGURES}

Figure

Page

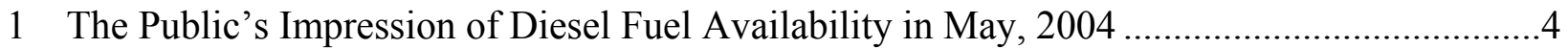

2 Diesel Vehicle Owners' Views on Clean Diesel Vehicles ......................................................

3 Gasoline Vehicle Owners' Views on Clean Diesel Vehicles ...................................................6

4 Gasoline Vehicle Owners' Views on Hybrid-Electric Vehicles...............................................

5 Hybrid-Electric Vehicle Owners' Views on Hybrid-Electric Vehicles .......................................

6 Intent to Purchase Diesel or Hybrid-Electric Vehicle............................................................13

7 Projections of Light-Duty Hybrid and Diesel Market Shares................................................14

8 Projected Diesel Market Shares in the United States................................................................

9 Nested Multinomial Logit Model Structure and Approximate Price Elasticities ......................20

10 Power Functions Describing the Cost of Limited Fuel Availability.......................................28

11 Technology Market Shares by Vehicle Type >2012 Diesel Only Scenario ............................33

12 Makes, Models, Configurations by Vehicle Type >2012 Diesel Only Scenario........................33

13 Technology Market Shares by Vehicle Type > 2012 Full Hybrid Scenario................................34

14 Makes, Models, Configurations by Vehicle Type >2012 Full Hybrid Scenario ........................35

15 Technology Market Shares by Vehicle Type >2012 Diesel \& Full Hybrid Scenario ...............36

16 Makes, Models, Configurations by Vehicle Type >2012 Diesel \& Full Hybrid Scenario.......37

17 Technology Market Shares by Vehicle Type >2012 Diesel \& ISAD Hybrid Scenario ............38

18 Makes, Models, Configurations by Vehicle Type >2012 Diesel \& ISAD Hybrid Scenario ...38

19 Diesel and Hybrid Vehicle Market Shares by Vehicle Type: 2008 Average Scenario ............39

20 Distribution of Hybrid Vehicle Sales by Degree of Hybridization, 2008 Average Scenario ..40

21 Diesel and Hybrid Market Shares by Vehicle Class, "Best Guess" Scenario ..........................40

22 Distribution of Hybrid Vehicle Sales by Degree of Hybridization, 2008 "Best Guess"

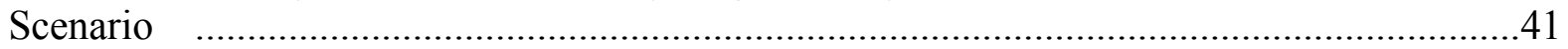

23 Hybrid and Diesel Market Shares by Vehicle Class, 2012 "Average” Scenario.......................41

24 Distribution of Hybrid Technology Types in the 2012 "Best Guess" Scenario .......................42

25 Comparison of Market Success in "Average" and "Best Guess" Scenarios ............................43

26 Distribution of Hybrid Vehicle Sales by Degree of Hybridization, 2012

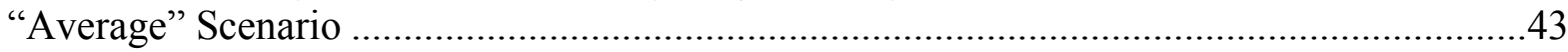

27 Distribution of Hybrid Vehicle Sales by Degree of Hybridization, 2012 "Best Guess"

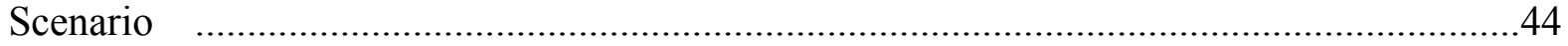

28 New Light-Duty Vehicle Average Fuel Economy by Scenario................................................45

29 Sensitivity Analysis of Diesel Market Share, >2012 Diesel/Full Hybrid Scenario..................49

30 Tornado Chart Showing Influence of Inputs on Diesel Market Share......................................50

31 Sensitivity Analysis of Hybrid Market Share, >2012 Diesel/Full Hybrid Scenario.................51

32 Tornado Chart Showing Influence of Inputs on Hybrid Market Share ..................................51

33 Sensitivity Analysis of LDV Fuel Economy, >2012 Diesel/Full Hybrid Scenario ...................52

34 Tornado Chart Showing Influence of Inputs on LDV Fuel Economy ....................................53

35 Comparison of Market Success in 2008 and 2012 under "Best Guess" Scenarios ..................55 

1 Estimated Additional Torque and Fuel Economy of Light-duty Diesel Vehicles ......................3

2 Estimated Incremental Retail Price Equivalent for Diesel Vehicles ...........................................6

3 Estimated Additional Torque and Fuel Economy of Hybrid Vehicles ........................................9

4 Estimated Incremental Retail Price Equivalent of Hybrid Systems by Vehicle Type..............10

5 Planned Introductions of Hybrid-Electric Vehicles in the U.S. Market ....................................11

6 (Part 1) Definitions of Vehicle Classes................................................................................2

6 (Part 2) California Energy Commission (CEC) Vehicle Classification System.......................21

7 Estimated Price Elasticities for Diesel and Hybrid Market Shares Based on a Survey

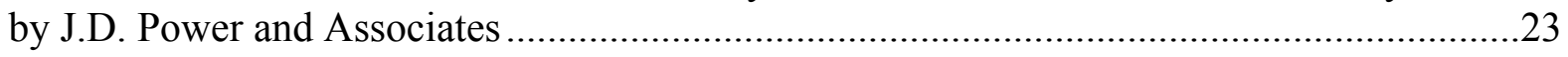

8 Price Slopes, Elasticities, Prices and Market Shares for Market Segments..............................24

9 Coefficients of the NMNL Vehicle Choice Model...............................................................26

10 Numbers of Diesel and Hybrid Configurations Offered, by Scenario.......................................32

11 Summary of Results of Diesel Hybrid Market Scenarios ........................................................46

12 Average Fuel Economy of Passenger Cars and Light Trucks ...............................................4

13 Assumptions for Sensitivity Analysis of Hybrid and Diesel Choice........................................48 



\section{ACKNOWLEDGMENTS}

The authors thank the U.S. Departments of Energy and Transportation, and Natural Resources Canada for supporting this research. We also thank the representatives of those agencies who provided invaluable guidance and advice throughout the course of the project.

Barry McNutt, Office of Petroleum and Transportation Fuels, Policy and International Affairs, U.S. Department of Energy

Ed Wall, Office of Freedom Car and Vehicle Technology, U.S. Department of Energy

Philip Patterson, Office of Energy Efficiency and Renewable Energy, U.S. Department of Energy

Thomas White, Office of Petroleum and Transportation Fuels, Policy and International Affairs, U.S. Department of Energy

John Maples, Energy Information Administration, U.S. Department of Energy

Peter Feather, National Highway Traffic Safety Administration, U.S. Department of Transportation

Kenneth Katz, National Highway Traffic Safety Administration, U.S. Department of Transportation

Peter Reilly-Roe, Transportation Energy Use Division, Natural Resources Canada

The authors thank these individuals and Steve Plotkin, Argonne National Laboratory for critical reviews of an earlier version of this report.

The authors also thank the many individuals from private industry in the U.S., Japan and Europe who met with us and shared their knowledge and insights, especially the following.

Bosch Corporation, Farmington Hills, Michigan:

Manuel Hesser, Customer Interface Engineering

Christopher Qualters, Product Manager, Common Rail Systems, Powertrain Division

Daimler Chrysler, Detroit, Michigan:

Bernard Robertson, Senior Vice President, Engineering Technologies and Regulatory Affairs

Philip Benjamin, Manager, Small Vehicle Product Team, Hybrid Vehicle Engineering

Reginald Modlin, JD, Director, Environmental and Energy Planning

Loren Beard, Senior Manager, Environmental and Energy Planning

Lawrence Oswald, CEO, Global Electric Motorcars, LLC, Daimler Chrysler

U.S. Environmental Protection Agency, Ann Arbor, Michigan:

Charles Gray, Director Advanced Technology Division, Office of Transportation and Air Quality

Karl Hellman, Assistant Director, Advanced Technology Division, OTAQ

Jeff Alson, Corporate Average Fuel Economy Policy Issues, OTAQ

Robert Heavenrich, Fuel Economy Trends, OTAQ

John White, Cooperative R\&D Agreements, OTAQ 
General Motors, Detroit Michigan:

Hazem Ezzat, Director, Powertrain Engineering

Shareef Ultari, Senior Research Engineer, Diesel Engine Research

Peter Savagian, Chief Engineer, Traction and Thermal Systems

Ford Motor Company, Detroit, Michigan:

Graham Hoare, Director, Powertrain Research \& Advanced Engineering

Larry Brouwer, Chief Engineer, Advanced Powertrains

William Stockhausen, Staff Technical Specialist, Strategic Powertrain Technologies, Powertrain Research \& Advanced Engineering

Robert Hammerle, Senior Staff Technical Specialist, Chemical Engineering Department

Richard Baker, Corporate Technical Specialist, Combustion \& Emissions Advanced Diesel Systems

Richard Bell, Manager, Worldwide Recycling Planning, Vehicle Environmental Engineering

Mike Tamor, Project Leader, Hybrid Electric Vehicle Design

Daimler-Chrysler, Stuttgart, Germany:

Harald Braun, Manager, Passenger Car Development, Powertrain Electronics, Alternative Drives

Gerhard Doll, Leader, V8 Diesel Engine Development

Andreas Graf, Manager, Regulatory Affairs, Emissions and Fuel Consumption

Gerhard Schweinle, Senior Manager, Regulatory Affairs and Government Liaison for Mercedes-Benz Passenger Cars

Oliver Storz, Manager, Emission Certification and Government Liaison Worldwide (excluding USA) Large Passenger Cars and in Use

Rudolph Thom, Director, Development MB-Passenger Cars Certification and Regulatory Affairs

FEV, Aachen, Germany:

Peter Walzer, Executive Vice President

Michael Krüger, Chief Engineer, Diesel Combustion Systems

Continental TEMIC, Landsberg, Germany:

Frank Blome, Director, Profit Center ISAD

Frank Kozlowski, Sales and Marketing, Profit Center ISAD

Horst Kornemann, Director, Product Line Electronic Drives, ISAD

Uwe Mohrstadt, Senior Manager, Sales and Marketing, ISAD

Bosch, Stuttgart, Germany:

Stefan Becher, Group Leader, Development Engine Test Field, Commercial Vehicle

Engines, Emission Legislation, Fuels

Marcus Parche, Vice President, Marketing

Thomas Wintrich, Head of Department, Advanced Engineering

Volkswagen, Wolfsburg, Germany

Ekkehard Pott, Advanced Gasoline Engines

Wolfgang Steiger, Director, Powertrain Group Research 
Japan Automotive Research Institute, Tsukuba, Ibaraki, Japan:

Kiyoyuki Minato, Senior Researcher

Hirota Keiko, Researcher

Chuo University, Tokyo, Japan:

Professor Tanishita, Department of Civil Engineering

Hitachi Automotive Systems, Hitachinaka, Japan

Fumitoshi Emura, Manager of Sales

Mr. Naiato, Senior Chief Engineer

Tadashi Fujikado, General Manager, Marketing and Planning Department

Tatsuo Horiba, Chief Researcher, Saitana Research Laboratory, Shin-Kobe Electric Machinery Co., Ltd.

Panasonic Electric Vehicle Energy, Nagoya, Japan

Yuichi Fujii, Executive Vice President

Osamu Takahashi, General Manager, Engineering Department

Tadashi Fujikado, General Manager, Marketing and Planning Department

Toyota Motor Corporation, Nagoya, Japan

Masatami Takimoto, Senior Managing Director, Powertrain Development Group and Fuel Cell Development Group

Toyota Motor Corporation, Toyotashi, Japan

Kenichiro Takama, Project General Manager, R\&D Management Division

Toshiyuki Sekimore, General Manager, Electric and Hybrid Vehicle Engineering Division

Takehisa Yaegashi, Senior General Manager, Powertrain Development Group

Toshiro Yoshida, General Manager Powertrain Planning Department

Takuku Masuoka, General Manager, Government and Regulatory Affairs Department, Engineering Administration Division

Fumiaki Ohya, General Manager, Government and Regulatory Affairs Department, Engineering Administration Division

Honda Motor Company, Ltd., Tokyo, Japan

Hikekazu Kanour, Chief Engineer, Advanced Product Planning Division Hiroo Shimada, Chief Engineer, Advanced Product Planning Division Kenji Nakano, Chief Engineer and Manager, Engineering Development H2 Hiroshi Shuto, Chief Engineer, Regulatory Information Coordination Department Satoshi Fujitani, Chief Engineer, Regulatory Information Coordination Department John German, Environmental and Energy Analyses, Honda of America

While all of the individuals mentioned above made significant contributions to the quality of this report, any errors or omissions it may contain are the sole responsibility of the authors. 



\section{ABSTRACT}

Diesel and hybrid technologies each have the potential to increase light-duty vehicle fuel economy by a third or more without loss of performance, yet these technologies have typically been excluded from technical assessments of fuel economy potential on the grounds that hybrids are too expensive and diesels cannot meet Tier 2 emissions standards. Recently, hybrid costs have come down and the few hybrid makes available are selling well. Diesels have made great strides in reducing particulate and nitrogen oxide emissions, and are likely though not certain to meet future standards. In light of these developments, this study takes a detailed look at the market potential of these two powertrain technologies and their possible impacts on light-duty vehicle fuel economy. A nested multinomial logit model of vehicle choice was calibrated to 2002 model year sales of 930 makes, models and engine-transmission configurations. Based on an assessment of the status and outlook for the two technologies, market shares were predicted for 2008, 2012 and beyond, assuming no additional increase in fuel economy standards or other new policy initiatives. Current tax incentives for hybrids are assumed to be phased out by 2008 . Given announced and likely introductions by 2008 , hybrids could capture $4-7 \%$ and diesels $2-4 \%$ of the light-duty market. Based on our best guesses for further introductions, these shares could increase to $10-15 \%$ for hybrids and $4-7 \%$ for diesels by 2012 . The resulting impacts on fleet average fuel economy would be about $+2 \%$ in 2008 and $+4 \%$ in 2012 . If diesels and hybrids were widely available across vehicle classes, makes, and models, they could capture $40 \%$ or more of the light-duty vehicle market. 



\section{INTRODUCTION}

Direct-injection diesel engines and hybrid-electric power trains can significantly increase fuel economy without sacrificing attributes consumers value, but at a higher cost. At present, only a few makes and models offer these power train options and there is considerable uncertainty about their future in the U.S. light-duty vehicle market. This study assesses the future market potential of these technologies in competition with conventional gasoline power trains, and their potential impact on new light-duty vehicle fuel economy. Estimates are developed of the market potential for these technologies in competition with the conventional gasoline internal combustion engines that dominate the U.S. market today.

Diesel and hybrid technologies each have the potential to increase any given light-duty vehicle's fuel economy by a third or more without loss of performance, yet these technologies have typically been excluded from technical assessments of fuel economy potential on the grounds that hybrids are too expensive and diesels cannot meet Tier 2 emissions standards (NRC, 2002). However, hybrid vehicles are already present in the automotive marketplace and are selling well; sales increased $26 \%$ from 2002 to 2003 despite the availability of only three hybrid models (CNN, May 17, 2004). In Europe, sales of modern, direct-injection, high-pressure-injection diesel cars comprised $44 \%$ of 2003 passenger car sales (Schmidt, 2004). Yet only one manufacturer offers light-duty diesels in the United States today and captures about $0.2 \%$ of the market. Diesels have achieved significant reductions particulate and nitrogen oxide emissions in recent years and appear to be poised to meet Tier 2 emissions standards for at least bin 8 and very likely bin 5 (Duleep, 2004).

Honda introduced the first hybrid vehicle into the U.S. market in 1999, the two-seater Honda Insight. Toyota followed with the Prius in 2000, a vehicle they had introduced into the Japanese market in 1997. Hybrid sales in the U.S. reached 38,000 units in 2002 (J.D. Power, 2003) and increased to 43,500 units in 2003 and from January to April 2004 23,000 hybrids were sold (Miller, 2004). Response to the redesigned model year 2004 Prius was especially strong: more than 12,000 purchase requests were made before the model was introduced in October 2003 (Toyota, 2004). As a result, Toyota raised its production plan for the U.S. from 36,000 to 47,000 units (Toyota, 2003). With demand for hybrids spurred on by higher fuel prices in 2004, manufacturers have been unable to keep pace with demand and waiting lists for hybrids have lengthened.

The potential impact of hybrid technology on new light-duty vehicle fuel economy if all vehicles were converted to hybrids was assessed by Burke and Abeles (2004). They estimated that if all new light-duty vehicles were mild hybrids, fleet average fuel economy would increase to 38 miles per gallon (mpg), at a cost increase of 7-9\%. If all were full hybrids $42 \mathrm{mpg}$ could be achieved for a price increase of 16-18\%. Their study did not address the market acceptance of hybrid technology, however.

In light of the fact that both technologies are present in the U.S. light-duty vehicle market today and are selling well, albeit with very limited product availability, it is no longer reasonable to assume that these technologies will play no role in determining future light-duty vehicle fuel economy. This study assesses the market potentials of hybrid and diesel technologies in the U.S. light-duty vehicle market, as well as their likely impacts on the fleet average fuel economy of 
new light-duty vehicles. The impacts on fuel economy are based on estimated consumer demand for these technologies, with no subsidies or further increases in fuel economy standards.

The estimated market potentials and fuel economy impacts assume no new policies to drive the market toward high fuel economy vehicles, such as higher CAFE standards or tax incentives for hybrid vehicles. Indeed, the existing federal tax incentives for hybrid vehicles are assumed to expire, as planned, before 2008. It is further assumed that manufacturers will neither lower nor raise the fuel economy of conventional gasoline vehicles as a result of the introduction of new diesel and hybrid products. No significant technological advances are assumed for any of the technologies except for those needed to control diesel $\mathrm{NO}_{\mathrm{X}}$ emissions to Tier 2, bin 5 levels. Economies of scale and learning-by-doing in the production of hybrid vehicles and emissions control systems for diesels are also assumed. Finally, the analysis is based on the mix of vehicles sold in the United States in model year 2002 and their attributes. No attempt has been made to project how consumers preferences or manufacturers offerings may change over the next 5-10 years, except for the introductions of new hybrid and diesel powertrains.

The following section briefly reviews the status and prospects for the cost and performance of diesel and hybrid technologies. In Section 3, previous projections of hybrid and diesel market shares are reviewed. In Section 4, the data and methods used to assess future market potential are presented. Readers less interested in mathematical details may wish to skim this section. In Section 5, results are presented for eight scenarios to 2012 and beyond. 


\section{HYBRID AND DIESEL TECHNOLOGY STATUS AND PROSPECTS}

Although hybrid and diesel vehicles already have a limited presence in the North American lightduty vehicle market, they both face challenges to their future market success. Diesels must find a way to meet future Tier 2 emissions standards at the bin 5 level if they are to capture more than a niche market in the United States. Both hybrids and diesels face the challenge of consumer acceptance of their higher costs. In this section the status and outlook for these technologies are briefly reviewed, and our assumptions about future attributes are presented. The review draws heavily on in-depth reviews of the status of these technologies (Duleep, 2003; 2004).

\subsection{DIESELS}

Turbo-charged, direct-injection, high-pressure common rail, light-duty diesel engines are a well established technology that captured $44 \%$ of the European passenger car market in model year 2003 (Schmidt's, 2004). While higher motor fuel prices in Europe are clearly part of the explanation for the diesel's success there, there is also no doubt that car buyers consider the modern diesel an acceptable alternative to the gasoline engine despite its higher price. Diesels have other advantages and disadvantages than simply fuel economy and cost that will affect their success in the North American market. Advantages such as greater driving range and higher torque may allow the diesel to capture a significant share of the North American market despite lower fuel costs.

\subsubsection{Diesel Advantages}

The diesel's much higher compression ratio, lean burn operation and direct injection make it not only more energy efficient but give it more torque than a spark-ignition gasoline engine of the same displacement. In addition, diesel fuel contains about $10 \%$ more energy by volume than gasoline, a fact that further increases the diesel's advantage in miles per gallon. Manufacturers are unlikely to try to downsize diesels to fully match the performance of a comparable gasoline engine vehicle. In our judgment, manufacturers will design diesel vehicles with not only higher fuel economy but also increased torque. Table 1 shows by calendar year the increases in fuel economy and torque we assume diesels will offer relative to a comparable gasoline vehicle. Tighter emissions standards account for the decrease in the diesel's fuel economy benefit from 2005 to 2008. Improved technology is assumed to restore most of the emissions penalty by 2012.

Table 1. Estimated Additional Torque and Fuel Economy of Light-Duty Diesel Vehicles

\begin{tabular}{ccc}
\hline & Torque & MPG \\
\hline 2005 & $25 \%$ & $35 \%$ \\
2008 & $25 \%$ & $30 \%$ \\
2012 & $25 \%$ & $33 \%$ \\
\hline
\end{tabular}

For a given make and model of vehicle, manufacturers are likely to offer the same size of fuel tank on gasoline and diesel versions. This implies that diesels will provide $30-35 \%$ greater 
range, an added plus. In a 2002 survey by J.D. Power and Associates (McManus, 2003), 32\% of respondents rated driving range as "extremely important" (8-10 on a scale of 1 to 10). Of those citing range as extremely important, 73\% gave "have to refuel less frequently" as a key concern, while $44 \%$ cited "saves time." This suggests that there is nuisance cost of refueling over and above the value of the time saved. Indeed, $27 \%$ said they simply "don't like to refuel." In the quantitative modeling presented below, only the value of time saved and not the avoided nuisance cost of refueling is considered, implying that we have most likely underestimated the value of greater range to consumers.

\subsubsection{Market Barriers}

Diesel fuel availability is a concern of many motorists. In a 2002 survey by J.D. Power and Associates (McManus, 2003), 46\% cited limited diesel fuel availability as a concern for clean diesels. In a more recent survey (Caravan, 2004), only 35\% of respondents said diesel fuel availability would be of no concern if they were considering buying a diesel vehicle (Figure 1). Another $20.8 \%$ considered it somewhat of a problem, but not a big deal, while another $8.2 \%$ viewed it as a problem, but not one that would prevent them from buying a diesel. On the other hand, only $27 \%$ said it was a serious enough problem that they either might not (7\%) or would not $(21 \%)$ buy a diesel because of it. In total, almost two thirds of respondents did not consider fuel availability a show stopper for diesels.

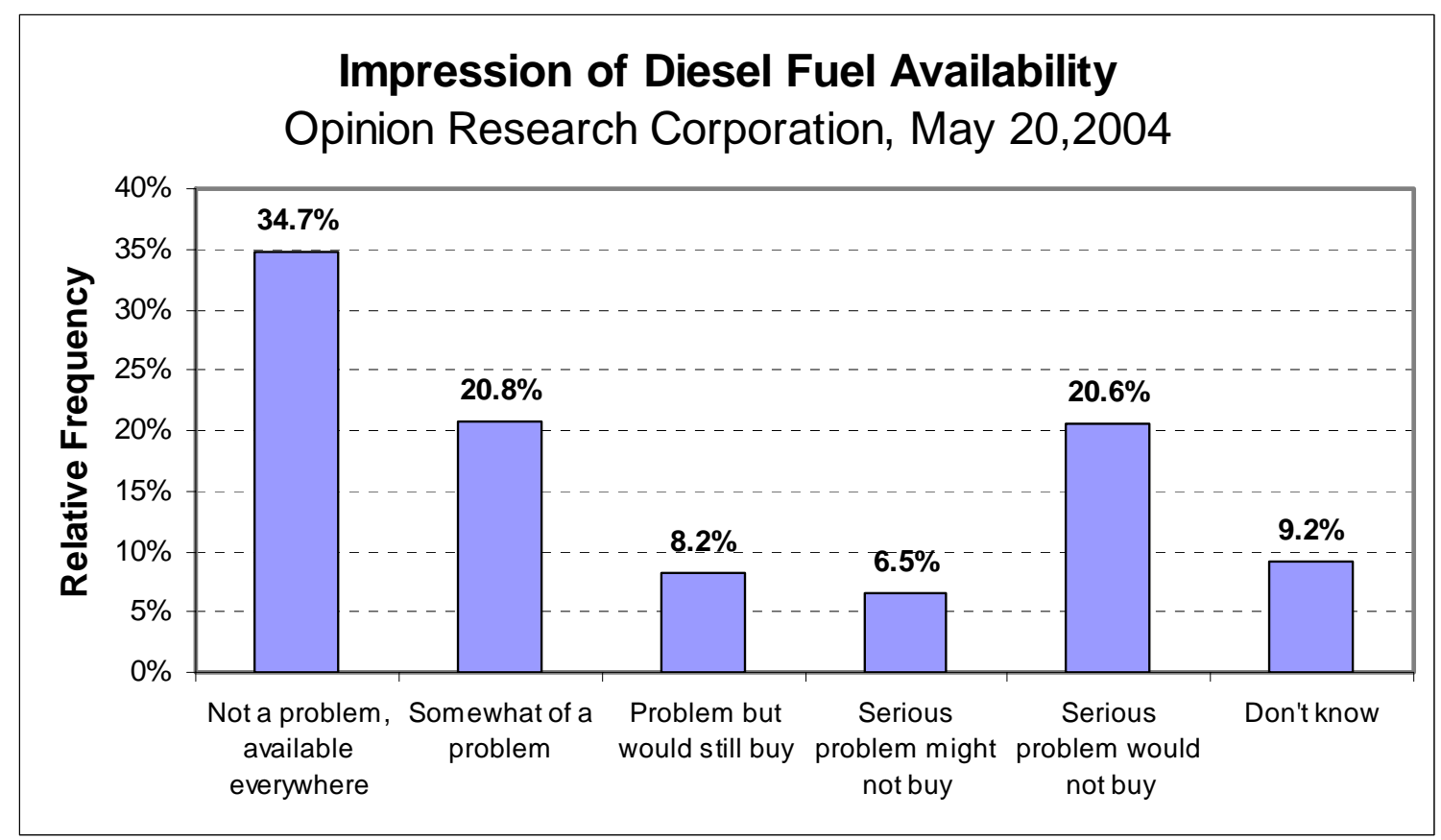

Figure 1. The Public's Impression of Diesel Fuel Availability in May, 2004

Owners of gasoline vehicles generally still believe that diesels are noisy, smelly and underpowered relative to gasoline vehicles. In the 2002 J.D. Power survey, $32 \%$ cited engine noise as a concern, and $27 \%$ cited exhaust odor. Thirty-one percent indicated lower performance was a concern. In large part, this is due to unfamiliarity with modern diesel technology. Compared with 1988 diesel technology, modern diesels have 100\% more torque, $60 \%$ less noise, 90\% lower emissions and 30\% less fuel consumption (Birch, 2003). Modern diesels are not noisier than gasoline engines, do not produce a diesel odor, and accelerate as well as comparable 
gasoline vehicles. This suggests that many of the negative perceptions about diesels held by car buyers could be overcome with advertising and greater exposure to modern diesel vehicles.

Two of the top three concerns emerging from the 2002 J.D. Power survey were the availability of service and repair locations, and the fact that the type of vehicle a car buyer wanted might not be available as a diesel. Both of these concerns would be addressed if more manufacturers offered diesels on more makes and models. Thus, a key question is whether diesels could significantly increase their market share even with the current level of fuel availability and limited product offerings, i.e., can the diesel solve its "chicken or egg" problem on its own?

Surveys of owners of gasoline vehicles and diesel vehicles conducted by J.D. Power and Associates (McManus, 2004) reveal two key insights about the potential market for diesel vehicles. First, diesel vehicle owners have strongly positive perceptions of diesel vehicles, except for their higher price (Figure 2). Second, owners of gasoline vehicles have generally positive perceptions of diesel vehicles, but they are more negative than those of the owners of diesel vehicles (Figure 3). Diesel owners perceive their vehicles to be much more reliable, powerful, and fuel efficient than gasoline vehicles. They see them as cleaner and having about equal acceleration performance. More than half, however, consider the price of a diesel to be "worse." More than half of gasoline vehicle owners believe diesels are more powerful and (surprisingly) cleaner; about three quarters consider them to be more fuel efficient. But they view diesels as about equally reliable, slower, and more expensive. Because the vast majority of gasoline owners are unfamiliar with diesels, it is likely that their perceptions would improve with greater exposure to diesels. These insights suggest that diesels are potentially a mass-market technology in the United States, provided that their price can be held at an acceptable level.

\section{Diesel Vehicle Owners: Clean Diesel v. Gasoline Vehicles}

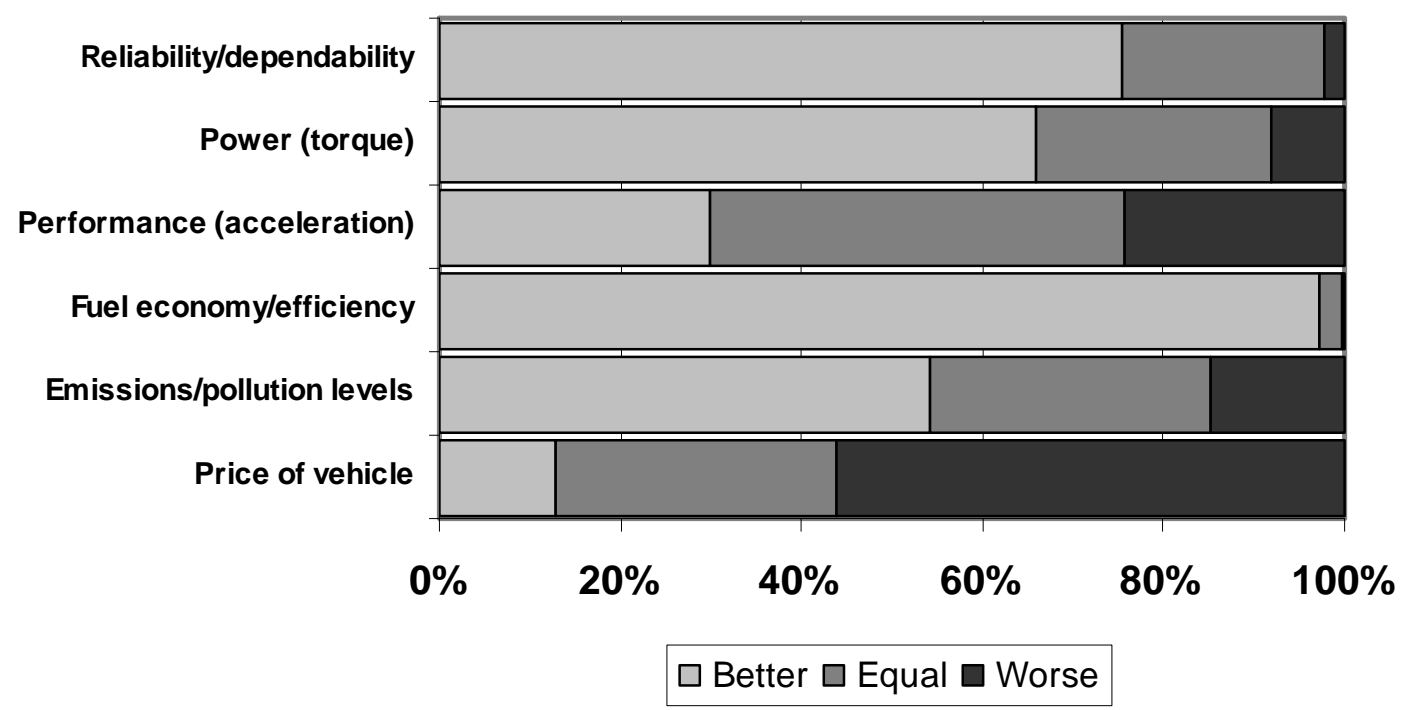

Figure 2. Diesel Vehicle Owners' Views on Clean Diesel Vehicles 


\section{Gasoline Vehicle Owners: Clean Diesel v. Gasoline Vehicles}

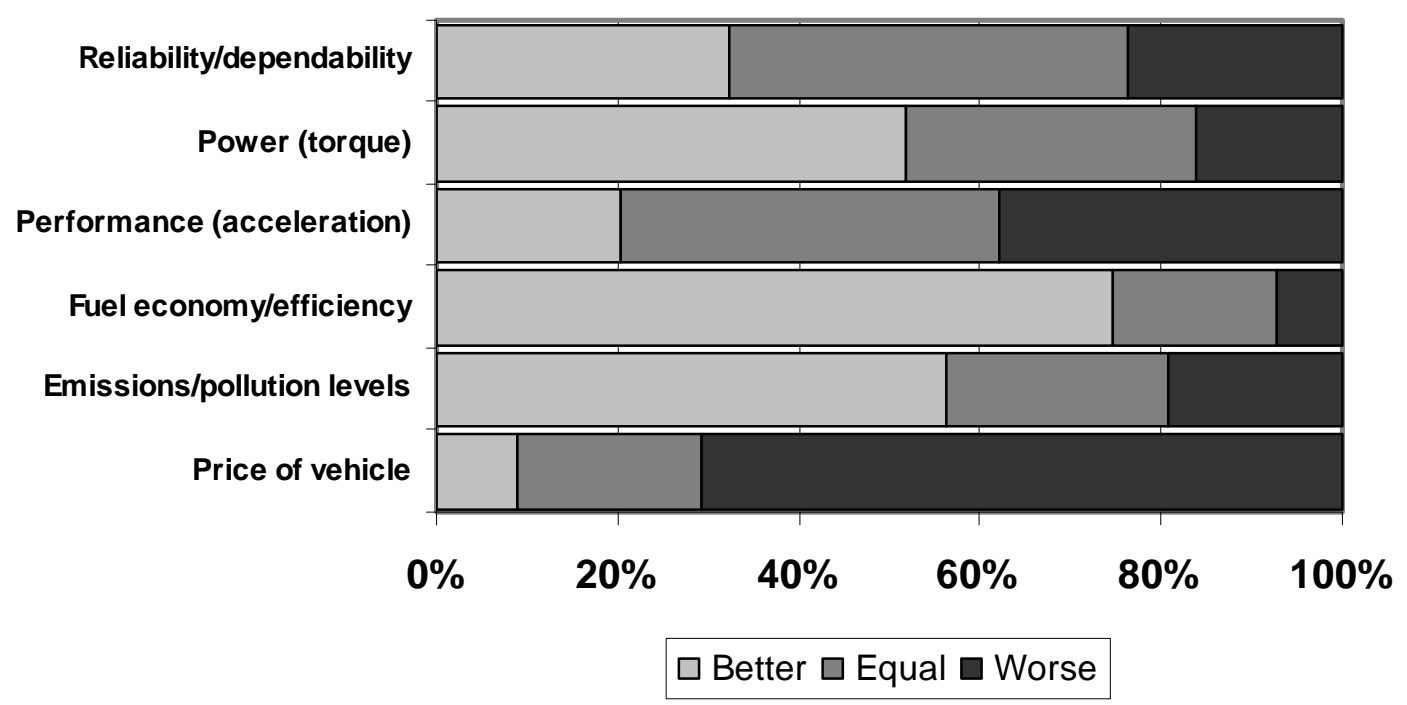

Figure 3. Gasoline Vehicle Owners' Views on Clean Diesel Vehicles

Undoubtedly the most significant downside of the diesel in the eyes of the consumer is its higher price. Diesels are more costly to manufacture chiefly because of their much higher pressure fuel injection systems and what we project will be far costlier emissions control systems. The estimates shown in Table 2 reflect the view that meeting Tier II bin 5 standards will add \$550 to the retail price of a small diesel vehicles and $\$ 750$ to the price of a larger one. The retail price equivalent (RPE) measures used throughout this report reflect a full mark-up over manufacturing costs, including all normal overheads and profits. The RPEs shown include the incremental costs of all necessary components, including all emissions control equipment.

Table 2. Estimated Incremental Retail Price Equivalent for Diesel Vehicles

\begin{tabular}{cccc}
\hline & $\begin{array}{c}\text { Small Vehicle } \\
(2.0-2.5 \mathrm{~L} \mathrm{I4})\end{array}$ & $\begin{array}{c}\text { Midsize Vehicle } \\
(3.0-3.5 \mathrm{~L} \mathrm{V6})\end{array}$ & $\begin{array}{c}\text { Large Vehicle } \\
(4.5-5.0 \mathrm{~L} \text { V6 })\end{array}$ \\
\hline 2005 & $\$ 1,750$ & $\$ 2,300$ & $\$ 2,500$ \\
2008 & $\$ 2,280$ & $\$ 2,925$ & $\$ 3,200$ \\
2012 & $\$ 2,300$ & $\$ 2,950$ & $\$ 3,250$ \\
\hline
\end{tabular}

We assume that diesels will have no greater durability than spark-ignition gasoline engines. We also assume that diesels will continue to have limited fuel availability, which we put at $33 \%$ of refueling outlets through 2008 (Hadder, 2004). However, with a larger number of light-duty diesel vehicles on the road, it is reasonable to assume that fuel availability will increase. The sensitivity of future market shares to this assumption was tested, however. 


\subsection{HYBRIDS}

Hybrid vehicle designs can span a spectrum from 12-volt stop-start systems to over 300-volt systems with a substantial range of all-electric drive. In addition, for any given level of electric power capability, manufacturers may choose to emphasize fuel economy or performance. Discussions with manufacturers and review of their product plans indicate that the carmakers have divergent views about the desirability of the different design options and their potentials for market success (Duleep, 2003). On the one hand, this will lead to a broad array of designs tested in the marketplace. On the other hand, it will take more time to sort out the winners and losers. Details of our assessment can be found in EEA, Inc. (Duleep, 2004).

It is assumed that all manufacturers face the same costs and can achieve the same technology performance. While it is clear that this is not the case today, it is our view that competition will drive the market in this direction in the future. The key assumptions about vehicle attributes used in this market analysis are given below. Assumed market introductions are listed in the appendix.

Four types of hybrid systems are used in this assessment. They are listed below in order of increasing use of electric power, regenerative braking, energy storage capacity and benefit to fuel economy.

1. Stop/Start (S/S): This hybrid system includes only the ability to shut off the engine when it would otherwise idle and to restart it instantly on demand. This provides no torque boost to aid acceleration, but offers a fuel economy advantage of $7.5 \%$ over the EPA test cycle.

2. Integrated Starter Alternator with Damping (ISAD): This hybrid system will operate at 42 volts and will allow some power to be contributed by the electric drive system in addition to the stop/start capability. An increase in torque of $10 \%$ and $12.5 \%$ higher fuel economy are expected.

3. Integrated Motor Assist (IMA): This 114 volt hybrid system is expected to be produced only by Honda through 2012. In comparison to the ISAD design it has a larger electric motor and greater battery power and energy storage and allows more electricity to be used for motive power. The system is expected to provide $15 \%$ higher torque and $20 \%$ greater fuel economy on average.

4. Full Hybrid (FH): These 300+ volt systems permit limited all-electric drive in addition to supplementing the power of the internal combustion engine. For cars, full hybrid systems should offer $20 \%$ more torque and $40 \%$ more miles per gallon; for light trucks increases of $15 \%$ in torque and $35 \%$ in fuel economy are expected.

\subsubsection{Hybrid Advantages}

Surveys show that consumers think of fuel economy (mentioned by $78 \%$ ) and low pollution (54\%) when they think of hybrid vehicles (McManus, 2003). Apparently because of early hybrid designs, they do not think of increased performance. Even owners of conventional gasoline vehicles see hybrids as exceptional when it comes to fuel economy and emissions (Figure 4), according to survey data developed by J.D. Power and Associates (McManus, 2004). But when it comes to acceleration performance and power, most gasoline vehicle owners believe hybrids 
are inferior to gasoline vehicles. Gasoline vehicle owners also give hybrids low grades for reliability, and they believe they are much worse when it comes to price.

Owners of hybrid vehicles have very different opinions about their vehicles (Figure 5). Not only do they consider them to be entirely superior when it comes to fuel economy and air pollution, but they perceive the hybrid's performance and power to be just as good as that of a conventional gasoline vehicle and they give hybrids better marks for reliability. Even hybrid owners, however, see hybrids as more expensive.

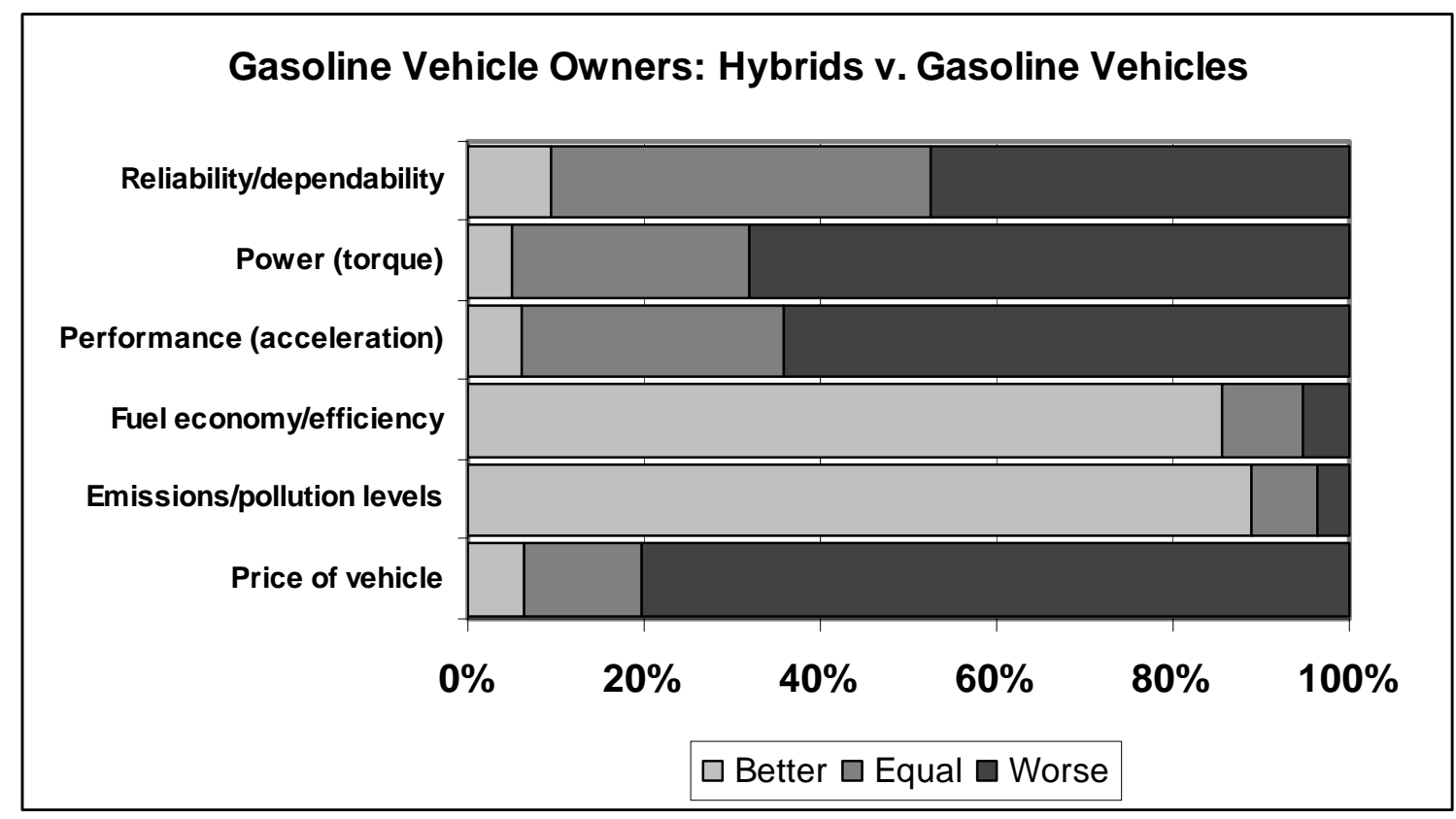

Figure 4. Gasoline Vehicle Owners' Views on Hybrid-Electric Vehicles

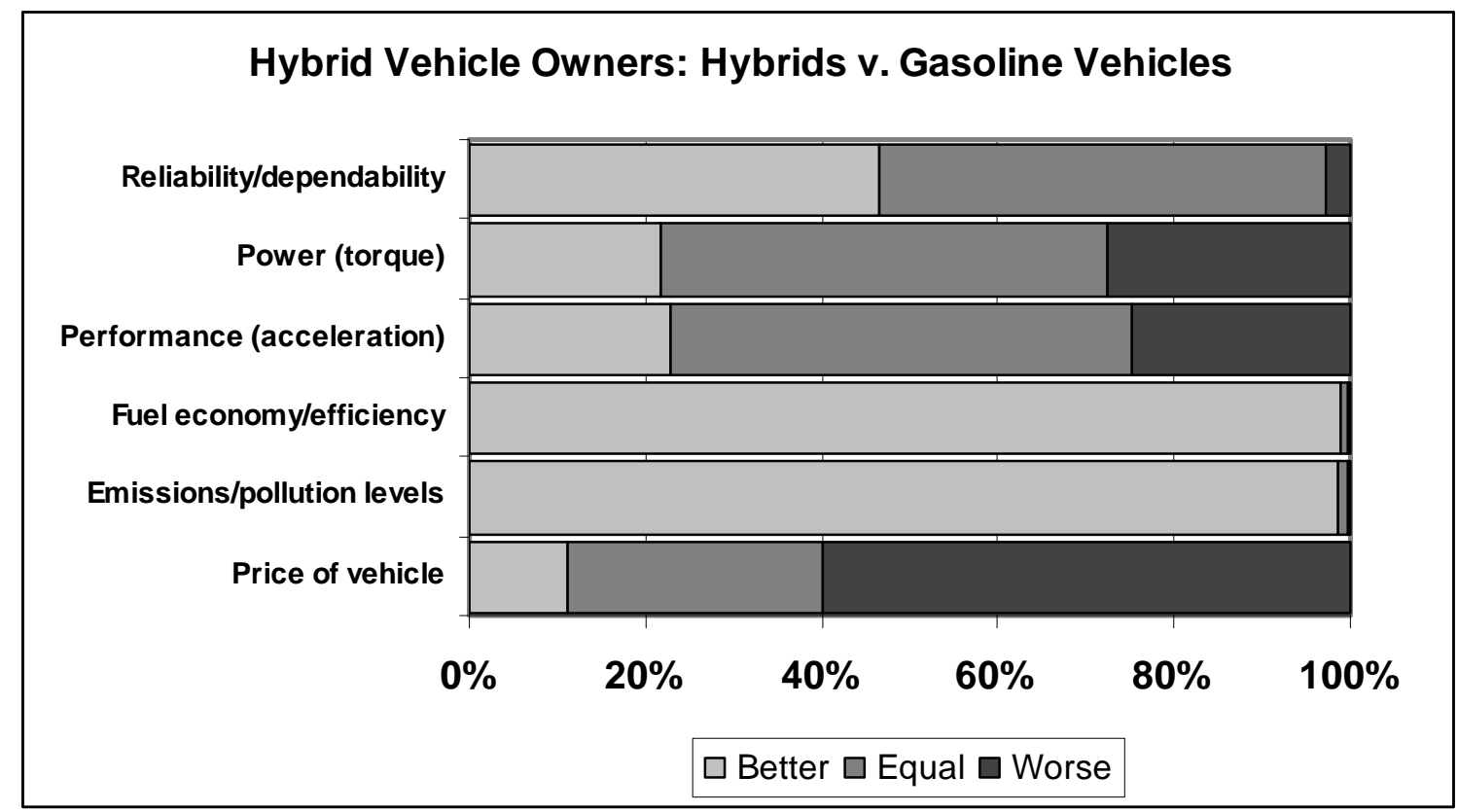

Figure 5. Hybrid-Electric Vehicle Owners' Views on Hybrid-Electric Vehicles 
Just as diesel owners had a more favorable impression of their vehicles than non-diesel owners, hybrid owners hold a better opinion of hybrids. On the one hand, there is almost certainly selfselection bias in these survey results. The more significant point, however, is that owners of these alternative power trains find them to be as good or better than gasoline vehicles in all respects except price. The fact that those who know these vehicles well are happy with them is important, since it implies that except for price there is no major market barrier to the success of either hybrids or diesels. Both technologies have mass-market potential.

The combination of a conventional gasoline engine and an electric motor with high torque at low rpm permits exceptional launch and acceleration. Just as for diesels, it is likely that manufacturers will offer consumers both increased fuel economy and increased torque in future hybrid designs (Table 3). Stop/start systems will offer no increase in torque because they do not have the ability to use the starter/alternator for motive power. With other systems, torque will increase with the power of the electric motor. The full hybrid system is estimated to give only a $15 \%$ torque increase and 35\% fuel economy benefit when used on larger light trucks.

Table 3. Estimated Additional Torque and Fuel Economy of Hybrid Vehicles

\begin{tabular}{lcc}
\hline \multicolumn{1}{c}{$\begin{array}{c}\text { Hybrid } \\
\text { System }\end{array}$} & $\begin{array}{c}\text { Change in } \\
\text { Torque }\end{array}$ & $\begin{array}{c}\text { Change in } \\
\text { MPG }\end{array}$ \\
\hline S/S & $0 \%$ & $7.5 \%$ \\
ISAD & $10 \%$ & $12.5 \%$ \\
IMA & $15 \%$ & $20 \%$ \\
Full (cars and small trucks) & $20 \%$ & $40 \%$ \\
Full (larger light trucks) & $15 \%$ & $35 \%$ \\
\hline
\end{tabular}

Although a hybrid vehicle's battery pack will take up additional space, we do not expect manufacturers to reduce the size of a hybrid's fuel tank in comparison to a conventional gasoline vehicle. The Honda Civic hybrid's fuel tank, for example, holds 13.2 gallons, exactly the same as conventional gasoline engine Civics. With fuel tanks of equivalent size, increased fuel economy will translate into increased range.

Hybrids may have other advantages that we make no attempt to take into account. With smaller engines and all-electric drive at low speeds, hybrids are likely to be quieter than conventional gasoline vehicles. With two powerplants, hybrids could offer a kind of low-speed 4-wheel drive at little additional cost. Finally, with the ability to generate high-voltage electric power and considerable capability for storing electricity, hybrids can electrify many functions now performed mechanically or hydraulically, and can even provide electrical outlets for household appliances and tools. It seems likely that some combination of features will be found that will add value for customers. In the analyses presented below, however, we do not attempt to add extra value to hybrids to take account of this likelihood.

Finally, hybrids are perceived to be environmentally friendly vehicles, and some car buyers are willing to pay something extra for a green vehicle. Fifty four percent of respondents to a J.D. Power and Associates survey who said they would consider buying a hybrid cited lower pollution as a reason (McManus, 2003). Nevertheless, we do not attempt to quantify the value of environmental friendliness in the quantitative analysis presented below. 


\subsubsection{Market Barriers}

Surveys of American consumers conducted by J.D. Power and Associates (McManus, 2003) indicate that insufficient power (34\%), price (27\%) and vehicle dependability (24\%) are consumers' top concerns about hybrid vehicles. Another $12 \%$ mentioned battery reliability as a concern. As a novel technology, it is understandable for consumers to be concerned about hybrids' reliability. Very likely, only experience will fully overcome this barrier, though Toyota and Honda have made effective use of customer guarantees such as extended warrantees to allay the concerns of early purchasers.

The incremental price of a hybrid system is undoubtedly the biggest barrier to its success. Hybrid costs have already begun to come down, and further reductions are expected. Toyota claims that the costs of batteries and motors were reduced by 30-35\% from the first to the second generation Prius (Duleep, 2003). By 2012, we expect that costs will fall to $\$ 3,000-\$ 4,000$ for full hybrid designs, and from $\$ 600$ to $\$ 640$ for simple stop/start systems (Table 4).

Table 4. Estimated Incremental Retail Price Equivalent of Hybrid Systems by Vehicle Type

\begin{tabular}{lcccc}
\hline \multicolumn{1}{r}{ Hybrid } & \multicolumn{5}{c}{ Midsize \& } \\
System & Small Cars & Large Cars & Small Trucks & Large Trucks \\
\hline Stop/Start & $\$ 600$ & $\$ 640$ & $\$ 640$ & -- \\
ISAD & $\$ 1,250$ & $\$ 1,385$ & $\$ 1,450$ & $\$ 1,625$ \\
IMA & $\$ 1,620$ & $\$ 1,790$ & -- & -- \\
Full Hybrid & $\$ 3,320$ & $\$ 3,920$ & $\$ 3,700$ & $\$ 4,100$ \\
\hline
\end{tabular}

\subsubsection{Manufacturers Near-Term Plans}

The six largest-selling manufacturers in the United States have announced planned introductions of sixteen additional hybrid vehicle configurations by 2008 (Table 5). This would bring the total number of hybrids in the market to nineteen. If these plans are realized hybrid options would be available not just as small to mid-size passenger cars, but in small and large SUVs and pick-ups, and in luxury as well as standard models. These announced introductions are the starting point for our "best guess" 2008 and 2012 scenarios described in Section 5, below and listed in detail in Appendix B. 
Table 5. Planned Introductions of Hybrid-Electric Vehicles in the U.S. Market

\begin{tabular}{|c|c|c|c|c|c|c|}
\hline Model & $\begin{array}{l}\text { Nameplate } \\
\text { (Division) }\end{array}$ & $\begin{array}{l}\text { Vehicle Name } \\
\text { (Model) }\end{array}$ & Manufacturer & Market Segment & Certainty & Sales Start \\
\hline Chevrolet Malibu Hybrid (BAS) & Chevrolet & Malibu & General Motors & Midsize-Entry & Announced & Jan-2007 \\
\hline Chevrolet Silverado Hybrid (AHS II) & Chevrolet & Silverado & General Motors & Pickup-Fullsize & Announced & Jan-2008 \\
\hline Chevrolet Silverado Hybrid (FAS) & Chevrolet & Silverado & General Motors & Pickup-Fullsize & Announced & May-2004 \\
\hline Chevrolet Tahoe Hybrid (AHS II) & Chevrolet & Tahoe & General Motors & SUV-Fullsize & Announced & Jul-2007 \\
\hline Dodge Ram Contractor Special & Dodge & Ram & DaimlerChrysler & Pickup-Fullsize & Announced & Oct-2004 \\
\hline Ford Escape Hybrid & Ford & Escape & Ford & SUV-Entry & Announced & Jul-2004 \\
\hline Ford Midsize Car Hybrid & Ford & Futura & Ford & Midsize-Premium & Announced & Oct-2007 \\
\hline GMC Sierra Hybrid (AHS II) & GMC & Sierra & General Motors & Pickup-Fullsize & Announced & Jan-2008 \\
\hline GMC Sierra Hybrid (FAS) & GMC & Sierra & General Motors & Pickup-Fullsize & Announced & May-2004 \\
\hline GMC Yukon Hybrid (AHS II) & GMC & Yukon & General Motors & SUV-Fullsize & Announced & Jul-2007 \\
\hline Honda Accord Hybrid & Honda & Accord & Honda & Midsize-Premium & Announced & Oct-2004 \\
\hline Honda Civic Hybrid & Honda & Civic & Honda & Compact-Premium & In Market & Apr-2002 \\
\hline Honda Insight & Honda & Insight & Honda & Compact-Premium & In Market & Dec-1999 \\
\hline Lexus RX400h & Lexus & $\mathrm{RX} 400 \mathrm{~h}$ & Toyota & SUV-Luxury & Announced & Oct-2004 \\
\hline Mercury Mariner Hybrid & Mercury & Mariner & Ford & SUV-Entry & Announced & Oct-2006 \\
\hline Nissan Altima Hybrid & Nissan & Altima & Nissan & Midsize-Premium & Announced & Oct-2006 \\
\hline Saturn VUE Hybrid (BAS) & Saturn & VUE & General Motors & SUV-Entry & Announced & Jan-2006 \\
\hline Toyota Highlander Hybrid & Toyota & Highlander & Toyota & SUV-Midsize & Announced & Apr-2005 \\
\hline Toyota Prius & Toyota & Prius & Toyota & Midsize-Premium & In Market & Jul-2000 \\
\hline
\end{tabular}

Source: J.D. Power and Associates, Hybrid-Electric Vehicle Outlook, First Quarter, 2004, Troy, Michigan. 



\section{RECENT MARKET ASSESSMENTS}

A recent survey by Opinion Research Corporation (Caravan, 2004) indicates substantial consumer interest in both diesel and hybrid technologies. In their 2004 survey, $8.6 \%$ of respondents indicated that they would definitely buy or were very likely to buy a diesel as their next vehicle (Figure 6). The respondents were evenly divided with $4.3 \%$ in each category. Almost seven percent indicated they would definitely buy a hybrid vehicle, with $8.3 \%$ indicating a hybrid purchase was very likely. The sum of the two most likely categories ("definitely" and "very likely") suggests the following maximum near-term market potentials: $8.6 \%$ for diesels and $15.2 \%$ for hybrids.

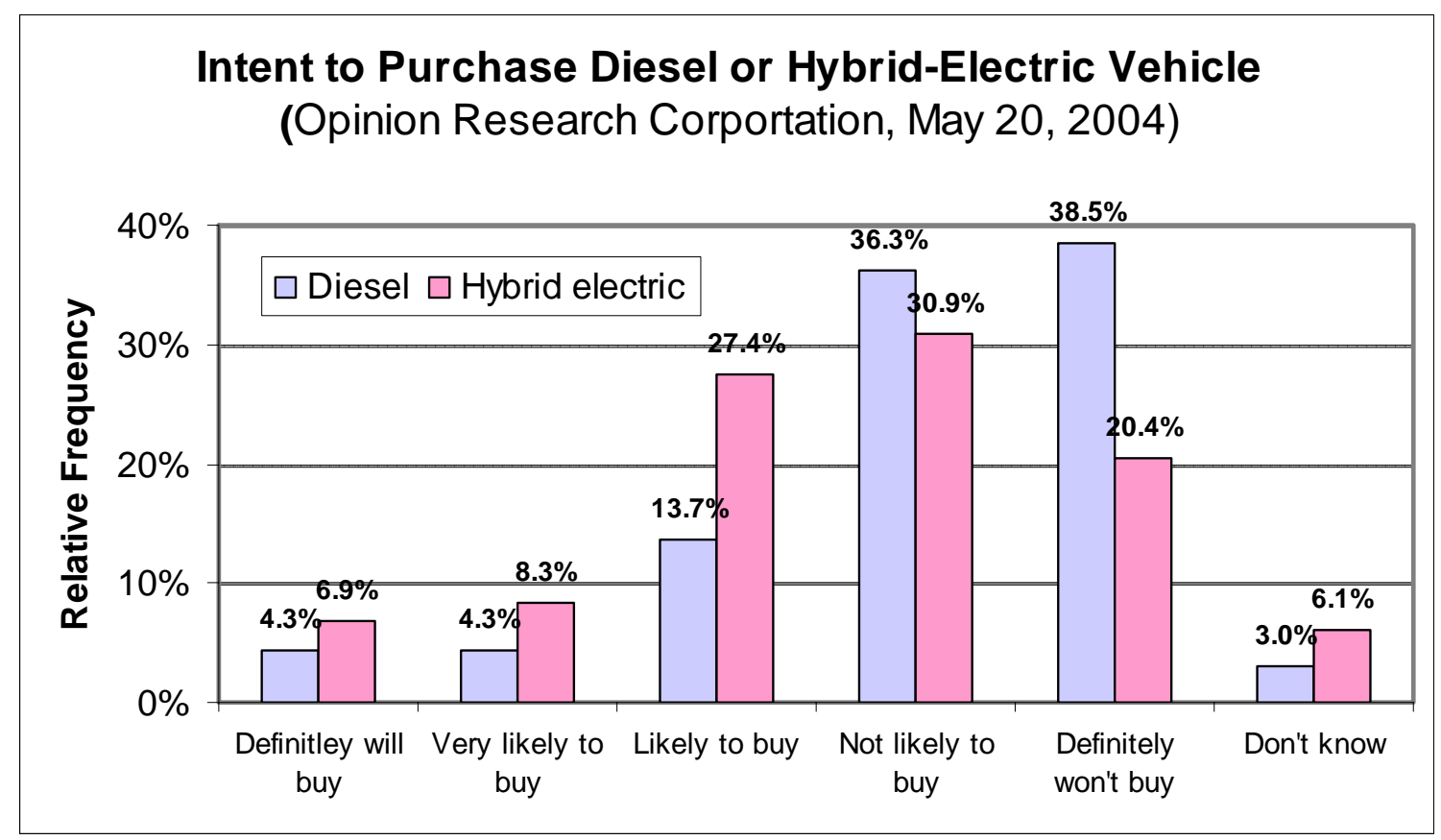

Figure 6. Intent to Purchase Diesel or Hybrid-Electric Vehicle (ORC, 2004)

In 2004, J.D. Power and Associates (McManus, 2004) presented a new, less optimistic forecast of hybrid market share to 2013 . From $0.6 \%$ of the market in 2004, hybrids were projected to grow to $2.5 \%$ of the market in 2008 and $3.2 \%$ in 2013, with a lower and upper bound of $2.1 \%$ to $4.1 \%$, respectively (Figure 7 ).

Robert Bosch GmbH (Qualters, 2004) carried out a study of the diesel's potential in the North American light-duty vehicle market. Key premises of the study were that emissions control strategies to achieve bin 8 would be available by 2007, bin 5 solutions by 2009, and that fuel availability would not hinder development of the diesel market. In addition, they assumed that total market volume would be approximately 17.5 million units, and that manufacturers' market shares would remain relatively static. The Bosch assessment did not consider competition from alternative power trains, such as the hybrid.

On the positive side, the Bosch study noted the enormous success of diesel engines in the larger (GVW class IIb) pick-up truck market, where they currently hold a 75\% market share. In 2003, 550,000 diesel pick-ups were sold in the North American market. Bosch's opinion is that some 
of the appeal of the diesel in this market segment must surely carry over, albeit to a lesser degree, into the lighter truck markets. They therefore conclude that the most likely path for diesel market penetration is to migrate downward from class IIb light trucks to large SUVs, lighter-duty pick-up trucks, standard and smaller sized SUVs, crossover vehicles and minivans and, finally, passenger cars. If such a strategy is pursued, they foresee the North American diesel market share expanding from about $5 \%$ today to nearly $15 \%$ by 2012 . The Bosch study includes class IIb light trucks $(>8,500 \mathrm{lbs}$. GVW) which are not included in this study. Excluding class IIb trucks, the Bosch projection for 2012 is $10 \%$ of the light-duty market as defined here (Figure 7). Approximately half of the new sales are expected to come in the light-duty pick-up market segment, and only a very small fraction would be attributable to passenger car diesel sales.

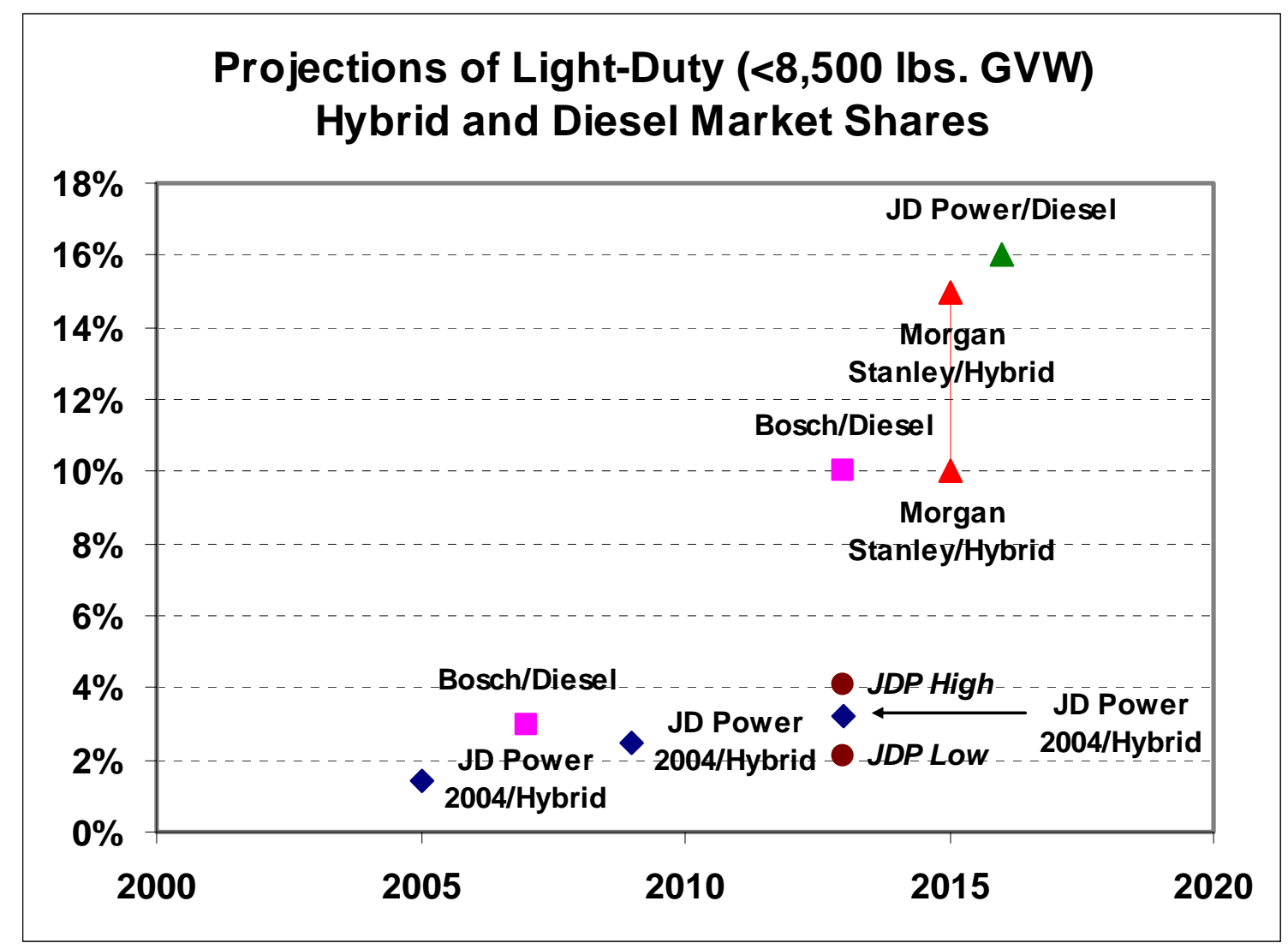

Figure 7. Projections of Light-Duty Hybrid and Diesel Market Shares (Passenger cars and class lla light trucks, only)

\subsection{DOE PROJECTIONS}

Projections of future diesel vehicles sales have been made by the U.S. Department of Energy's Office of Energy Efficiency and Renewable Energy (EERE) and by the Energy Information Administration (EIA, 2004; Patterson, 2004). The EIA's projection foresees diesel sales reaching 585,000 units by 2005, increasing to 716,000 in 2010 and reaching 765,000 units in 2015 . Both the EIA's and EERE's projections nominally include class IIb light trucks $(>8,500$ lbs. GVW). However, only the EIA forecast appears to have been calibrated to the current level of class IIb diesel sales. Current class IIb diesel sales amount to approximately $5 \%$ of total class 1 and 2 light truck sales. Over $95 \%$ of the light-duty diesels are projected to be light trucks. The 
EERE projection foresees only 179,000 light-duty diesels by 2010 , followed by a rapid expansion to 2.1 million diesels in 2015 (Figure 8). Over 40\% of the diesels in the EERE 2015 forecast are passenger cars.

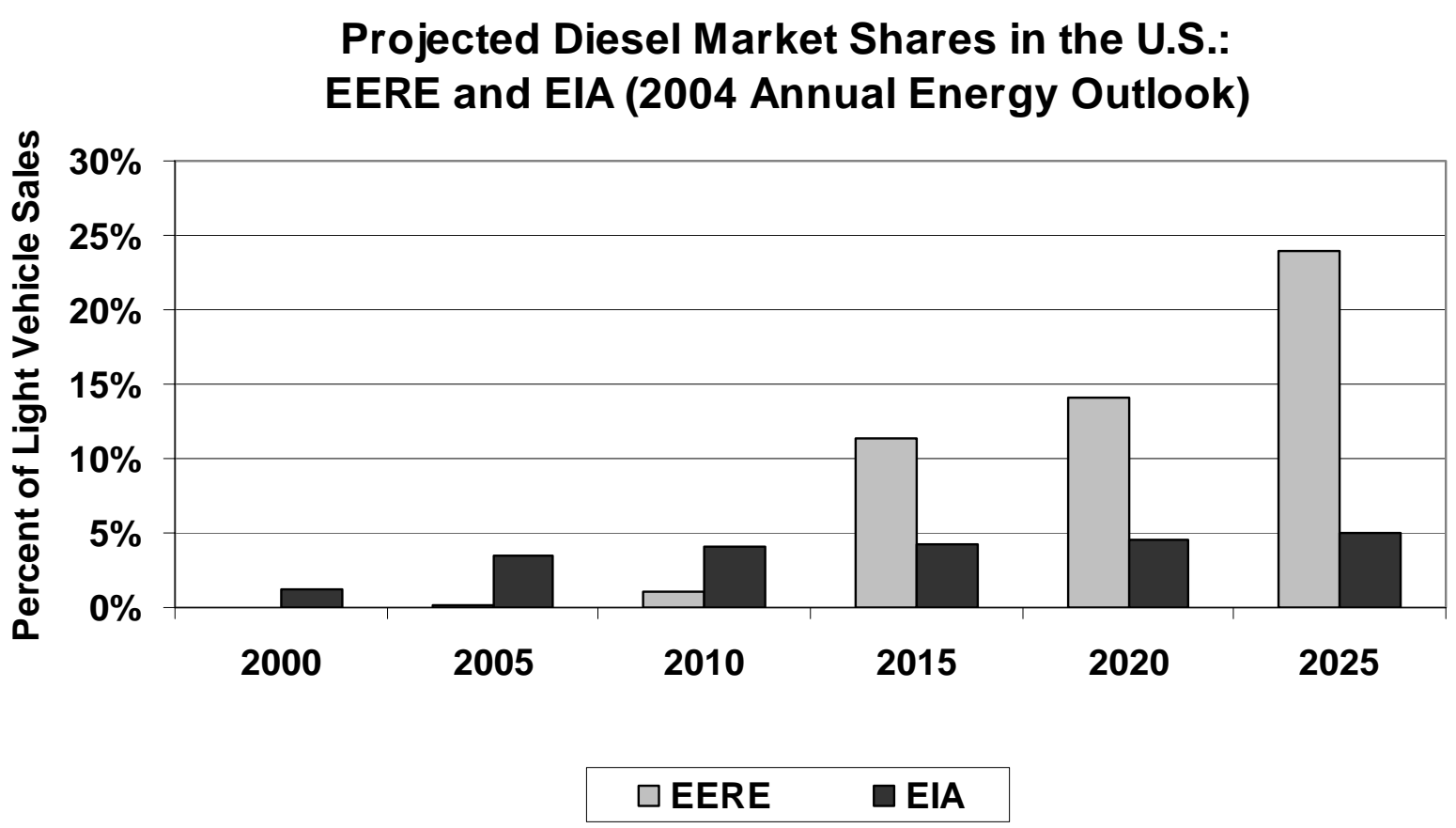

Figure 8. Projected Diesel Market Shares in the United States

These studies reflect a considerable range of uncertainty but also substantial competitive market potential for diesels and hybrids over the next decade. In the sections that follow, we describe a methodology and data for estimating future market success, based on explicit assumptions about both the attributes of hybrid and diesel technologies and the values consumers attach to them. 



\section{METHODOLOGY AND DATA}

Evaluating the future market potentials of hybrid and diesel technologies requires: (1) estimating the extent to which manufacturers will offer products with diesel or hybrid options, and (2) predicting consumers' response to those offerings. The key piece is consumer acceptance, since it is reasonable to assume that if enough consumers are willing to pay for diesels and hybrids, manufacturers will, eventually, produce them in a variety of shapes and sizes. In the near term, to 2008 and even to 2012, the number of diesel or hybrid offerings will be limited by several factors:

(1) risk: uncertainty about the market's response to these technologies will lead manufacturers to proceed with caution;

(2) response time: redesigning vehicles to accommodate hybrid or diesel power trains takes time because engineering expertise is in limited supply and because accelerating the normal rate of retooling increases costs; and

(3) technology status: the technological readiness of both technologies is evolving; for the diesel, there remains a question of how successfully it can reduce pollutant emissions; for the hybrid the question is how quickly and how far it can be moved down the learning curve and its costs reduced.

Indeed, it is likely that almost all hybrid or diesel vehicles that will be available in 2008 have already been announced by manufacturers.

\subsection{SCENARIOS OF DIESEL AND HYBRID INTRODUCTIONS}

Our method for estimating the future market successes of diesels and hybrids consists of two steps. First, we specify a detailed scenario of diesel and hybrid product introductions. Second, we use a quantitative model of vehicle choice to predict the share of the new vehicle market those new products will capture. Scenarios are defined by, (1) time period (2008, 2012 and $>2012$ ), (2) technologies introduced (diesel, hybrid, type of hybrid), and (3) the makes-modelsengines-transmissions to which the technologies are applied.

For 2008, our scenarios are based primarily on manufacturers' product announcements, with a few additional models added based on our judgment. For 2012 we have augmented the 2008 introductions with additional, likely product introductions, based on our judgment. The makes and models for which diesel and hybrid powertrains are assumed to be available in 2008 and 2012 are listed in tables A.1 and A.2 in the appendix. The $>2012$ scenarios are intended to represent market tendencies driven by customer demand and largely unconstrained by make and model availability.

If not every single vehicle configuration offers a diesel and a hybrid option, which configurations will offer them? This question is critically important to the calibration of the consumer choice model. Unfortunately, there is no obviously correct answer to this question, so we test two alternatives in the 2008 and 2012 analyses: (1) the announced or most likely (based on our judgment) configuration of each nameplate, and (2) an "average" configuration for each nameplate. A precise mathematical definition of an average configuration is provided in 
Appendix A. We use the average configuration method as a lower bound estimate since it is reasonable to assume that manufacturers would tend to offer hybrids or diesels on the configurations that would sell best.

In all, eight scenarios were analyzed:

1. $>2012$ all configurations potentially have diesel available

2. $>2012$ all configurations potentially have full hybrid available

3. $>2012$ all configurations potentially have both full hybrid and diesel

4. $>2012$ all configurations potentially have both ISAD hybrid and diesel

5. 2008 best guess, best-judgment make/model/configuration

6. 2008 product plans, average make/model/configuration

7. 2012 best guess, best judgment make/model/configuration

8. 2012 augmented product plan, average make/model/configuration

Diesel and hybrid vehicles will have to sell well enough for manufacturers to achieve scale economies or the product lines will be canceled. Because drivetrains can be used on more than one nameplate, determining exactly how many diesel engines or hybrid drivetrains of a particular design a manufacturer may be selling is difficult and beyond the scope of this study. Instead we eliminate low-selling models with a simple rule of thumb: if the sum of diesel or hybrid sales for a given nameplate (make and model name) is less than a specified threshold, all configurations of that nameplate are deleted and sales shares are recomputed. The default assumption for the 2008 scenarios is 5,000 units, for 201210,000 units must be sold and for $>2012$ the limit is raised to 25,000 units. In addition, in the $>2012$ scenarios every configuration must sell more than 2,000 units or it is deleted.

Finally, a sensitivity analysis was carried out on scenario 3 ( $>2012$ Full Hybrid \& Diesel) to generate a distribution of outcomes and identify the most important factors determining the market success of diesels and hybrids.

\subsection{CONSUMER CHOICE MODEL}

The model of consumer choice must be able to predict the effects of introducing new products into the market as well as predicting the impacts of changes in vehicle attributes such as price, fuel economy, range and power. In addition, it must be possible to calibrate the model to the base year sales of the nearly 1,000 makes, models and configurations in the National Highway Traffic Safety Administration fuel economy database. Furthermore, it is desirable to recognize that there are different segments of the light-duty vehicle market and that consumer preferences and sensitivity to price may vary across these segments, affecting their propensity to accept diesel or hybrid vehicles. The Nested Multi-Nomial Logit (NMNL) random utility model can be used to carry out all of these tasks.

Random utility models such as the NMNL assume that consumers' vehicle choice decisions can be approximately represented as a problem of picking the vehicle which achieves the highest score on a ranking function. The simplest form of ranking, or utility function, is a weighted sum of relevant vehicle attributes such as price, performance, reliability, functionality, and so on. Recognizing that not every consumer attaches the same value to each attribute, and that there 
may be unmeasured or unmeasurable yet relevant attributes, a random component that varies across individual consumers is added to the ranking function. Let $u_{i j}$ be the ranking score for the $\mathrm{i}^{\text {th }}$ vehicle for the $\mathrm{j}^{\text {th }}$ individual, let $w_{l}$ be the weight of the $l^{\text {th }}$ attribute, $x_{i l}$, and let $\varepsilon_{i j}$ be the $\mathrm{j}^{\text {th }}$ individual's random component for the $i^{\text {th }}$ make and model. By convention, the weight for vehicle price, $w_{P}=1$, so that the units of $w_{l} x_{i l}$ are dollars.

$$
u_{i j}=b\left(A_{i}+\sum_{l=1}^{K} w_{l} x_{i l}+\varepsilon_{i j}\right)
$$

Equation 1

In equation $1, A_{i}$ is a constant term reflecting the value, in dollars, of attributes of vehicle $i$ not included in the set of measured attributes, $\mathrm{x}_{i l}$. The parameter $\mathrm{b}$ is a critical parameter in that it determines the sensitivity of consumers' choices to changes in the dollar values of alternatives. Because $\mathrm{w}_{\mathrm{p}}=1$, the coefficient of price (or price slope) is $\mathrm{b}$.

Assuming that the random terms follow the type I extreme value distribution (a somewhat skewed bell shaped distribution similar to the normal distribution), then the probability that the $i^{\text {th }}$ make and model will be chosen, given that the choice will be made from the $\mathrm{k}^{\text {th }}$ vehicle class, is given by the multinomial logit (MNL) function.

$$
p_{i \mid k}=\frac{e^{b u_{i}}}{\sum_{l=1}^{L} e^{b u_{l}}}
$$

Equation 2

Given a large enough population of car buyers, $p_{i}$ will also be the market share of the $i^{\text {th }}$ make and model. Sales for that carline can then be estimated by multiplying total light-duty vehicle sales by the predicted market share, $S_{i}=p_{i} S$. In equation $2, b$ is the coefficient of vehicle price and is also the inverse of the variance of the random utility term, $\varepsilon$.

The NMNL model assumes that choices within a class of vehicles, e.g. choices among makes and models of small SUVs, follow the logit model of equation 2. Choices among vehicle classes follow a similar logit model, in which the utility function for a class is a probability-weighted average of the utility scores of the vehicles within the class. The expected utility of class $k, U_{k}$, is given by the following log sum.

$$
U_{k}=\frac{1}{b} \ln \left(\sum_{i=1}^{n_{k}} e^{u_{i k}}\right)
$$

Equation 3

The probability that a consumer will choose a vehicle from class $\mathrm{k}$ is then given by the following logit function.

$$
p_{k}=\frac{e^{A_{k}+B U_{k}}}{\sum_{K=1}^{n} e^{A_{K}+B U_{K}}}
$$


Here $\mathrm{K}$ is used to index summation over all vehicle classes and $\mathrm{n}$ is the number of vehicle classes. $A_{K}$ is a vehicle class-specific constant term analogous to the vehicle constant term $A_{i}$ in equation 1. Likewise, $\mathrm{B}$ is a slope parameter that determines the sensitivity of choices among vehicle classes to changes in their expected value. The probability that vehicle $\mathrm{i}$ will be chosen from class $\mathrm{k}$, which is equivalent to its expected market share, is given by the product of equations 2 and 4 , the class and conditional vehicle choice probabilities $p_{i k}=p_{i \mid k} p_{k}$.

\subsection{MARKET SEGMENTATION AND CHOICE MODEL STRUCTURE}

The market structure assumed for this analysis is shown in Figure 9. Light-duty vehicles are divided into five classes $(\mathrm{k}=1,5)$ : (1) standard passenger vehicles, (2) luxury vehicles, (3) sportscars, (4) pick-up trucks, and (5) standard vans. Standard passenger vehicles are further divided into passenger cars and passenger trucks. Passenger cars contain small, compact and midsize-large cars; passenger trucks comprise minivans, as well as small and large SUVs. Luxury vehicles are further divided into cars and trucks, sportscars are divided into luxury and standard segments, and pick-ups are split into small and large size classes (Table 6).

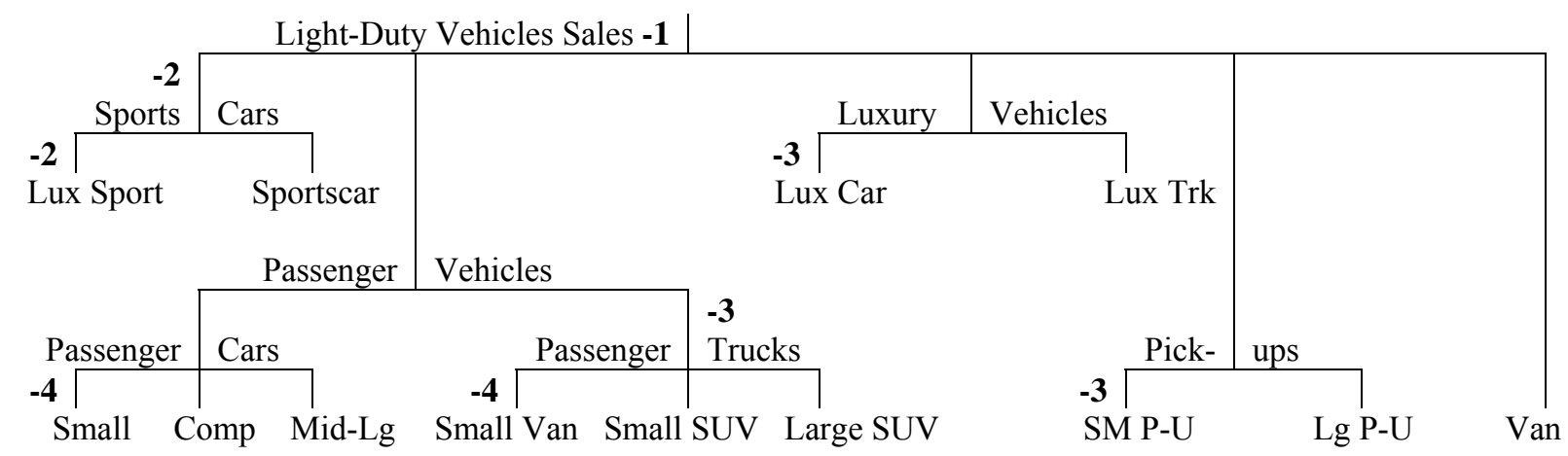

Make/Model/Configuration Choices -7 to -9

Figure 9. Nested Multinomial Logit Model Structure and Approximate Price Elasticities (shown in bold numbers)

A useful feature of the NMNL model is the ability to group more similar vehicle types into "nests" within which demand will be more sensitive to price (elastic) than choices among the nests. The implication of Figure 9, for example, is that the choice among a small, compact and midsize-large car will be more price sensitive than the choice between a car and all sizes of passenger trucks. Choices among (1) standard van, (2) pick-up, (3) luxury vehicle, (4) passenger vehicle, and (5) 2-seater vehicle will be even less price sensitive, because these vehicle types serve very different functions. Within the lowest level nests, choice among makes and models of large SUVs, for example, will be most sensitive to small price changes. A price elasticity of -7 , for example, implies that a $2 \%$ increase in price would produce a $14 \%$ reduction in market share. 
Table 6 (Part 1). Definitions of Vehicle Classes

\begin{tabular}{lccr}
\hline \multicolumn{1}{c}{ Vehicle Class } & \multicolumn{3}{c}{ Number of } \\
& CEC Class & Configurations & Price \\
\hline 1. Minicompact \& Subcompact & 1,2 & 102 & $<\$ 35,000$ \\
2. Compact & 3 & 125 & $<\$ 35,000$ \\
3. Midsize \& Large & & 94 & $<\$ 35,000$ \\
4. Small Van & 9 & 36 & $<\$ 35,000$ \\
5. Small SUV & 11,13 & 162 & $<\$ 35,000$ \\
6. Large SUV & 12 & 13 & $<\$ 35,000$ \\
7. Small Pick-up & 7 & 64 & $<\$ 35,000$ \\
8. Large Pick-up & 8 & 56 & $<\$ 35,000$ \\
9. Luxury Sedan & $1-5$ & 117 & $>\$ 35,000$ \\
10. Luxury Truck & $7-16$ & 43 & $>\$ 35,000$ \\
11. Standard Sportscar & 6 & 37 & $<\$ 35,000$ \\
12. Luxury Sportscar & 6 & 49 & $>\$ 35,000$ \\
13. Standard Van & 10 & 32 & $<\$ 35,000$ \\
\hline
\end{tabular}

Table 6 (Part 2). California Energy Commission (CEC) Vehicle Classification System

\begin{tabular}{|c|c|c|}
\hline \multicolumn{3}{|c|}{ Passenger Cars } \\
\hline CEC Classes & \multicolumn{2}{|c|}{$\begin{array}{c}\text { Passenger Volume } \\
\text { (Cubic Feet) }\end{array}$} \\
\hline 1. Mini & \multicolumn{2}{|c|}{ Under 82} \\
\hline 2. Sub Compact & \multicolumn{2}{|c|}{$82-89$} \\
\hline 3. Compact & \multicolumn{2}{|c|}{$90-95$} \\
\hline 4. Mid Size & \multicolumn{2}{|c|}{$96-105$} \\
\hline 5. Large & \multicolumn{2}{|c|}{$106+$} \\
\hline 6. Sports & \multicolumn{2}{|c|}{ Under 89} \\
\hline \multicolumn{3}{|c|}{ Trucks } \\
\hline & Passenger \& & Gross Vehicle \\
\hline CEC Class & $\begin{array}{l}\text { Cargo Volume } \\
\text { (cu feet) }\end{array}$ & $\begin{array}{c}\text { Weight Rating } \\
\text { (lbs) }\end{array}$ \\
\hline 7. Compact Pickup & & $<4,500$ \\
\hline 8. Standard Pickup & & $4,500-8,500$ \\
\hline 9. Compact Van & $<=170$ & \\
\hline 10. Standard Van & $>170$ & \\
\hline 11. Compact Utility & $120-170$ & \\
\hline 12. Standard Utility & $>170$ & \\
\hline 13. Mini Utility & $<120$ & \\
\hline 16. Truck Chassis Only & & \\
\hline
\end{tabular}




\subsection{CHOICE MODEL CALIBRATION}

Calibration of the NMNL model to base year 2002 sales and vehicle attributes requires three steps. First, price slopes must be estimated for every nest and for every level of choice shown in Figure 1. The price slopes are critical parameters and are used in estimating coefficients for all the other attributes. Second, values per unit must be estimated for all variables included in the NMNL model. Attribute values are converted to NMNL model coefficients by multiplying values per unit by the purchase price coefficient. Third, intercept terms must be estimated to insure that the NMNL model exactly predicts the base year market shares of, (1) every make, model and configuration, and (2) every vehicle market segment shown in Figure 9.

Price slopes not only determine the sensitivity of demand to purchase price but to all other variables included in the model. In the NMNL model, the price coefficients define the importance of unobserved attributes, factors left out of the formal model. If choice is highly price-sensitive, it implies that consumers perceive vehicles to be very similar except for the factors explicitly included in the model. If choice is relatively insensitive to price, it implies that most of the important factors on which consumers base their choices are not explicitly represented in the model. If choice is insensitive to price, the choice model will tend to give all vehicles an equal share of the market. In considering how sensitive choice may be to price, it is important to keep in mind that choices at the lowest level nests in Figure 1 are among similar vehicles, including diesel, hybrid or conventional gasoline versions of the same make and model. Thus, it is reasonable to assume a high degree of similarity with respect to attributes excluded from the model and, therefore, relatively high sensitivity to price. At the highest level, the choice among a sportscar, standard passenger vehicle, luxury vehicle, pick-up truck and standard van will be based primarily on factors not explicitly included in our NMNL model. Choices at this level should be much less sensitive to price. Indeed, the theory of NMNL models requires that price sensitivity uniformly decrease as one moves from the lowest level choices upward. This theoretical requirement is very useful in calibrating the model's price slopes.

Given the price and attribute coefficients, intercepts must be estimated for every make, model and configuration. This allows the expected utilities of classes to be computed. Given the class expected utilities and class price slopes, intercept terms can be calculated for each market segment. This calibration insures that the NMNL model exactly predicts each make, model and configuration share, and all the class shares for the base year.

\subsection{PRICE SLOPES}

Price slopes are computed using their relationship to price elasticity, vehicle price, and market share in the NMNL model. Let $\beta_{\mathrm{k}}$ be the price elasticity for choices in vehicle class $\mathrm{k}, \mathrm{P}_{\mathrm{k}}$ the average price of a vehicle in the class, and let $p_{k}$ be the average market share for vehicle configurations in class $\mathrm{k}$. Then the price slope for class $\mathrm{k}$ is given by equation 5 .

$$
b_{k}=\frac{\beta_{k}}{P_{k}\left(1-p_{k}\right)}
$$


The same relationship can be used to calculate price elasticities for choices among vehicle classes.

McManus (2004) presents useful survey data on the potential sensitivity of diesel and hybrid market shares to their incremental prices. For each of the two alternative powerplants, a J.D. Power and Associates survey asked respondents how likely they would be to buy that powerplant if it cost a certain amount more than a comparable gasoline engine vehicle. Demand, in terms of market share, was set equal to the sum of those responding they would definitely or probably want to buy the powertrain in question. For the diesel, the cost increments were $\$ 1,500, \$ 2,500$, and $\$ 3,500$ (2003 dollars). For the hybrid the cost increments were $\$ 3,000, \$ 4,000$ and $\$ 5,000$. Table 7 shows the market shares and cost increments, and implied price elasticities based on the midpoint formula for computing arc elasticities. In both cases, the price elasticities for the initial price increment are just over -8 , indicating highly elastic demand. In both cases price elasticities decrease with increasing price.

Table 7. Estimated Price Elasticities for Diesel and Hybrid Market Shares Based on a Survey by J.D. Power and Associates

\begin{tabular}{lcccc}
\hline Price Increase & Market Share & $\begin{array}{c}\text { Relative Change } \\
\text { in Price } \\
\text { (Base }=\$ 25,026)\end{array}$ & $\begin{array}{c}\text { Relative } \\
\text { Change in } \\
\text { Share }\end{array}$ & $\begin{array}{c}\text { Arc Elasticity } \\
\text { Using Midpoint } \\
\text { Formula }\end{array}$ \\
\hline Diesel & & & & \\
$\$ 0$ & .75 & - & - & - \\
$\$ 1,500$ & .44 & .0599 & -0.514 & -8.6 \\
$\$ 2,500$ & .34 & .0400 & -0.261 & -6.5 \\
$\$ 3,500$ & .28 & .0400 & -0.182 & -4.6 \\
\hline \multicolumn{1}{c}{ Hybrid } & & & & \\
$\$ 0$ & .59 & - & - & - \\
$\$ 3,000$ & .21 & .1199 & -0.971 & -8.1 \\
$\$ 4,000$ & .19 & .0400 & -0.057 & -1.4 \\
$\$ 5,000$ & .18 & .0400 & -0.061 & -1.5 \\
\hline
\end{tabular}

The inferences shown in Table 7 must be interpreted with caution because they are based on what consumers say they would do rather than what they actually did, and because of the crudeness of the estimation method. Nonetheless, the numbers are generally consistent with other price elasticity estimates from the economic literature. Greene (1986) analyzed the choice between gasoline and diesel engines for the same make and model in the U.S. market between 1979 and 1983 and found a price elasticity of approximately -10 (Greene, 1994). For choices between makes and models, Irvine (1993) obtained price elasticities ranging from -4.6 to -17.0, with a mean of -10.4. Berry et al. (1995) analyzed choices among 2,217 carlines from 1971 to 1990 and found that elasticities for 1990 model year cars ranged from -6.5 to -3.1 , with price sensitivity generally decreasing with increasing price. In a similarly comprehensive analysis, Bordley (1994) found an average own price elasticity of -5 for choices among makes and models. Bordley also found a price elasticity of -2 for choices among broad market segments (e.g., subcompact, sports car, etc.). Finally, there is a general consensus that the price elasticity of demand for light-duty vehicles overall is close to -1 (Kleit, 1990; McCarthy, 1996; Bordley, 1994). 
Price slope coefficients are calculated from assumed price elasticities, base year vehicle prices and market shares, as shown in equation 5. The default price elasticities assumed at each level of the choice structure are shown in Figure 9. The resulting price slopes and the data used to compute them are provided in Table 8 .

Table 8. Price Slopes, Elasticities, Prices and Market Shares for Market Segments

\begin{tabular}{lcccccc}
\hline & 2002 Market & Make/Model & Average & Price & Average & Price \\
& Share (\%) & $\begin{array}{c}\text { Count } \\
\text { Elasticity }\end{array}$ & $\begin{array}{c}\text { Price } \\
\text { Slope }\end{array}$ \\
\hline All Vehicle Classes & & & $20.00 \%$ & -2 & $\$ 25,026$ & -0.000100 \\
Passenger Vehicle & $72.59 \%$ & & $50.00 \%$ & -3 & $\$ 22,769$ & -0.000207 \\
$\quad$ Passenger Car & $43.35 \%$ & & $33.33 \%$ & -4 & $\$ 20,349$ & -0.000295 \\
Small Car & $7.61 \%$ & 102 & $0.98 \%$ & -7 & $\$ 17,226$ & -0.000410 \\
Midsize Car & $14.53 \%$ & 125 & $0.80 \%$ & -7 & $\$ 19,234$ & -0.000367 \\
Large Car & $21.22 \%$ & 94 & $1.06 \%$ & -7 & $\$ 22,233$ & -0.000318 \\
$\quad$ Passenger Truck & $29.24 \%$ & & $33.33 \%$ & -4 & $\$ 26,357$ & -0.000228 \\
Minivan & $7.01 \%$ & 36 & $2.78 \%$ & -7 & $\$ 25,651$ & -0.000281 \\
Small SUV & $20.40 \%$ & 162 & $0.62 \%$ & -7 & $\$ 26,208$ & -0.000269 \\
Large SUV & $1.83 \%$ & 13 & $7.69 \%$ & -7 & $\$ 30,718$ & -0.000247 \\
$\quad$ Pick-up & $15.31 \%$ & & $50.00 \%$ & -3 & $\$ 22,451$ & -0.000267 \\
Small Pick-up & $5.19 \%$ & 64 & $1.56 \%$ & -7 & $\$ 19,099$ & -0.000372 \\
Large Pick-up & $10.12 \%$ & 56 & $1.79 \%$ & -9 & $\$ 24,170$ & -0.000379 \\
$\quad$ Luxury & $8.53 \%$ & & $50.00 \%$ & -3 & $\$ 47,429$ & -0.000127 \\
Luxury Sedan & $3.95 \%$ & 117 & $0.85 \%$ & -7 & $\$ 47,256$ & -0.000149 \\
Luxury Truck & $4.59 \%$ & 43 & $2.33 \%$ & -7 & $\$ 47,578$ & -0.000151 \\
$\quad$ Sportscar & $2.88 \%$ & & $50.00 \%$ & -2 & $\$ 29,534$ & -0.000135 \\
Standard Sportscar & $2.30 \%$ & 37 & $2.70 \%$ & -7 & $\$ 23,393$ & -0.000308 \\
Luxury Sportscar & $0.57 \%$ & 49 & $2.04 \%$ & -9 & $\$ 54,159$ & -0.000170 \\
$\quad$ Van & & & & & & \\
Standard Van & $0.69 \%$ & 32 & $3.13 \%$ & -7 & $\$ 23,726$ & -0.000305 \\
\hline
\end{tabular}

\subsubsection{Estimating the Value of Attributes}

Attribute coefficients are calculated from the estimated value in dollars of one unit of an attribute. The slope coefficient for an attribute is its value per unit times the appropriate price slope. To the greatest extent possible, attribute values are derived from assumptions or taken from the existing economic literature. For example, it is possible to calculate the value of a change in fuel economy by calculating the present value of fuel savings. While this method requires making a number of arguable assumptions, it has the advantage of transparency. The behavior of the model is directly dependent on its coefficients which can be directly traced to specific assumptions about consumer behavior. Another virtue of this approach is that it makes it possible to test the sensitivity of model predictions to key assumptions such as the price of fuel, consumer discount rates, or the value of time spent refueling. 


\subsubsection{Fuel Economy}

The value of fuel economy is derived from assumptions about vehicle use, the consumer's payback period and discount rate. EPA test fuel economy numbers are discounted to more accurately reflect real-world driving experience. For conventional gasoline vehicles, EPA composite MPG numbers are multiplied by 0.85 . Although there is not yet definitive evidence, it appears that hybrid vehicle MPG should be discounted more severely $(0.80)$ and diesel powered vehicles less (0.925). Since fuel costs are in units of dollars per mile, the attribute weight for fuel cost must be in units of present value miles, in other words miles driven over the consumers' payback period, discounted to present value. The assumptions for these calculations are shown in Table 9. The annual miles by vehicle class for the first year of ownership are shown in the first column. Usage decreases with age and the rates of decline are given in the second column. It is assumed that consumers demand a simple 3-year payback, that is, they count the first three years of undiscounted fuel savings.

Fuel economy determines the fuel cost per mile of travel, which equals the price of fuel, $\mathrm{P}_{\mathrm{f}}$, divided by fuel economy in miles per gallon, $\mathrm{E}$. Thus, the value weight translates fuel cost per mile of travel into present value dollars (equivalent to dollars spent on purchase price). In effect, it answers the question, "How much is a change of $\$ 1$ per mile in fuel costs worth at the time of purchase?" This depends on how many miles the vehicle will be driven over time, $M(t)=M_{0} e^{-\delta t}$ , the buyer's payback period, $\mathrm{L}$, and discount rate, $r .{ }^{1}$ The present value of fuel cost is given by the following equation, in which $\mathrm{w}_{\mathrm{f}}$ is the fuel cost per mile weight.

$$
V_{f}=\int_{t=0}^{L} \frac{P_{f}}{E} M_{o} e^{-\delta t} e^{-r t} d t=\frac{P_{f}}{E} \int_{t=0}^{L} M_{o} e^{-\delta t} e^{-r t} d t=\frac{P_{f}}{E} w_{f}
$$

Equation 6

Equation 6 reveals that the fuel cost per mile weight is in units of discounted or present value miles. Multiplying $\mathrm{w}_{\mathrm{f}}$ by the appropriate class-specific price slope yields the coefficient for fuel cost per mile. The reference assumptions are that consumers value fuel costs using a simple 3year payback period, i.e., $\mathrm{L}=3, \mathrm{r}=0$ (Table 9). This same assumption was one of two used in the National Academy of Sciences (NRC, 2002) assessment of U.S. fuel economy regulations, and is also roughly consistent with a recent nationwide random sample survey (Caravan, 2004) which indicated a 2.5 year payback period with an unspecified discount rate. Estimates based on a recent survey of California residents implied payback periods ranging from 2 to 10 years (Adler, et al., 2004).

\subsubsection{Range}

The value of increased range is the present value of time that need not be spent refueling. As noted above, it is likely that there is also a nuisance value associated with refueling events. However, in the absence of specific evidence about the nuisance cost of refueling and because we would prefer to undervalue rather than overvalue the attributes of diesel and hybrid vehicles in our analysis, the value of range is based solely on the value of time spent refueling without any additional nuisance value.

\footnotetext{
${ }^{1}$ It may be more accurate to view the discount rate as a required rate of return on an investment in fuel economy.
} 
Table 9. Coefficients of the NMNL Vehicle Choice Model

\begin{tabular}{|c|c|c|c|c|c|c|c|c|c|c|c|c|c|c|}
\hline & \multirow[b]{2}{*}{$\begin{array}{l}\text { Annual } \\
\text { Miles }\end{array}$} & \multicolumn{5}{|c|}{ FUEL ECONOMY SLOPES } & \multicolumn{3}{|c|}{ RANGE SLOPES } & \multicolumn{3}{|c|}{ FUEL AVAILABILITY } & \multicolumn{2}{|c|}{ PERFORMANCE } \\
\hline & & $\begin{array}{l}\text { Rate of Use } \\
\text { Decrease/yr }\end{array}$ & $\begin{array}{c}\text { Payback } \\
\text { Horizon } \\
(\mathrm{yrs})\end{array}$ & $\begin{array}{l}\text { Discount } \\
\text { Rate }\end{array}$ & $\begin{array}{l}\text { Present } \\
\text { Value } \\
\text { Miles }\end{array}$ & $\begin{array}{c}\text { Fuel } \\
\text { cost/mi } \\
\text { Slopes } \\
\end{array}$ & $\begin{array}{l}\text { Tank } \\
\text { Size } \\
\text { (gals) }\end{array}$ & $\begin{array}{c}\text { Minutes } \\
\text { Per } \\
\text { Refuel }\end{array}$ & $\begin{array}{c}\text { Value of Time } \\
(2002 \$ / h r)\end{array}$ & Slopes & $\begin{array}{c}\mathrm{C} \\
\text { Scale }\end{array}$ & $\begin{array}{c}\mathrm{B} \\
\text { Exponent }\end{array}$ & $\begin{array}{c}\text { Value of } \\
1 \mathrm{~N}-\mathrm{m} \\
(2002 \$)\end{array}$ & Slopes \\
\hline Small Car & 15,502 & $4.6 \%$ & 3 & $0.0 \%$ & 42,534 & -17.456 & 13.6 & 6.6 & $\$ 17.91$ & -34.5427 & -0.5 & -0.33333 & $\$ 7$ & 0.00287 \\
\hline Midsize Car & 15,502 & $4.6 \%$ & 3 & $0.0 \%$ & 42,534 & -15.604 & 14.5 & 6.7 & $\$ 20.00$ & -35.0513 & -0.5 & -0.33333 & $\$ 7$ & 0.00257 \\
\hline Large Car & 15,502 & $4.6 \%$ & 3 & $0.0 \%$ & 42,534 & -13.536 & 17.4 & 7.1 & $\$ 23.12$ & -36.9490 & -0.5 & -0.33333 & $\$ 7$ & 0.00223 \\
\hline Minivan & 17,239 & $4.3 \%$ & 3 & $0.0 \%$ & 47,569 & -13.352 & 20.7 & 7.5 & $\$ 26.67$ & -44.3941 & -0.5 & -0.33333 & $\$ 10$ & 0.00196 \\
\hline Small SUV & 17,955 & $5.7 \%$ & 3 & $0.0 \%$ & 48,262 & -12.970 & 18.9 & 7.3 & $\$ 27.25$ & -42.7935 & -0.5 & -0.33333 & $\$ 10$ & 0.00188 \\
\hline Large SUV & 17,955 & $5.7 \%$ & 3 & $0.0 \%$ & 48,262 & -11.914 & 26.0 & 8.1 & $\$ 31.94$ & -51.5016 & -0.5 & -0.33333 & $\$ 10$ & 0.00173 \\
\hline Small Pick-up & 19,151 & $5.8 \%$ & 3 & $0.0 \%$ & 51,381 & -19.131 & 19.1 & 7.3 & $\$ 19.86$ & -46.1849 & -0.5 & -0.33333 & $\$ 10$ & 0.00261 \\
\hline Large Pick-up & 19,151 & $5.8 \%$ & 3 & $0.0 \%$ & 51,381 & -19.480 & 25.8 & 8.1 & $\$ 25.13$ & -66.1052 & -0.5 & -0.33333 & $\$ 10$ & 0.00265 \\
\hline Luxury Sedan & 15,502 & $4.6 \%$ & 3 & $0.0 \%$ & 42,534 & -6.355 & 19.2 & 7.3 & $\$ 49.14$ & -60.6890 & -0.5 & -0.33333 & $\$ 15$ & 0.00224 \\
\hline Luxury Truck & 15,502 & $4.6 \%$ & 3 & $0.0 \%$ & 42,534 & -6.407 & 26.1 & 8.1 & $\$ 49.47$ & -68.5169 & -0.5 & -0.33333 & $\$ 15$ & 0.00226 \\
\hline $\begin{array}{l}\text { Standard } \\
\text { Sportscar }\end{array}$ & 15,502 & $4.6 \%$ & 3 & $0.0 \%$ & 42,534 & -13.081 & 15.5 & 6.9 & $\$ 24.32$ & -36.3521 & -0.5 & -0.33333 & $\$ 7$ & 0.00215 \\
\hline $\begin{array}{l}\text { Luxury } \\
\text { Sportscar }\end{array}$ & 15,502 & $4.6 \%$ & 3 & $0.0 \%$ & 42,534 & -7.216 & 17.5 & 7.1 & $\$ 56.31$ & -76.7129 & -0.5 & -0.33333 & $\$ 7$ & 0.00119 \\
\hline Standard Van & 19,151 & $5.8 \%$ & 3 & $0.0 \%$ & 51,381 & -15.648 & 32.5 & 8.9 & $\$ 24.67$ & -57.2262 & -0.5 & -0.33333 & $\$ 10$ & 0.00213 \\
\hline
\end{tabular}


Total lifetime refueling cost is equal to the miles driven per year divided by the effective vehicle range (which gives the total number of refueling events per year) multiplied by the time required to refuel (in hours), multiplied by the value of time (in \$/hr), integrated over the consumers' ownership horizon and discounted to present value.

$$
V_{R}=\int_{t=0}^{L} \frac{v H}{R} M_{o} e^{-\delta t} e^{-r t} d t=\frac{1}{R} \int_{t=0}^{L} v H M_{o} e^{-\delta t} e^{-r t} d t=\frac{w_{R}}{R}
$$

Equation 7

Equation 7 reveals that range should appear as the inverse of range in the NMNL model.

The reference assumptions are a three year time horizon, zero discount rate, $\$ 20$ per hour, an average refueling time of 6 minutes, and an effective storage volume of $80 \%$ of the total fuel tank volume. It is not clear that consumers use the same method to value future time spent refueling as they use to value future fuel savings. However, in the absence of specific evidence, we choose to use consistent methods and assumptions.

\subsubsection{Torque/acceleration/power}

The value of acceleration or power-to-weight is very subjective and a wide range of estimates can be found in the literature. Greene (2001) used a value of $\$ 12.50$ per horsepower (in 1990\$, or about $\$ 16$ in $2002 \$$ ), based on studies by Donndenlinger and Cooke (1997) and Greene and Liu (1988). This is equivalent to $\$ 375$ (2002 \$) per second reduction in 0-60 mph acceleration time. A recent study using stated preference survey data from California (Adler et al., 2004) found values over $\$ 1,000$ per second.

Although there is no exact relationship between torque and horsepower, for most vehicles the ratio is typically about $3 / 2$. This would make the value per $\mathrm{Nm}$ about $\$ 10$ in 2002. A value of $\$ 7$ per $1 \mathrm{Nm}$ of torque is assumed for all vehicles except luxury cars and trucks, for which a value of $\$ 15 / \mathrm{Nm}$ is used. For example, the willingness to pay for an increase in torque from 300 to $400 \mathrm{Nm}$ would be $\$ 700$ to $\$ 1,500$, roughly what consumers would pay for a 6-instead of a 4-, or an 8 -instead of a 6-cylinder engine.

The hybrid's increase in torque is likely to be more pronounced when accelerating from a stop or when rpm is otherwise low, while the diesel's torque will be most noticeable at mid-range engine speed. In the absence of information about the relative value of these two kinds of power, no attempt has been made here to resolve the issue of whether "off the line" acceleration is more valuable than passing acceleration (Santini, 2004). Both are assigned the same value.

\subsubsection{Fuel Availability}

The cost of limited fuel availability is assumed to be a power function of the fraction, $x$, of refueling outlets that offer the fuel in question.

$$
V_{A}=C x^{a}
$$


Greene (1998) found that either a power function or an exponential function fit survey data on the perceived cost of low fuel availability. Nicholas et al. (2004) used a power function to fit data on the extra travel time necessary to refuel on home to work trips in the Sacramento area as the number of service stations was reduced in a simulation modeling analysis. Greene (2001) assumed that the value (cost) of $5 \%$ availability in present, purchase price equivalent dollars was $-\$ 2,750$, while the cost of $10 \%$ availability would be only about $-\$ 1,000$. A power curve fitted to the Nicholas et al. (2004) simulation results and assuming a value of time of $\$ 20.00$ per hour, results in costs of about $-\$ 2500$ at just under $0.5 \%$ availability, decreasing to $-\$ 500$ at about $10 \%$ availability (Figure 10). The associated coefficients are $\mathrm{C}=-0.546$ and $\mathrm{a}=-0.345$. For this analysis, coefficient values of $\mathrm{C}=-0.5$ and $\mathrm{a}=-0.33$ were used. These estimates of the cost of limited fuel availability are considered to be conservative because they do not include any estimate of the risk of running out of fuel or of waiting for a pump if queues form, and because the value of many new car buyers' time is likely to be substantially higher than $\$ 20 / \mathrm{hr}$.

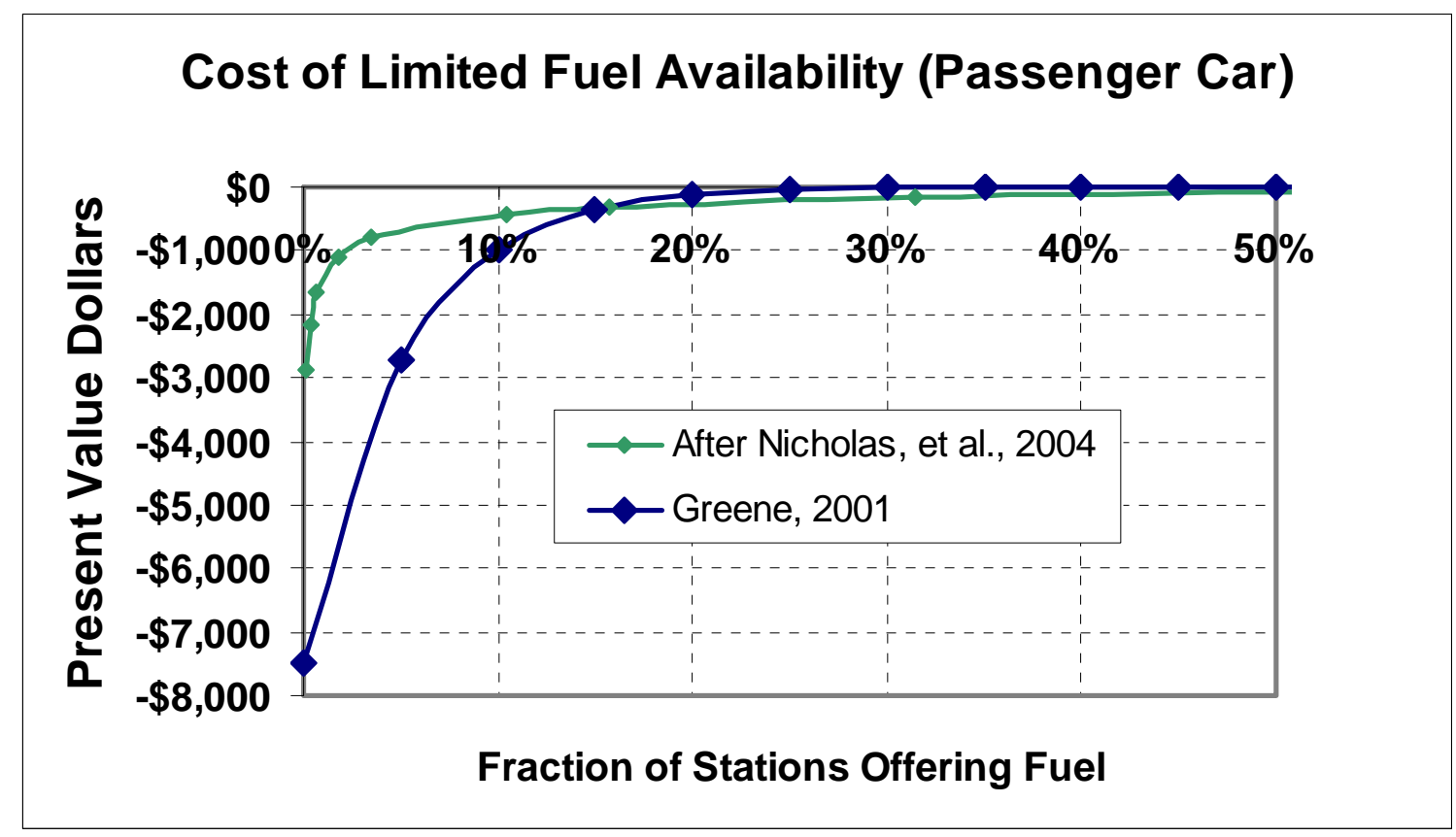

Figure 10. Power Functions Describing the Cost of Limited Fuel Availability

According to the Census Bureau, approximately 42,000 non-truck-stop stations offered diesel fuel in 1997 (Hadder, 2004, p. D-6) out of a total of 127,000 refueling outlets (33\%). Because all truck-stops can be assumed to offer diesel fuel the number of diesel fuel outlets undoubtedly exceeds 42,000. On the other hand, The Census Bureau (2004, table 4.17) report 171,000 retail fueling outlets in 2002 based on a National Petroleum Survey. Despite considerable uncertainty in these numbers, we assume $33 \%$ as the baseline availability in 2008 .

\subsubsection{High Quality Diesel Fuel}

Every potential diesel manufacturer interviewed for this study expressed a desire to see higher quality diesel fuel in the U.S. market. In this study, we do not consider the potential impact of high-quality diesel fuel availability on the market potential for diesel vehicles. However, we note that widely available high-quality diesel fuel could only increase the market potential of light-duty diesels. 
Manufacturers were unanimous in requesting diesel fuel that would meet the World-wide Fuel Charter requirements for Category 4 Diesel Fuel. None thought that high quality diesel fuel would be essential for meeting Tier 2 emissions standards; the low-sulfur diesel coming to U.S. markets in 2006-7 would be adequate for that purpose. Rather, high-quality diesel fuel would allow manufacturers to deliver benefits to diesel car buyers in terms of quicker, easier ignition at low temperatures, faster, smoother warm-up, cleaner injectors and fuel system and reduced engine wear.

Hadder (2004) has analyzed the likely fuel production, logistics and resulting consumer costs of high-quality diesel fuel significantly different from the ultra-low sulfur diesel fuel required to be in the market in 2010, and satisfying the World-wide Fuel Charter requirements. Depending on the volume of sales and market share, the distribution costs of high-quality diesel could add 0-5 cents per gallon to its pump price. Hadder found that the added costs of refining high-quality diesel, principally distillate dearomatization and cetane improver, would add about 3 cents per gallon. Finally, because the energy content per gallon of high-quality diesel is likely to be slightly lower than that of ultra-low sulfur diesel, consumers would suffer another 2 cents per gallon cost increase due to reduced fuel economy. All told, consumers could be expected to pay 6-10 cents per gallon more for high-quality diesel than for ultra-low sulfur diesel. This is, in general, less than the additional cost of premium gasoline versus unleaded regular. Premium gasoline, however, is often required to avoid engine knock. It is highly unlikely that manufacturers would require high-quality diesel fuel, though it might be recommended. Thus, high-quality diesel would be a customer option, purchased only when consumers felt it delivered more in benefits than it cost. In this respect, the availability of high-quality diesel could only increase the desirability of diesel vehicles.

\subsubsection{Extra Features of Hybrids or Diesels}

No attempt was made in this analysis to estimate the potential extra value that hybrids may be able to create due to the availability to generate and store high-voltage electricity or to impute extra value to diesels based on durability or other factors.

\subsubsection{Make, Model and Configuration Intercepts}

Configuration-specific intercepts ensure that the NMNL model exactly predicts base year market shares. The intercepts represent the value to the consumer of all vehicle attributes not explicitly included in this model (all attributes other than price, fuel economy, range, torque and fuel availability). The formulas for computing vehicle and class intercepts can be found in Appendix A.

\subsubsection{Minimum Sales Thresholds}

After introducing the diesel and hybrid vehicles and predicting their market shares, we then delete diesel or hybrid carlines that fail to achieve minimum sales thresholds. This is done by summing sales of diesel or hybrid configurations to the make and model level, and checking for adequate sales to achieve scale economies. Diesels or hybrids with sales less than the threshold value $(5,000$ in $2008 ; 10,000$ in $2012 ; 25,000$ for $>2012)$ sold within a given nameplate are deleted. In addition, in the $>2012$ scenarios each configuration must sell at least 2,000 units. Market penetrations are then be re-estimated. 



\section{RESULTS}

Eight scenarios were developed, two each for 2008 and 2012, and four for beyond 2012 (>2012). For 2008, assumptions about the introductions of hybrid and diesel vehicles are based primarily on manufacturers' announced product plans (a list of makes and models assumed to be introduced can be found in Appendix B). A "best guess" forecast is based on these announcements plus our own judgments about probable new introductions. In general, we believe that diesels and hybrids will most often be introduced on the better selling versions of makes and models. A lower forecast was also constructed based on the assumption that the diesel or hybrid configuration will be an average configuration of its make and model. The mathematics of this method are described in Appendix A. The 2012 scenario builds on the planned introductions of the 2008 scenario and extends them, again based on our judgment. The average 2012 scenario uses the same method of averaging configuration intercept terms as the 2008 scenario.

Two other factors are assumed to differ between 2008, 2012 and $>2012$. In 2008, the minimum sale for the hybrid or diesel versions of a nameplate is set at 5,000 units, reflecting a willingness of manufacturers to accept low volumes during the first few years. In 2012, the minimum production volume is raised to 10,000 . For the $>2012$ scenarios, a minimum make and model sales volume of 25,000 units is assumed. In addition, in the $>2012$ scenarios a minimum sales limit of 2,000 units is enforced for each individual diesel or hybrid configuration. For 2008, diesel fuel is assumed to be available at 33\% of retail outlets. In 2012 and $>2012$, assuming that more diesel vehicles are on the road, availability is increased to $50 \%$.

Because consumers value diversity of choice, the sales of diesel and hybrid vehicles are strongly dependent on the number of makes, models and configurations offered for sale (Table 10). However, economies of scale work against offering many makes and models; the more configurations offered, the fewer sold per configuration. The initial number of makes, models and configurations offering diesel and hybrid versions is strictly an assumption. The model, however, determines which makes and models will exceed the assumed sales thresholds (5,000 for 2008, 10,000 for 2012 and 25,000/2,000 for >2012). This will depend not only on the attractiveness of diesel or hybrid vehicles, but on competition between them. For example, in the Diesel Only scenario, 257 diesel vehicles exceed the sales thresholds. When diesels must also compete with full hybrids in the Diesel/Full Hybrid scenario, the number of diesel vehicles that exceed the sales thresholds drops to 210 .

\subsection{THE LONG-RUN POTENTIAL MARKET SHARES OF DIESEL AND HYBRID VEHICLES}

We begin by exploring the implications of consumers' preferences, unconstrained by the availability of diesel and hybrid offerings. Four $>2012$ scenarios address the question, "How big could the diesel and hybrid markets become if hybrids and diesels were generally available throughout the light-duty vehicle market?" No particular date is attached to these scenarios because they are intended to represent the long-run tendencies of the marketplace. Assuming that customers' preferences will eventually dictate manufacturers' decisions, these scenarios should indicate the direction in which the market will move after the initial hurdles have been 
overcome. How fast and how far the market will move will depend on a number of factors, including the rates of technological progress and learning, manufacturers' willingness to take risks, future fuel prices, government policies towards fuel economy and greenhouse gas emissions, and the evolution of consumers' preferences.

Table 10. Numbers of Diesel and Hybrid Configurations Offered, by Scenario

\begin{tabular}{lcc}
\hline \multicolumn{1}{c}{ SCENARIO } & No. of Diesel & No. of Hybrid \\
(921 Conventional Gasoline Configurations) & Configurations & Configurations \\
\hline 2008 Best Guess & 38 & 54 \\
2008 Average Configuration & 35 & 46 \\
2012 Best Guess & 46 & 90 \\
2012 Average Configuration & 46 & 72 \\
>2012 Diesel Only & 257 & 0 \\
>2012 Hybrid Only & 0 & 235 \\
>2012 Diesel/Full Hybrid & 210 & 155 \\
>2012 Diesel/ISAD & 176 & 228 \\
\hline
\end{tabular}

Rather than guessing which models manufacturers will choose to introduce, we initially assume that all models, body styles and engine-transmission combinations, (except sports cars for diesels and standard vans for both technologies) will be available in conventional gasoline, hybrid and diesel versions. However, if the total diesel or hybrid sales within a make and model do not sum to at least 25,000 units, all diesel or hybrid configurations for that make and model are canceled. In addition, if any individual configuration's sales fall below 2,000 units, that configuration of the make and model is also deleted. No such minimum sales requirements are imposed on conventional gasoline vehicles, which should tend to bias our estimates against hybrids and diesels, to some degree. This will also produce a shift in the distribution of sales toward makes and models with successful diesel or hybrid options.

Four $>2012$ scenarios have been created. Two introduce only diesels or only full hybrids to explore how each competes head-to-head against gasoline. A third assumes that both diesels and full hybrids are widely available, but no other types of hybrids are considered. A final scenario introduces diesels and only the milder ISAD-type hybrids, to determine whether a less expensive but lower fuel economy hybrid would be more or less successful than the full hybrid design.

\subsubsection{Diesels Only}

In head-to-head competition with gasoline, and under the availability assumptions described above, diesels succeed in capturing $31 \%$ of the light duty vehicle market. Were there no minimum sales volume constraints, diesels would have had a 38\% market share. Diesels do better in the light truck market, as anticipated by the Bosch North American diesel market study. Diesel passenger truck sales amount to 1.9 million units, 960,000 diesel pick-ups are sold, and luxury trucks include 250,000 diesels (Figure 11). But 1.8 million diesel passenger cars are also sold, 1.1 million of which are large cars. The tendency to predict a greater diesel market share for trucks is underlined by the fact that more diesel passenger trucks are sold despite the fact that there are fewer configurations of passenger trucks (82) to choose from than passenger cars (95) (Figure 12). 
In the light truck segment, diesel light-duty vehicles average $31.3 \mathrm{MPG}$ in comparison to 24.3 for gasoline. The $31 \%$ diesel market share produces a $7.4 \%$ increase in new light-duty vehicle average fuel economy.

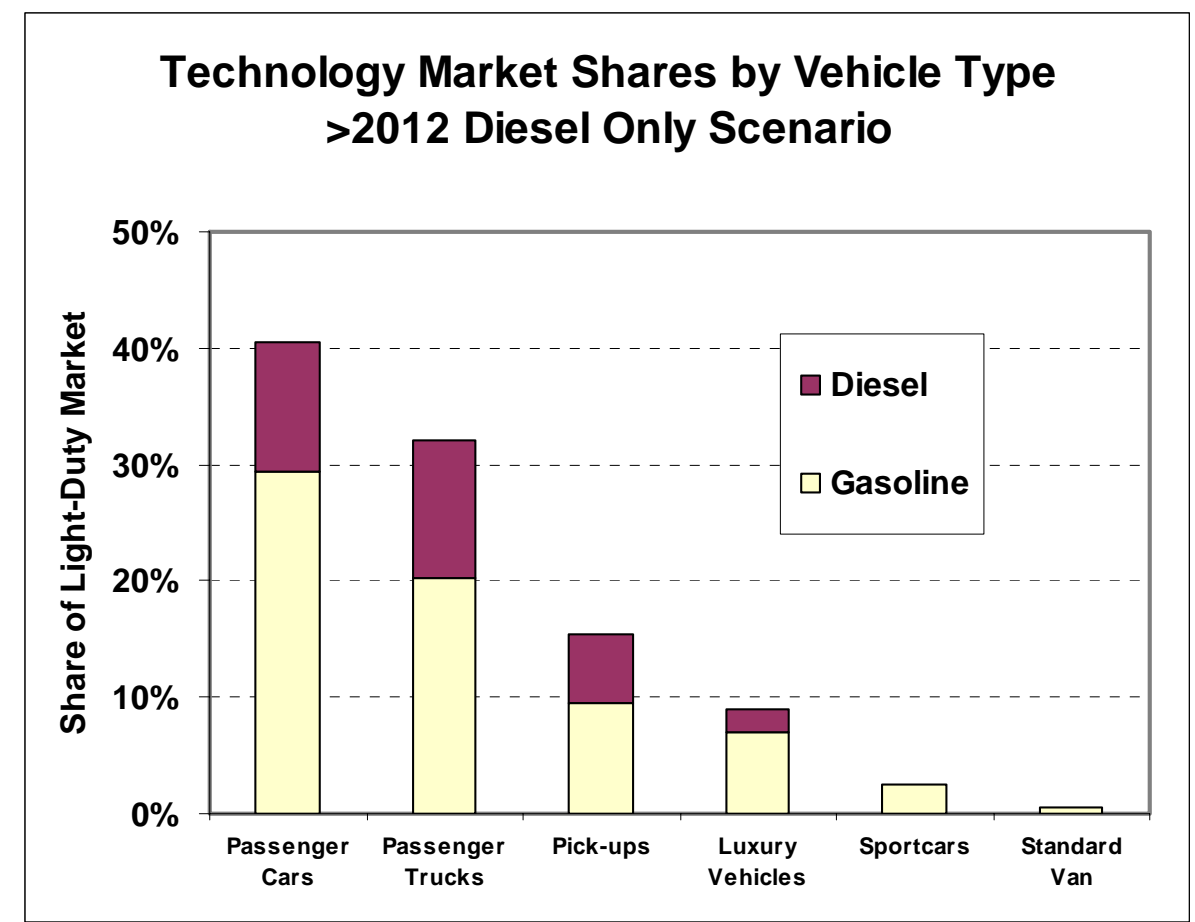

Figure 11. Technology Market Shares by Vehicle Type >2012 Diesel Only Scenario

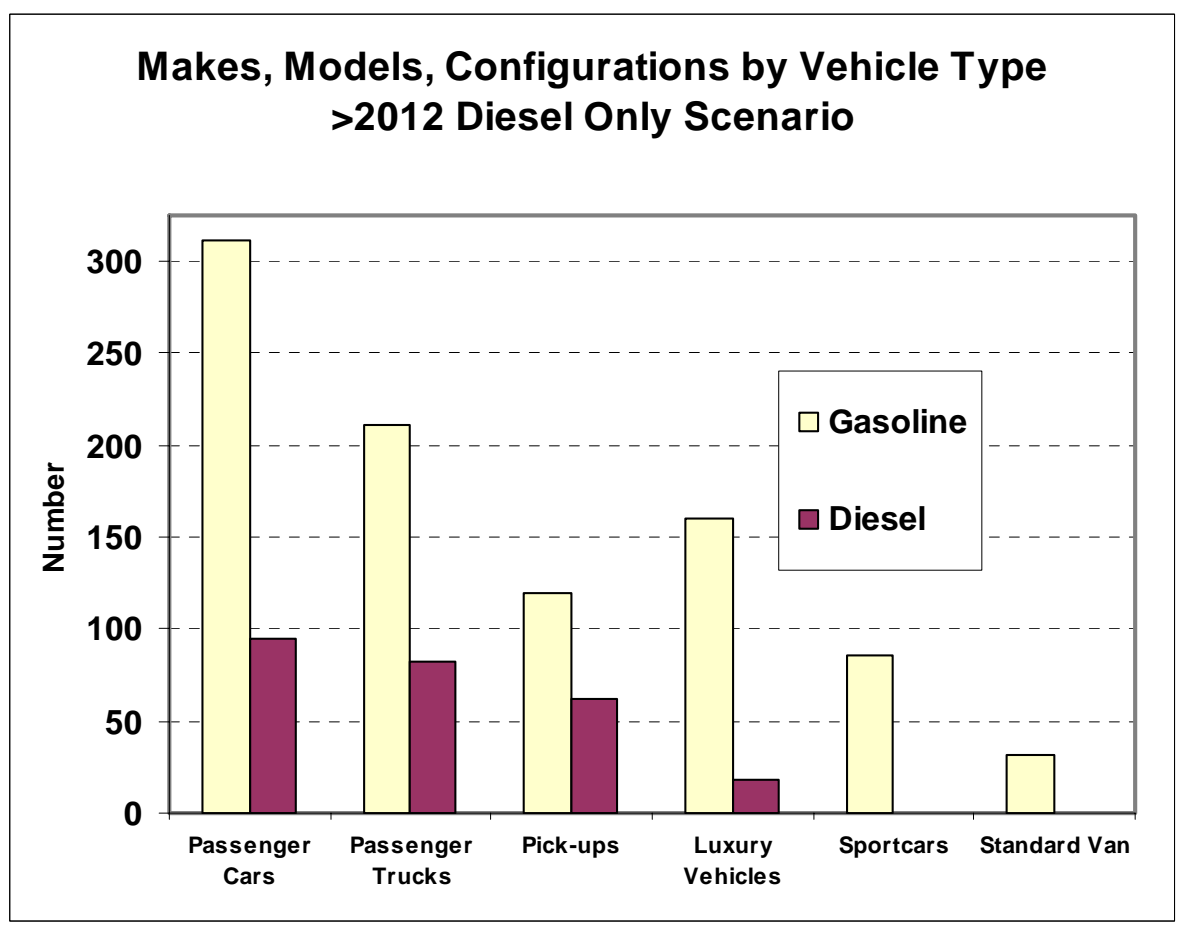

Figure 12. Makes, Models, Configurations by Vehicle Type >2012 Diesel Only Scenario 


\subsubsection{Full Hybrids Only}

Full hybrids take $26 \%$ of the market in direct competition with conventional gasoline engines, (this compares with $31 \%$ for diesels). The somewhat smaller market share for hybrids is a result of the diesel's lower price (see Tables 2 and 4 ) and slightly greater torque (25\% versus $15-20 \%)$. The hybrid's greater fuel economy (35-40\% versus $33 \%)$ and therefore greater range are not enough to make up for the diesel's price and torque advantages. Thus, the diesel seems to offer customers value closer to its purchase price premium than the hybrid, but only a little closer.

Hybrids do reasonably well across vehicle types, selling 1.5 million passenger cars, 1.6 million passenger trucks, 700,000 pick-ups and 270,000 luxury vehicles (mostly trucks) (Figure 13). Hybrids also have fewer passenger car than light truck configurations available (Figure 14).

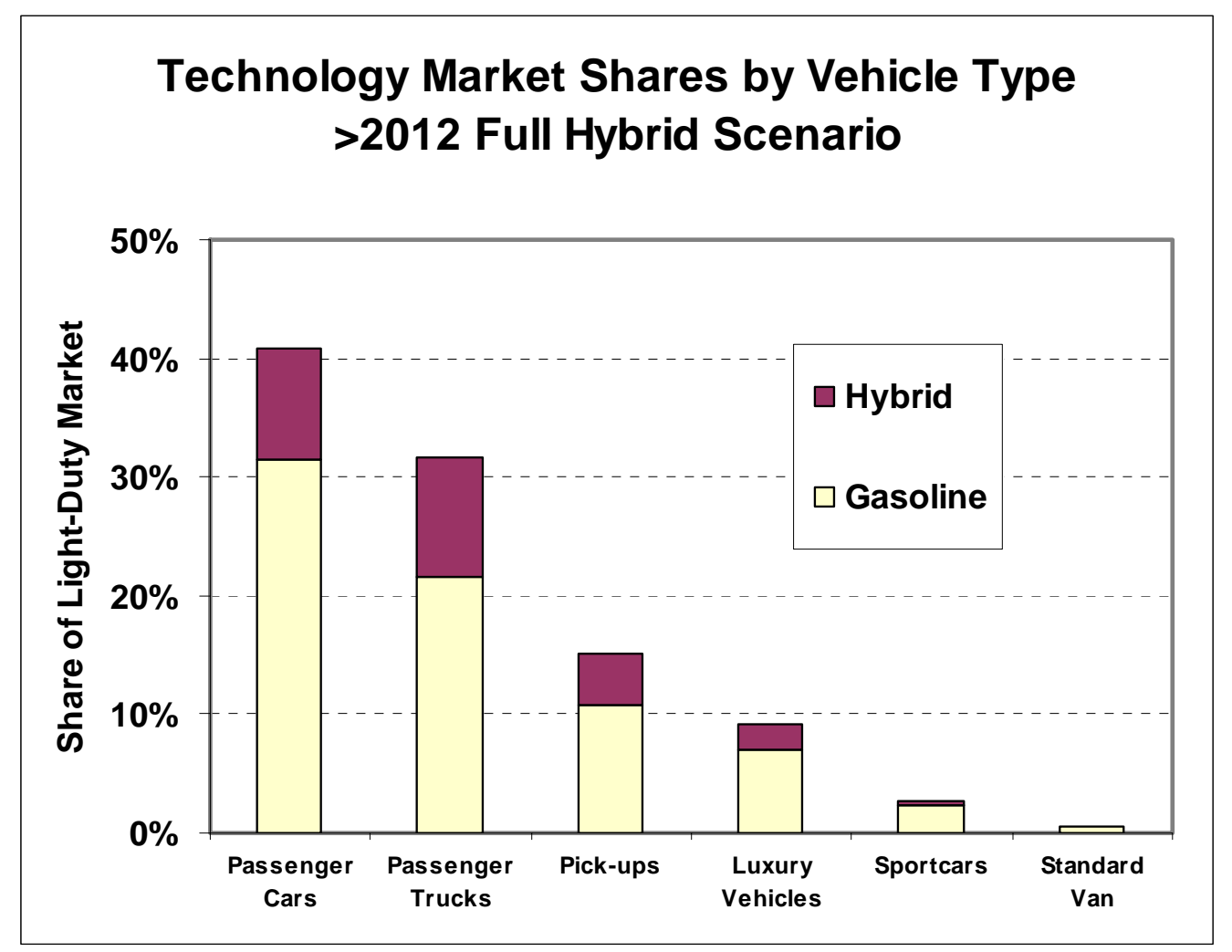

Figure 13. Technology Market Shares by Vehicle Type >2012 Full Hybrid Scenario 


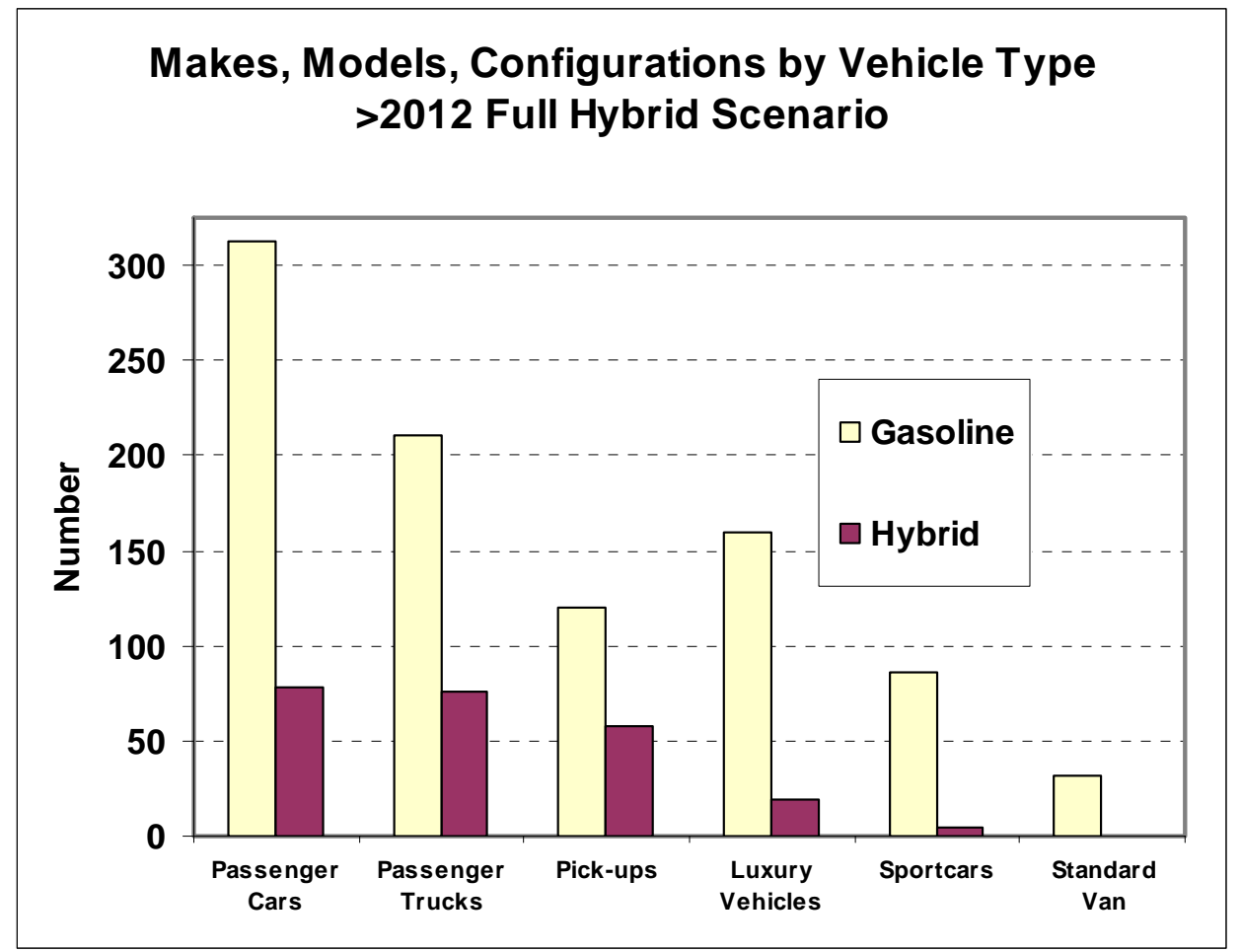

Figure 14. Makes, Models, Configurations by Vehicle Type >2012 Full Hybrid Scenario

The $26 \%$ market share of full hybrids raises overall new light-duty vehicle fuel economy to 25.9 from 24.3 , a $6.7 \%$ increase. Although full hybrids are assumed to deliver $40 \%$ better fuel economy for any given passenger car or small light truck and 35\% for any large light truck, on average the hybrid light-duty vehicle fleet has only $32 \%$ higher fuel economy. The reason for this is that hybrids tend to sell better on the less efficient vehicle configurations. Thus, a greater proportion of the less-efficient configuration hybrids meet the sales threshold. Whereas the average fuel economy of all gasoline vehicles is 24.3 , the average fuel economy of the gasoline vehicles for which hybrid versions are available in the Full Hybrid scenario is 23.5. The addition of new makes and models for these somewhat lower mpg configurations causes a shift in sales in their favor, also increasing the market shares of the classes to which they belong. Such a shift towards vehicle configurations and classes where new options are introduced is an inherent feature of the NMNL model. The mathematics of the model guarantee that introducing new makes and models will produce such sales shifts. The extent of the shifts depends on the NMNL model structure, on its parameters, and on the number and characteristics of the new makes and models introduced. The effect is to reduce the fuel economy increase caused by introducing diesels and hybrids. Another feature of our methodology that also mitigates potential fuel economy gains is the fact that we do not apply the same sales thresholds to gasoline vehicles that we apply to diesel or hybrid vehicles. As a result, there is no culling of lower fuel economy gasoline vehicles in cases where introduction of diesels or hybrids may cause their sales to fall below the threshold level. These two aspects of our method should make our estimates of potential fuel economy increases conservative, all other things equal. 


\subsubsection{Diesels and Full Hybrids}

With equal assumptions about availability of makes and models to start with, diesels do slightly better than hybrids in a three-way competition with conventional gasoline vehicles. Together they capture $40 \%$ of the light-duty vehicle market, with diesels taking $23.8 \%$ to the hybrids' $16.5 \%$ (Figure 15). Both technologies appear to compete better in the light-truck market than in the passenger car market. The diesel's greater success is consistent with the head-to-head results presented above. Not surprisingly, more diesel vehicle makes, models and configurations turn out to be available than hybrid versions (Figure 16).

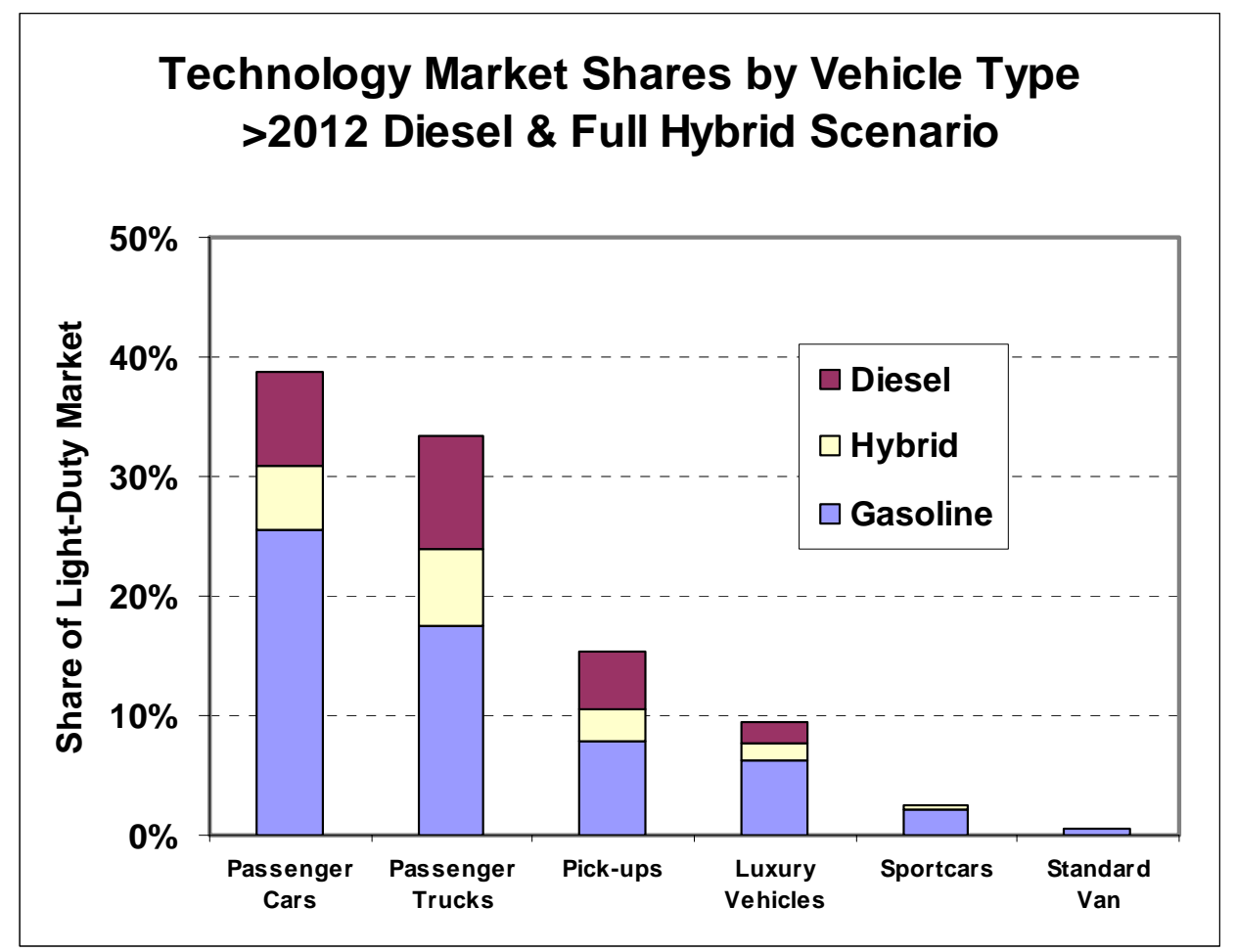

Figure 15. Technology Market Shares by Vehicle Type >2012 Diesel \& Full Hybrid Scenario

The combined effect of both technologies is to raise overall light-duty vehicle fuel economy by almost $10 \%$ to 26.7 MPG. On average, hybrids get 31.3 MPG and diesels 31.0 , in comparison to 24.3 for gasoline vehicles. 


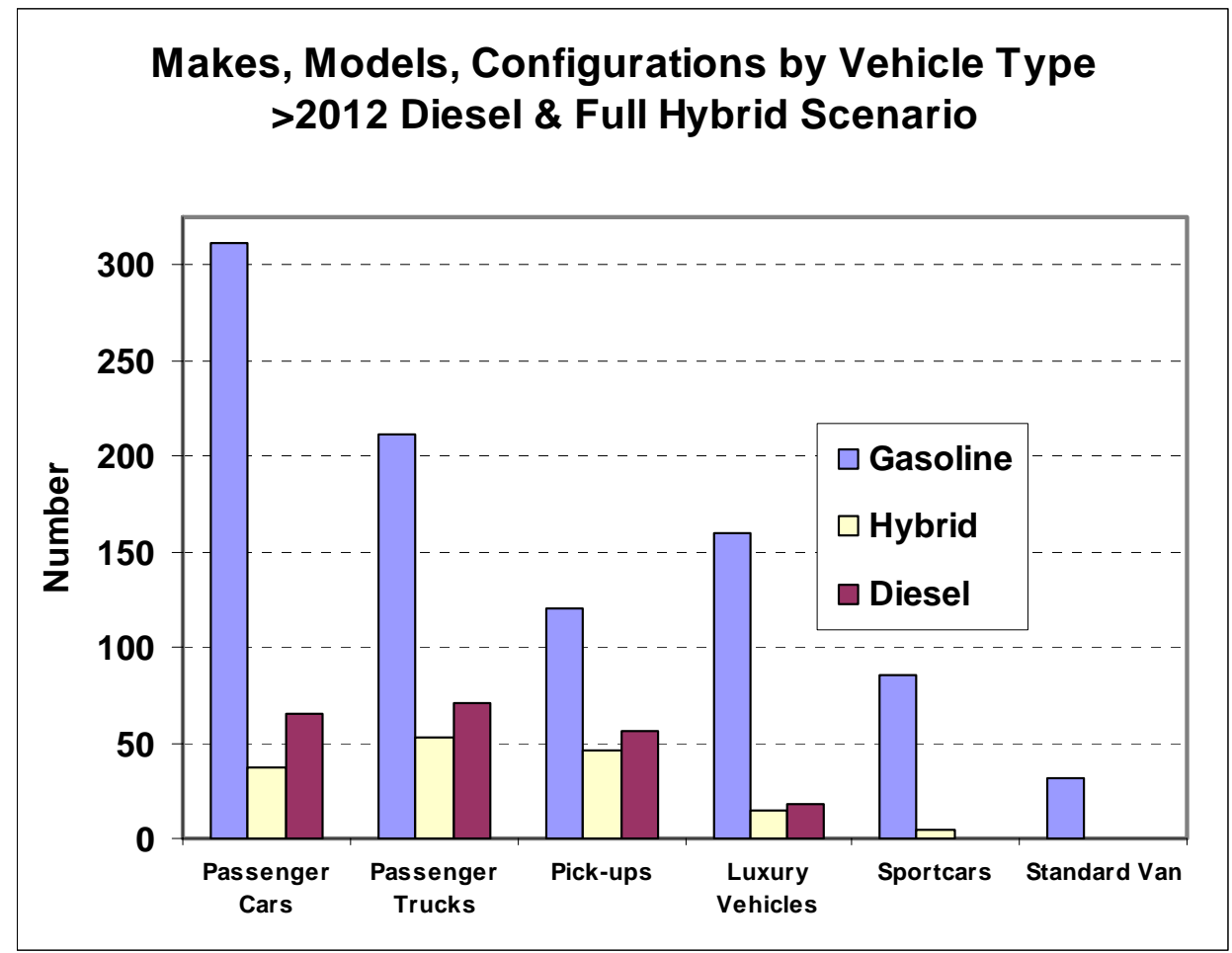

Figure 16. Makes, Models, Configurations by Vehicle Type >2012 Diesel \& Full Hybrid Scenario

\subsubsection{Diesels and ISAD Hybrids}

Mild, ISAD hybrids offer only a $12.5 \%$ increase in fuel economy versus a $35-40 \%$ increase for a full hybrid design. ISADs also increase torque only $10 \%$ in comparison to $15-20 \%$ for a full hybrid. On the other hand, the ISAD system is considerably less expensive, $\$ 1,385$ versus $\$ 3,920$ for a midsize or large passenger car. The lower cost of the ISAD hybrid more than offsets its smaller benefits, with the result that ISAD hybrids capture a larger share of the market $(27 \%)$ than diesels $(19 \%)$ in a three-way competition with conventional gasoline vehicles. The assumption that consumers count only the first three years of fuel savings, rather than the full discounted present value of fuel savings over the life of a vehicle has a great deal to do with the preference seen here for less expensive but less fuel efficient vehicles.

This is the first scenario in which more hybrid passenger cars are sold than hybrids or diesels in any other vehicle class (Figure 17). There are also more makes, models and configurations of hybrids than diesels in every vehicle class (Figure 18). But ISAD hybrids achieve only 26.8 MPG in comparison to 24.3 MPG for conventional gasoline vehicles and 30.6 MPG for diesels. As a consequence, despite the greater combined market share of hybrids and diesels, overall light-duty vehicle MPG increases by only $7 \%$ to 26.0 .

The result that hybrid market share would be higher for milder hybrid technology than for full hybrid technology is consistent with Santini's (2004) findings that mild hybrids and stop/start hybrids are more cost-effective than full hybrids. 


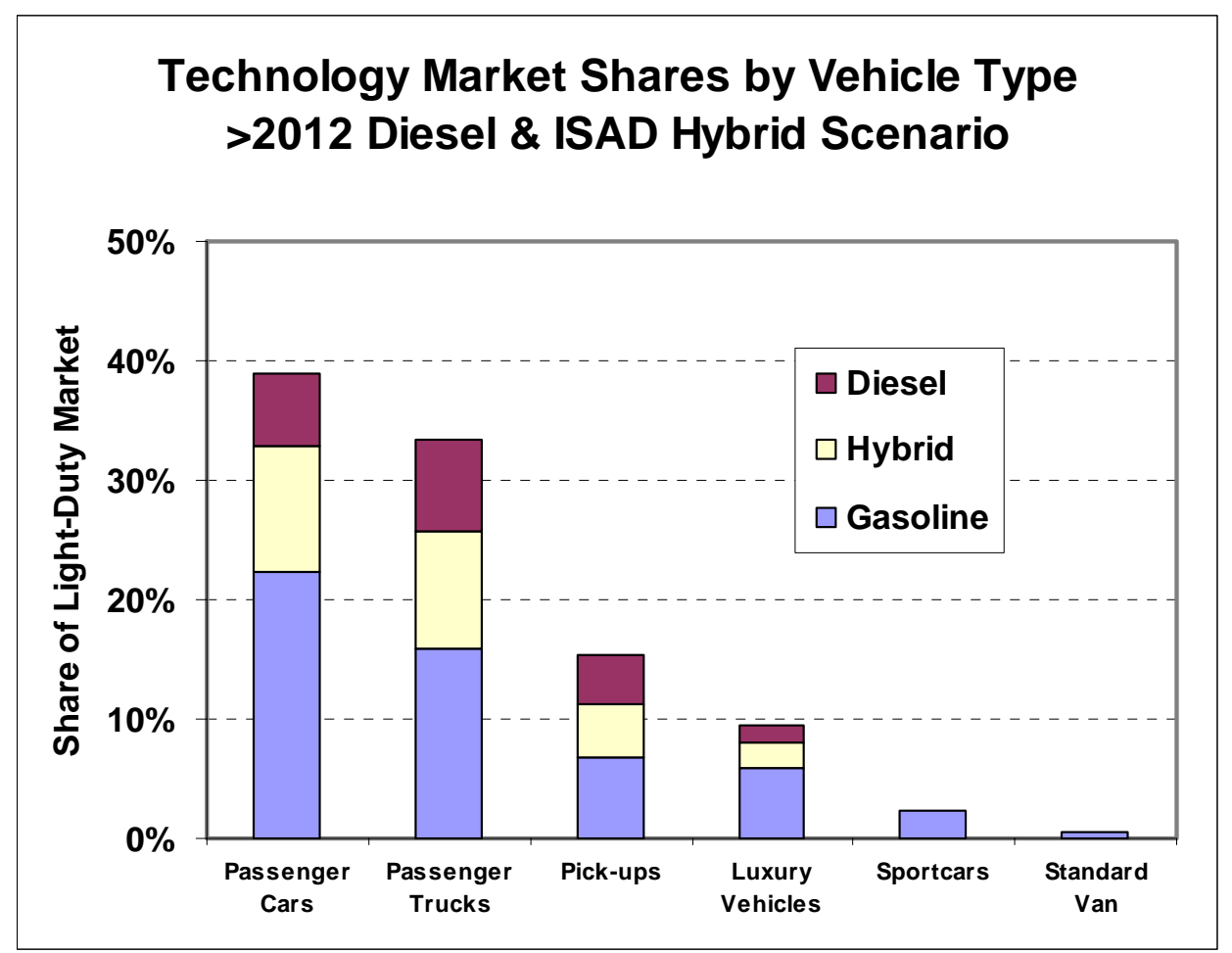

Figure 17. Technology Market Shares by Vehicle Type >2012 Diesel \& ISAD Hybrid Scenario

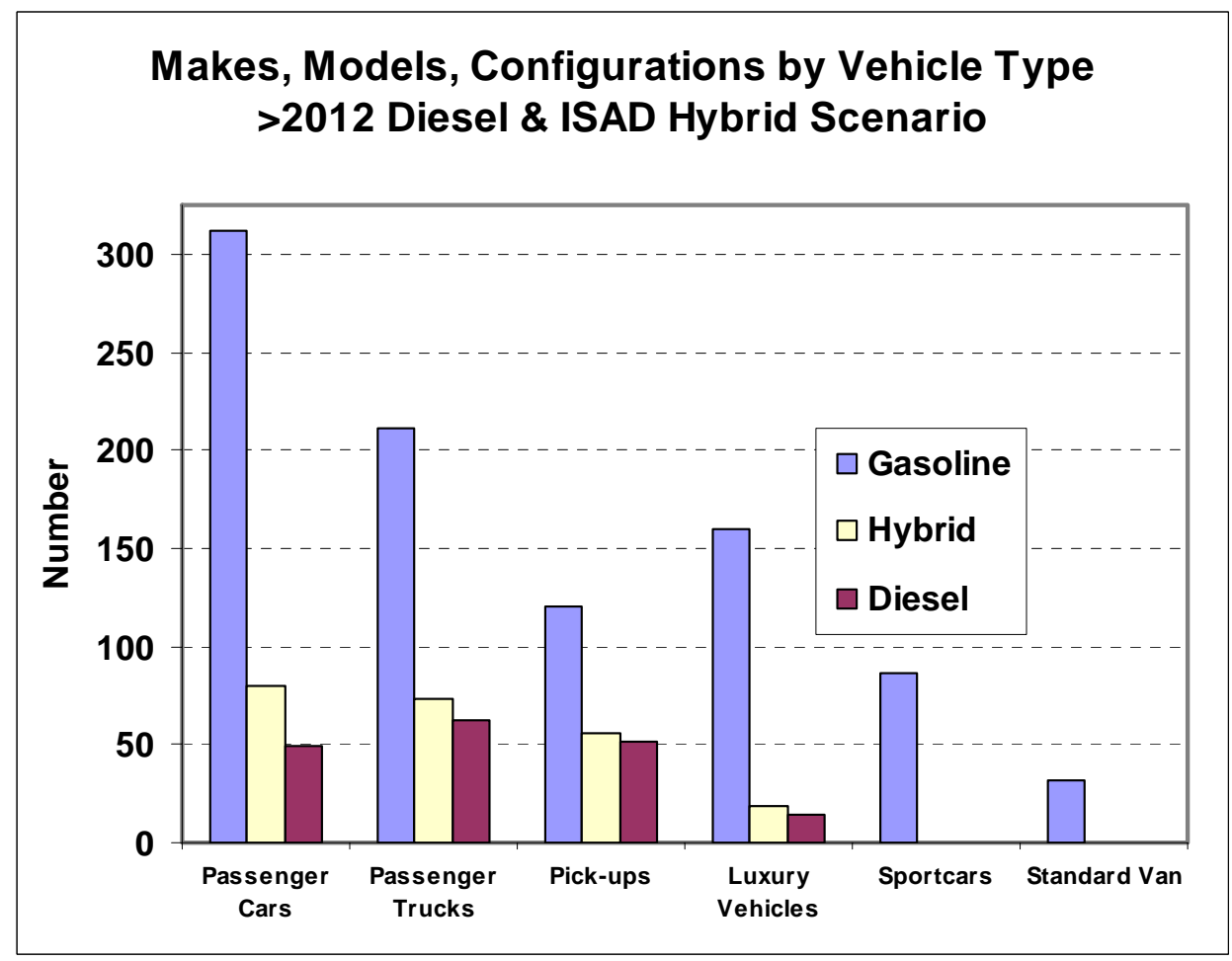

Figure 18. Makes, Models, Configurations by Vehicle Type >2012 Diesel \& ISAD Hybrid Scenario 


\subsection{SCENARIOS}

The two 2008 scenarios produce diesel market shares ranging from $2.4 \%$ ( 0.4 million units) to $3.9 \%$ ( 0.6 million units) of light-duty vehicle sales. The higher estimate is obtained under our "best guess" assumptions. The lower estimate is based on the assumption that the diesel will be similar to the average configuration for the make and model in question (i.e., an average intercept is used). Diesel sales are concentrated in the passenger truck, luxury truck, and pick-up truck market segments in 2008 (Figures $19 \& 21$ ).

The predicted market shares for hybrid vehicles are larger, ranging from 4.6\% (750,000 units) assuming average intercepts to $7.1 \%$ (1.1 million units) when the best-guess configurations are assumed. In large part, the greater success of hybrids can be attributed to the fact that more hybrid configurations are expected to be introduced ( 54 hybrids versus only 38 diesels in the best-guess scenario). Manufacturers are planning to move more cautiously into the diesel market, most likely due to uncertainties about the diesel's ability to meet the Tier 2, bin 5 emissions standard. Hybrids are more concentrated in the passenger vehicle segments (Figures $19 \& 21)$.

In the 2008 average scenario, 450,000 passenger cars, 220,000 passenger trucks and 70,000 luxury vehicles are hybrids. Only 16,000 hybrid pick-ups are sold and there are no hybrid sportscars or standard vans. In the "best-guess" scenario, 640,000 passenger cars are hybrids, as are 360,000 passenger trucks. Among hybrid technologies, full hybrids are the most prevalent, followed by stop-start and IMA, with ISAD capturing only a small share of the market (Figures $20 \& 22)$.

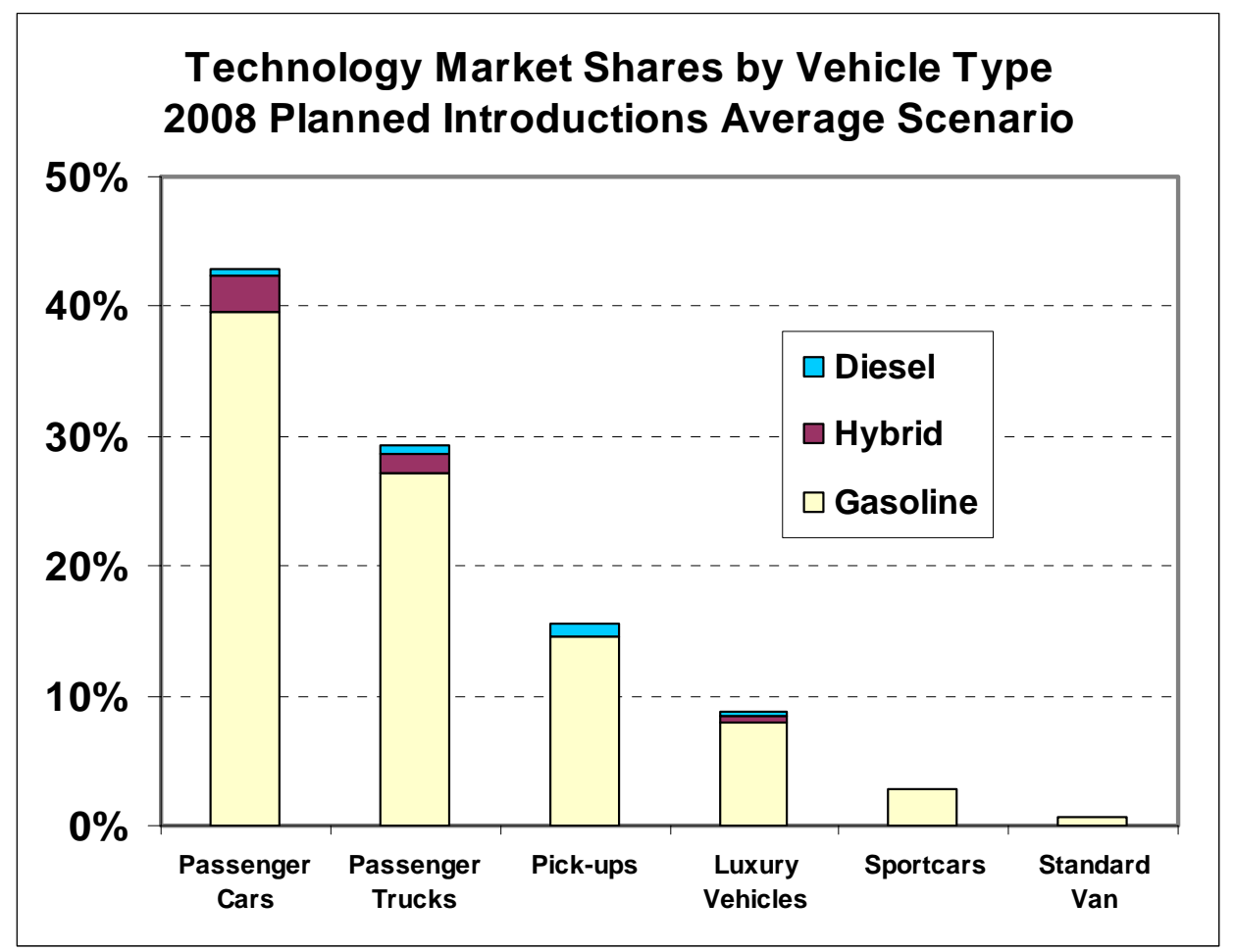

Figure 19. Diesel and Hybrid Vehicle Market Shares by Vehicle Type: 2008 Average Scenario 


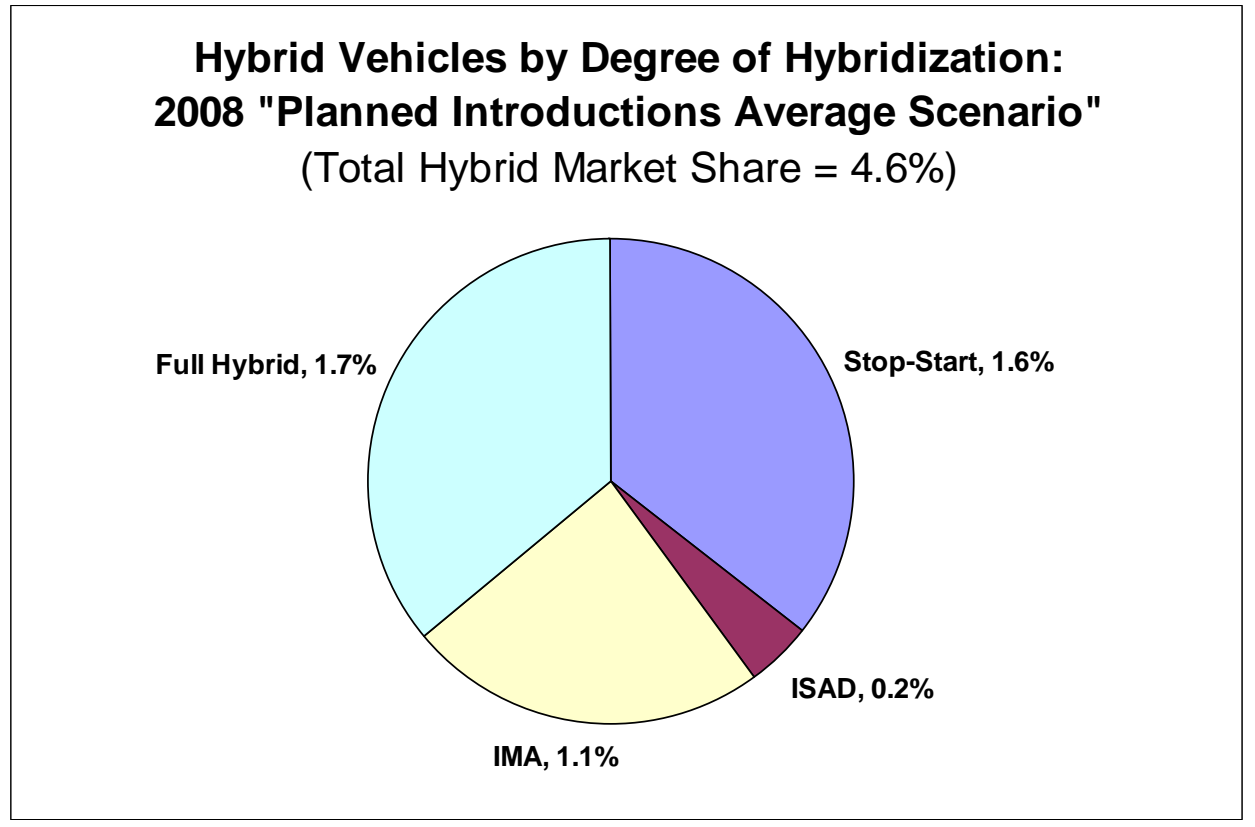

Figure 20. Distribution of Hybrid Vehicle Sales by Degree of Hybridization, 2008 Average Scenario

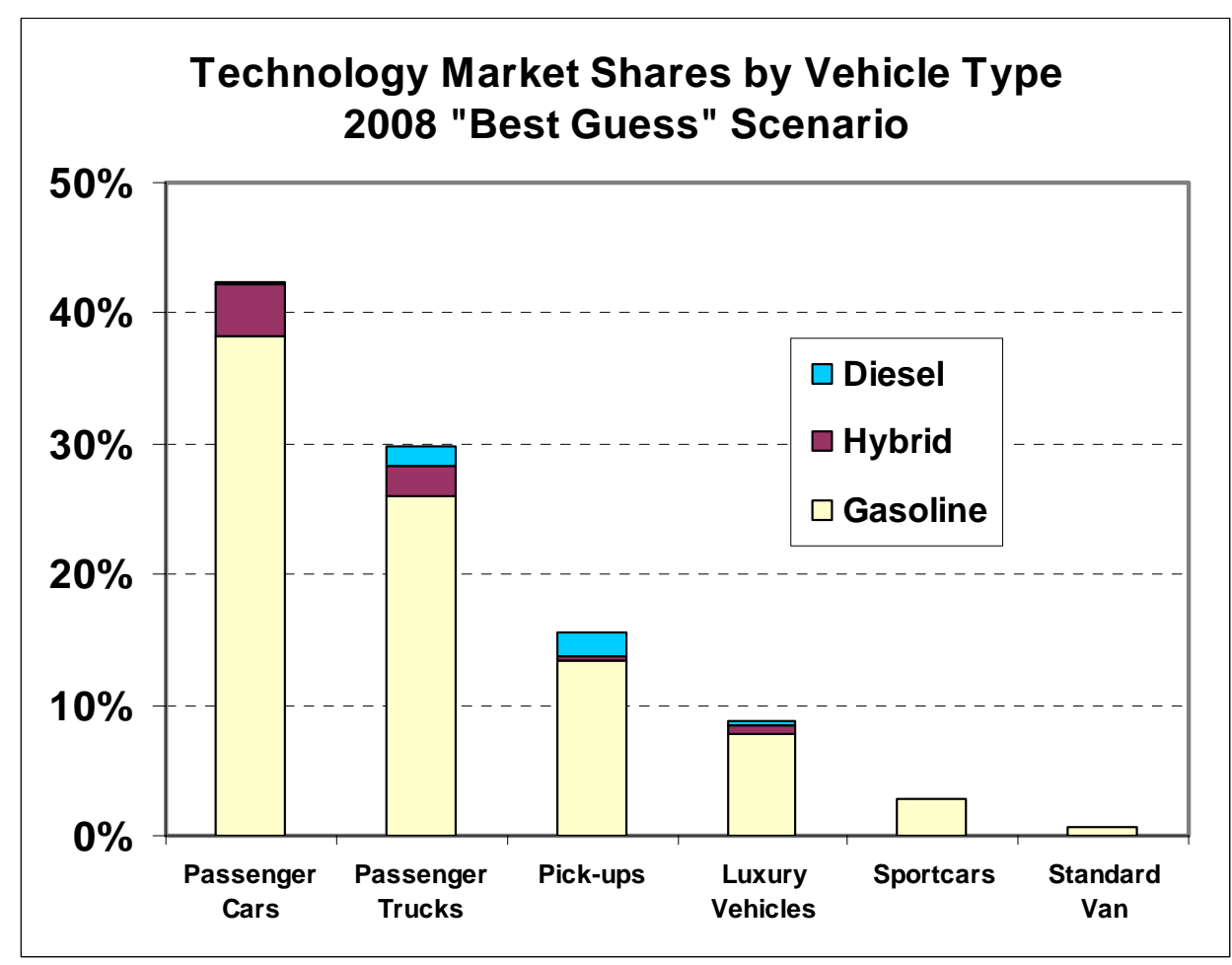

Figure 21. Diesel and Hybrid Market Shares by Vehicle Class, "Best Guess" Scenario 


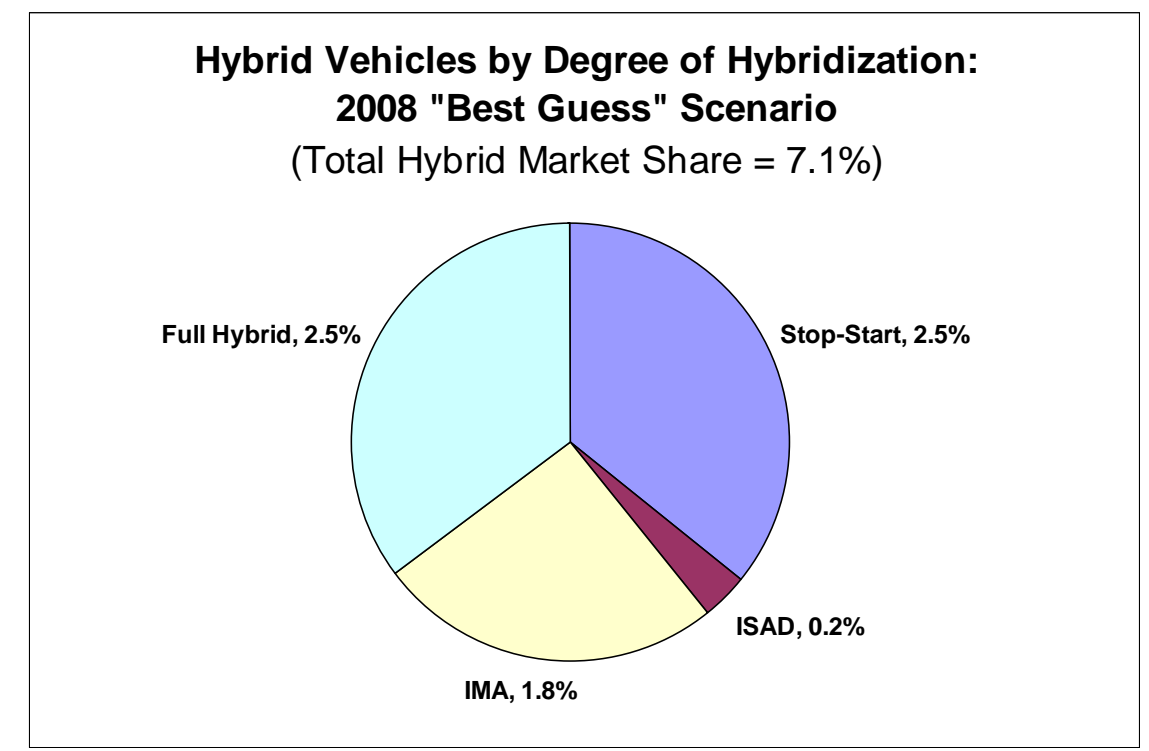

Figure 22. Distribution of Hybrid Vehicle Sales by Degree of Hybridization, 2008 "Best Guess" Scenario

\subsection{SCENARIOS}

In the 2012 scenarios, diesel's market share ranges from $4.1 \%(680,000$ units $)$ in the average scenario (Figure 23) to 7.2\% (1.2 million units) in the "best guess" scenario (Figure 24). While light trucks still predominate, sales of diesel passenger trucks (small and large SUVs; no diesel minivans are assumed in the 2012 scenarios) outnumber diesel pick-ups. In both scenarios passenger cars are a small market for diesels (30,000 units in the "best guess" scenario; 50,000 in the "average" scenario). Diesels also make inroads in the luxury truck market with 170,000 to 180,000 luxury diesel trucks sold in the average and best guess 2012 scenarios, respectively.

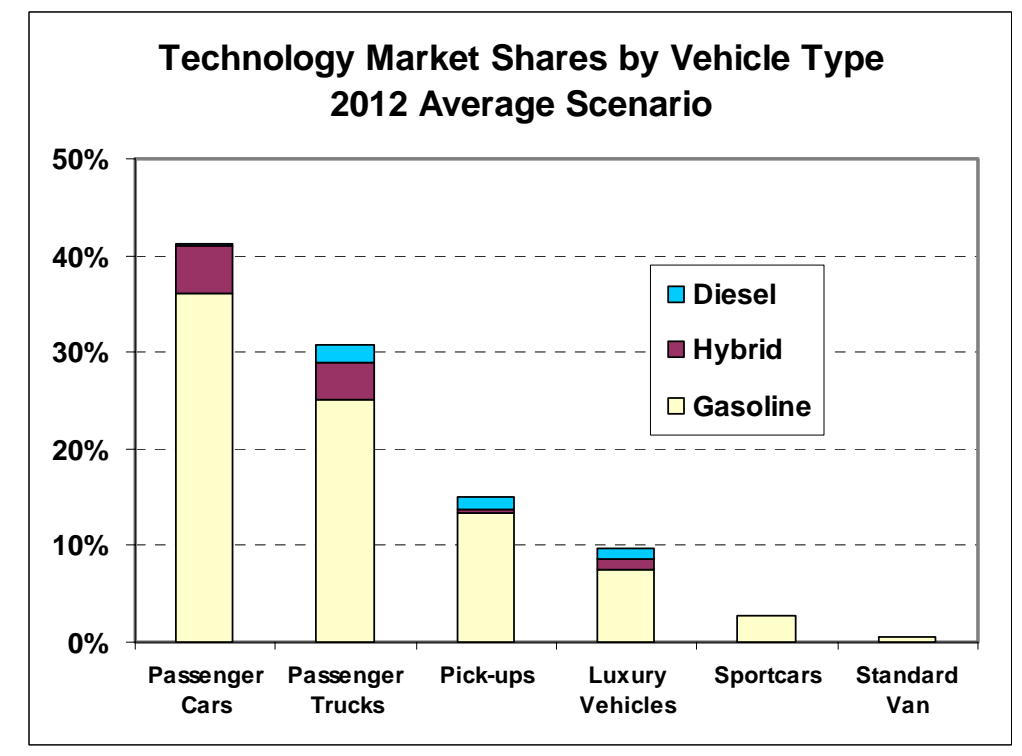

Figure 23. Hybrid and Diesel Market Shares by Vehicle Class, 2012 “Average” Scenario 
The 2012 hybrid share ranges from 10\% (1.7 million units) for the average scenario to $15 \%$ ( 2.5 million units) in the "best guess" scenario (Figure 25). Passenger cars are still the largest hybrid market ( 0.86 to 1.25 million units), followed by passenger trucks ( 0.56 to 0.92 million units), but hybrids also achieve some success among pick-ups $(60,000$ to 70,000$)$ and luxury vehicles (190,000 to 220,000 units).

In the 2012 "Average" scenario, full hybrids still capture more than half of the hybrid market, followed by the inexpensive stop-start system, IMA and then ISAD systems (Figure 26). In the "best guess" scenario, stop-start and IMA systems take a larger share of the hybrid market (Figure 27). While this produces greater overall hybrid sales, it also diminishes their relative impact on fuel economy.

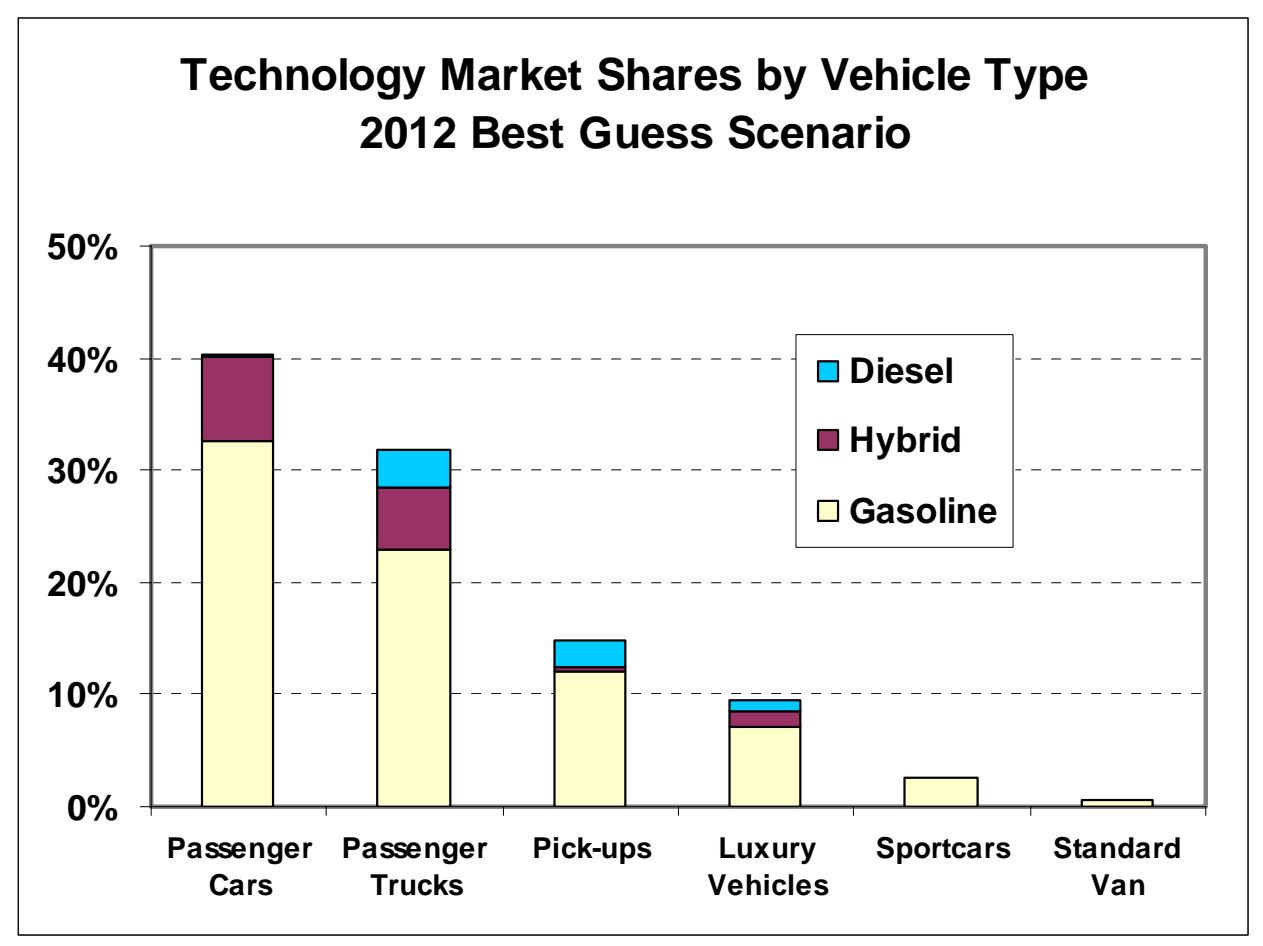

Table 24. Distribution of Hybrid Technology Types in the 2012 "Best Guess" Scenario 


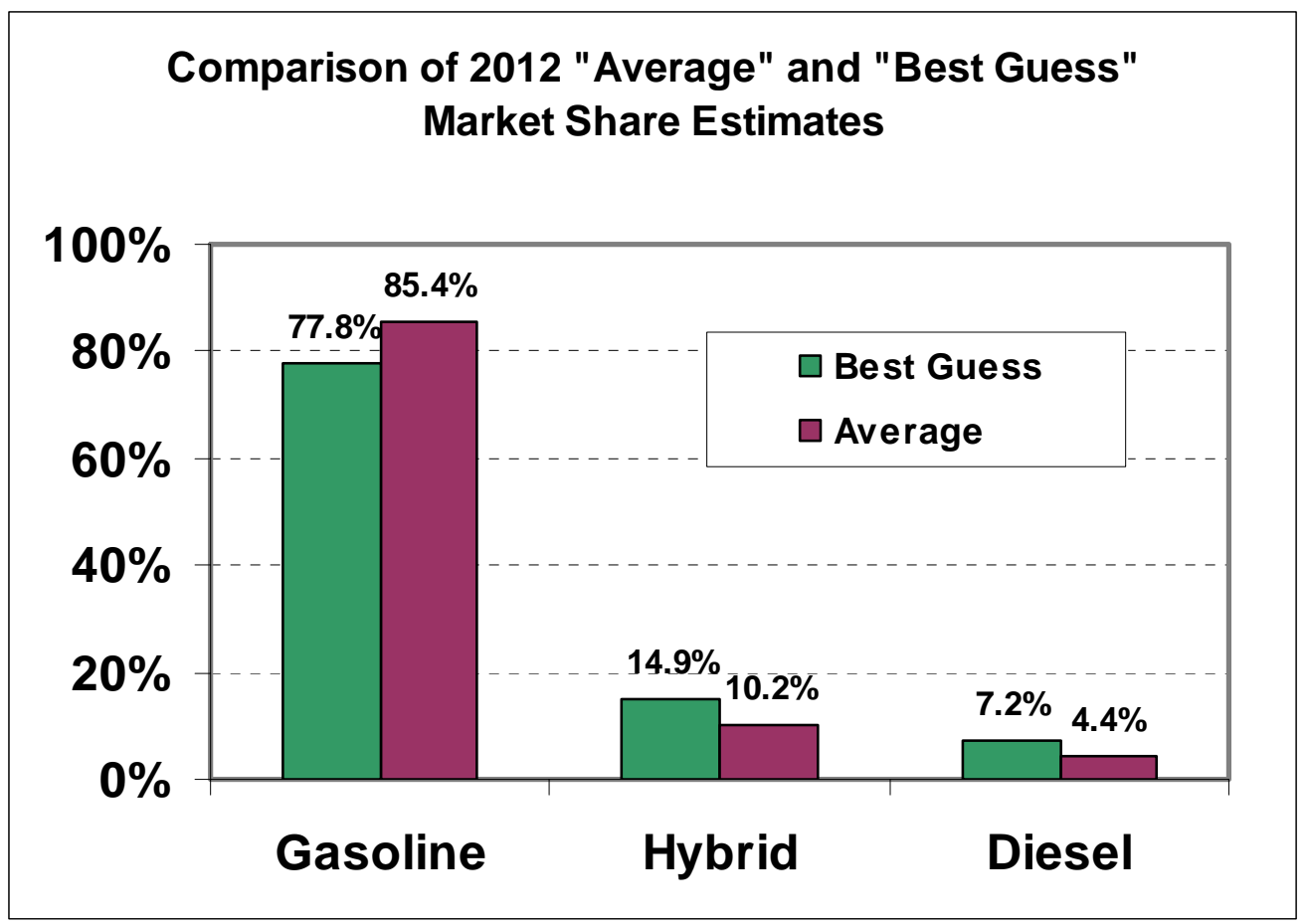

Figure 25. Comparison of Market Success in "Average" and "Best Guess" Scenarios

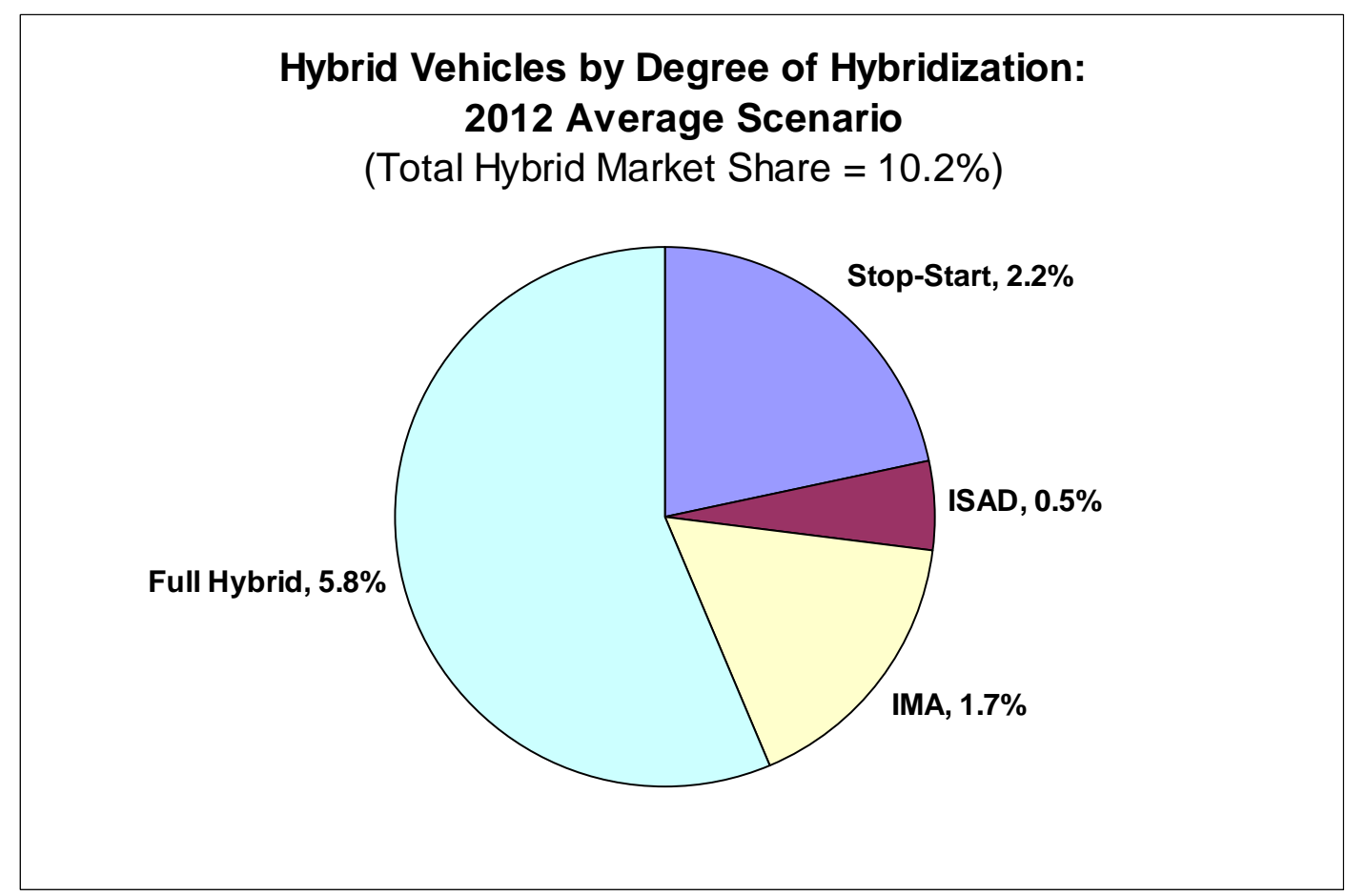

Figure 26. Distribution of Hybrid Vehicle Sales by Degree of Hybridization, 2012 “Average” Scenario 


\section{Hybrid Vehicles by Degree of Hybridization: 2012 "Best Guess Scenario" \\ (Total Hybrid Market Share $=14.9 \%)$}

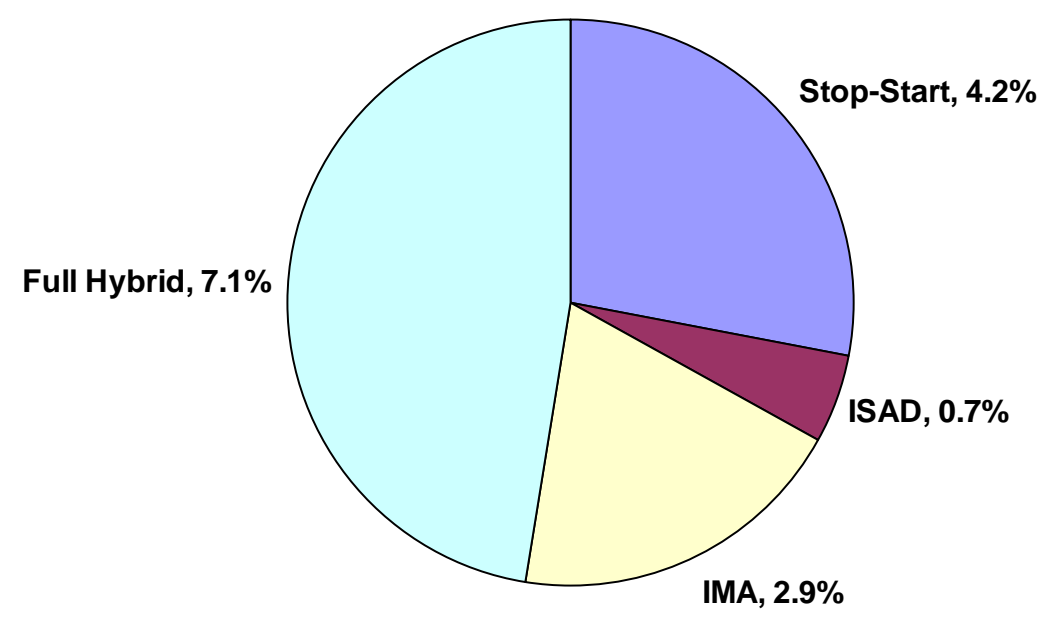

Figure 27. Distribution of Hybrid Vehicle Sales by Degree of Hybridization, 2012 "Best Guess" Scenario

The difference in combined diesel and hybrid sales between the 2012 "average" and "best guess" scenarios is an indication of the uncertainty of future market success, even given the specific makes and models assumed to be introduced: a combined $15 \%$ versus $22 \%$ of the market, respectively (Figure 25). This reflects the critical importance of the specific configurations on which manufacturers choose to offer these technologies. If diesels and hybrids are available on the more popular body styles and trim lines, they will fare better than if they are available only in a single, average style. This boosts sales and helps makes and models get over the 10,000 units sales threshold. In the "average configuration" scenario, only 72 configurations of hybrids are available (Table 10) whereas in the best guess scenario there are 90 different hybrid configurations.

\subsection{IMPACTS ON FUEL ECONOMY}

The potential impacts of diesel and hybrid technology on new passenger car and light truck fuel economy are estimated by comparing the actual fuel economy of model year 2002 light-duty vehicles to the fuel economy of the hypothetical new vehicle fleets of the 2008, 2012 and $>2012$ scenarios. The scenario fleets contain all the conventional gasoline makes and models of the model year 2002 fleet, plus the assumed introductions of diesel and hybrid vehicles of the scenario in question. Whereas new diesel and hybrid vehicles must meet the minimum sales thresholds described in the previous section, all conventional gasoline makes and models are retained, regardless of their sales volumes. The total number of light-duty vehicles sold is assumed to remain constant but the sales distribution changes in response to the introductions of diesel and hybrid vehicles, as predicted by the NMNL model described in previous sections. 
Because low-selling gasoline makes and models are not culled from the set of choices available to consumers, the NMNL will always predict some degree of shift in sales in favor of those vehicles introducing new hybrid and diesel configurations, simply because of the greater variety of choices they offer consumers. As will be seen below, this generally produces a modest shift in the sales distribution in favor of lower fuel economy vehicle configurations. In part, this is a product of our assumptions about which makes and models will offer diesels and hybrids. In part, it is a result of the fact that these technologies produce greater fuel savings on the lowest fuel economy vehicles and therefore sell best in those applications.

Fuel economies are calculated as a sales-weighted harmonic mean of all make, model and configuration fuel economies. The fuel economies of gasoline vehicles are assumed to remain constant at the 2002 levels. Diesel and hybrid fuel economies are estimated by multiplying the model year 2002 fuel economy of the corresponding gasoline version of the vehicle by one plus the fractional improvements in fuel economy given in tables 1 and 3 . In the few cases where there is no comparable gasoline vehicle, we have estimated the fuel economy of the new product. With the exception of the increase in torque we assume will be provided with diesel and hybrid vehicles, we assume no changes in the size, weight or performance of vehicles relative to model year 2002. We make no attempt to determine whether manufacturers would change the designs and fuel economies of gasoline vehicles as a result of increased sales of diesels and hybrids.

The moderate market successes of diesel and hybrid technologies raise average fuel economy by $1.5 \%$ to $2 \%$ in the 2008 scenario, $3 \%$ to $4 \%$ in the 2012 scenarios and up to $10 \%$ beyond 2012 (Table 11). These scenarios assume no significant policy changes that would drive up fuel economy and no significant change in the price of motor fuel. In the 2008 and 2012 "best guess" scenarios, fuel economy increases from 24.3 MPG to 24.8 and 25.2, respectively (Figure 28). Fuel economy increases the most in the $>2012$ Diesel/Full Hybrid scenario, reaching 26.7 MPG.

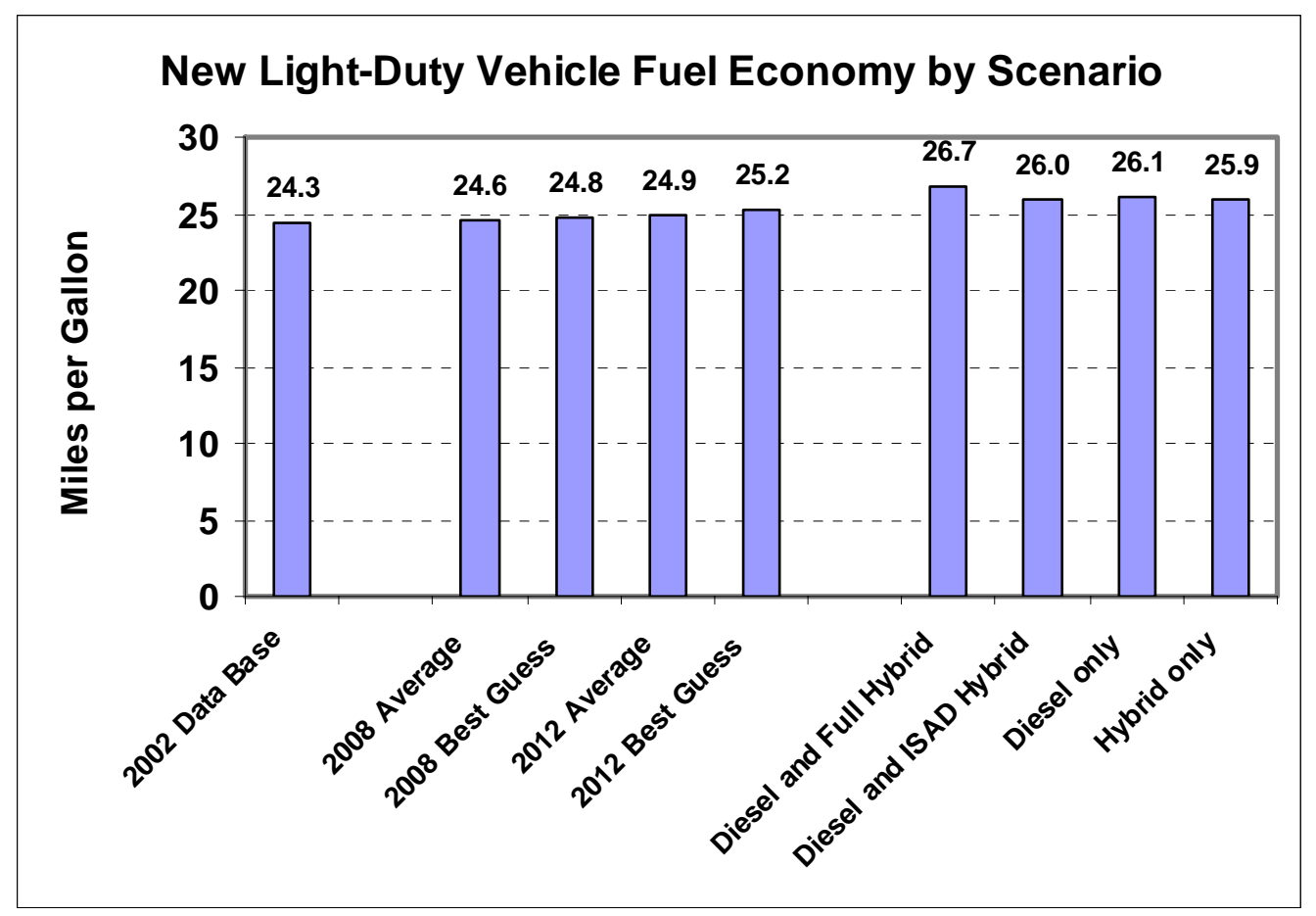

Figure 28. New Light-Duty Vehicle Average Fuel Economy by Scenario 
Table 11. Summary of Results of Diesel Hybrid Market Scenarios

\begin{tabular}{|c|c|c|c|c|c|c|c|c|c|c|c|}
\hline \multirow[t]{2}{*}{ Scenario } & \multicolumn{4}{|c|}{ Shares $(\%)$} & \multicolumn{2}{|c|}{ Sales $(1,000 \mathrm{~s})$} & \multicolumn{4}{|c|}{ Fuel Economy (MPG) } & \multirow{2}{*}{$\begin{array}{c}\text { MPG Gain } \\
\text { Total (\%) }\end{array}$} \\
\hline & Gasoline & Hybrid & Diesel & Gasoline & Hybrid & Diesel & Gasoline & Hybrid & Diesel & Total & \\
\hline 2002 Data Base & $99.6 \%$ & $0.1 \%$ & $0.2 \%$ & & & & 24.3 & 58.4 & 43.4 & 24.3 & \\
\hline 2008 Average & $93.0 \%$ & $4.6 \%$ & $2.4 \%$ & 15,092 & 752 & 387 & 24.2 & 32.1 & 27.9 & 24.6 & $1.5 \%$ \\
\hline 2008 Best Guess & $89.1 \%$ & $7.1 \%$ & $3.9 \%$ & 14,484 & 1,148 & 627 & 24.3 & 31.6 & 26.8 & 24.8 & $2.0 \%$ \\
\hline 2012 Average & $85.4 \%$ & $10.2 \%$ & $4.4 \%$ & 14,041 & 1,675 & 722 & 24.2 & 31.5 & 26.5 & 24.9 & $2.8 \%$ \\
\hline 2012 Best Guess & $77.8 \%$ & $14.9 \%$ & $7.2 \%$ & 12,791 & 2,457 & 1,189 & 24.2 & 31.8 & 26.1 & 25.2 & $4.3 \%$ \\
\hline >2012 Diesel and Full Hybrid & $59.7 \%$ & $16.5 \%$ & $23.8 \%$ & 9,643 & 2,658 & 3,847 & 24.3 & 31.3 & 31.0 & 26.7 & $9.6 \%$ \\
\hline$>2012$ Diesel and ISAD Hybrid & $53.8 \%$ & $27.0 \%$ & $18.2 \%$ & 8,692 & 4,362 & 3,094 & 24.3 & 26.8 & 30.6 & 26.0 & $7.0 \%$ \\
\hline >2012 Diesel only & $69.2 \%$ & $0.0 \%$ & $30.8 \%$ & 11,180 & 0 & 4,969 & 24.3 & -- & 31.3 & 26.1 & $7.4 \%$ \\
\hline >2012 Hybrid only & $74.1 \%$ & $25.9 \%$ & $0.0 \%$ & 11,959 & 4,189 & 0 & 24.3 & 32.0 & -- & 25.9 & $6.7 \%$ \\
\hline Total Vehicle Sales & 16,148 & & & & & & & & & & \\
\hline
\end{tabular}


In the 2008 and 2012 scenarios light truck fuel economy gains are somewhat greater than the increases for passenger cars. For example, in the 2012 "best guess" case, light truck MPG is $6.3 \%$ higher than the 2002 base level of $21.0 \mathrm{MPG}$, while passenger car MPG increases by $3.2 \%$ over the 2002 base of 28.8 (Table 12).

Table 12. Average Fuel Economy of Passenger Cars and Light Trucks

\begin{tabular}{lccccc}
\hline & $\begin{array}{c}2008 \\
\text { Best Guess }\end{array}$ & $\begin{array}{c}2008 \\
\text { Average }\end{array}$ & $\begin{array}{c}2012 \\
\text { Best Guess }\end{array}$ & $\begin{array}{c}2012 \\
\text { Average }\end{array}$ & $\begin{array}{c}2002 \\
\text { Base }\end{array}$ \\
\hline Passenger cars & 29.4 & 29.2 & 29.7 & 29.4 & 28.8 \\
Light trucks & 21.7 & 21.4 & 22.3 & 21.8 & 21.0 \\
All light-duty vehicles & 24.9 & 24.7 & 25.2 & 24.9 & 24.3 \\
\hline
\end{tabular}

These fuel economy impacts may seem small at first. How could technologies offering $30 \%$ to $40 \%$ better fuel economy and capturing $40 \%$ of the market raise MPG by only about $10 \%$ ? Part of the answer is harmonic averaging. Consider two types of vehicles with initially equal fuel economy. The harmonic mean of a $0 \%$ increase (1.0) with a share of 0.6 and a $35 \%$ increase (1.35) with a share of 0.4 is only $11.6 \%$, not $0.35 \times 0.40 \times 100 \%=14 \%$.

$$
\frac{1}{\left(\frac{0.6}{1.0}+\frac{0.4}{1.35}\right)}=1.116 \Rightarrow 11.6 \%
$$

Equation 9

The difference between the value of $11.6 \%$ produced by this rough calculation and the model's calculation of $9.5 \%$ is the result of sales mix shifts that mitigate against fuel economy increases. Hybrid and diesel technologies tend to sell better on vehicles with low fuel economy than on those with the highest fuel economy because the value of the fuel saved is greater relative to the cost of the technology. For example, in the Full Hybrid and Diesel scenario in which any vehicle could be a hybrid or diesel providing it meets minimum sales requirements, 25 of 37 hybrid passenger car models turn out to be large cars, and 113 of 155 total hybrid models are trucks. For diesels, 143 models are trucks out of a total of 210. The success of the new technologies in those market segments increases their overall market share. In addition to raising fuel economy, this causes an overall sales mix shift towards lower fuel economy vehicles, which mitigates the technologies' fuel economy benefit. To some degree these sales shifts are an artifact of our methodology, as described above.

Deleting diesel and hybrid makes and models selling under 25,000 units also has a significant effect on fuel economy. If all makes and models selling over 5,000 are included in the Full Hybrid and Diesel scenario, the average MPG of a hybrid increases from 31.3 (all $<25,000$ excluded) to 32.3. Including diesel makes and models with sales in the interval 5,000-25,000 raises the average MPG of a diesel car from 31.1 to 31.5. Overall, had the lower limit on sales volume been 5,000 instead of 25,000 in the $>2012$ diesel/full hybrid case, light-duty vehicle average MPG would have been 27.6, an increase of 14\% instead of 9.5\%. Diesels would capture $28 \%$ of the market instead of $24 \%$, and hybrids would claim a $23 \%$ market share instead of $16 \%$. When the higher sales limits are imposed, small and midsize cars are the greatest losers. The number of small and midsize makes and models offered drops from 140 hybrids to only 12, and 
from 161 diesels to only 34 . In the following section the sensitivity of the model's predictions to assumptions about scale economies is tested and measured.

\subsection{SENSITIVITY ANALYSIS}

The sensitivity of the choice model's predictions to eight key factors was tested using Monte Carlo simulation. In a Monte Carlo simulation inputs are treated as random variables rather than fixed parameters. Samples are drawn from the distributions of the random variables, the model is run, and the process is repeated (here 1,000 times), producing a distribution of output values rather than a single set of values. Given the resulting data base of outputs, one can measure the sensitivity of outputs of interest (e.g., diesel or hybrid market shares) to the input variables by means of regression analysis.

The eight parameters are the incremental prices of (1) hybrid and (2) diesel vehicles, (3) the general sensitivity of vehicle choices to price, the prices of (4) gasoline and (5) diesel fuel (these are so highly correlated, about 0.95 , that they should count as only one variable), (6) the overall sensitivity of vehicle choice to price diesel fuel availability, (7) the minimum nameplate, and (8) configuration sales volumes, for hybrids or diesels to be viable on a particular make and model. Table 13 lists the variables and describes the assumed probability distributions. Most of the distributions have the same or almost the same means as the $>2012$ scenarios described above. A notable exception is the minimum production volume, which has a mean of 15,000 units. This will result in considerably greater hybrid and diesel sales and higher fuel economy than the other $>2012$ scenarios.

Table 13. Assumptions for Sensitivity Analysis of Hybrid and Diesel Choice

\begin{tabular}{lcccc}
\hline \multicolumn{1}{c}{ Input Variable } & Mean/Mode & Distribution & Minimum & Maximum \\
\hline Incremental Price of Hybrid Vehicle & $\begin{array}{c}1.0 \\
\text { (relative) }\end{array}$ & Triangular & $-50 \%$ & $+50 \%$ \\
Incremental Price of Diesel Vehicle & $\begin{array}{c}1.0 \\
\text { (relative) }\end{array}$ & Triangular & $-50 \%$ & $+50 \%$ \\
Price Sensitivity & $\begin{array}{c}1.0 \\
\text { (relative) }\end{array}$ & Triangular & $-50 \%$ & $+100 \%$ \\
Price of & $\$ 1.50$ & Triangular & $\$ 1.25$ & $\$ 2.00$ \\
$\quad$ Gasoline / & $\$ 1.50$ & & $\$ 1.25$ & $\$ 2.00$ \\
$\quad$ Diesel Fuel & $50 \%$ & Triangular & $20 \%$ & $80 \%$ \\
Availability of Diesel Fuel & 15,000 & Triangular & 5,000 & 25,000 \\
Minimum Nameplate Sales & 1,500 & Triangular & 500 & 2,500 \\
Minimum Configuration Sales & & & & \\
\hline
\end{tabular}

Of the inputs chosen, all are factors exogenous to the consumer's choice except price sensitivity. It would have been of interest to test the sensitivity of the model's predictions to assumptions about the value of fuel savings, range, torque, etc., but these factors are interdependent with the price sensitivity of vehicle choice in ways that are too complex for the Monte Carlo simulation to handle easily. 
The sensitivity analysis was carried out using the $>2012$, Diesel/Full Hybrid scenario. This scenario produced the greatest impact on fleet average fuel economy. Given the probability distributions shown in Table 13, the simulation produced a 90\% confidence interval for diesel market share of $16 \%$ to $34 \%$, with an expected value of $25 \%$ (Figure 29). This is higher than the original $>2012$ Diesel/Full Hybrid scenario partly because the mean minimum production threshold is lower, 15,000 versus 25,000 units. This allows a greater number of diesel and hybrid makes and models to be offered.

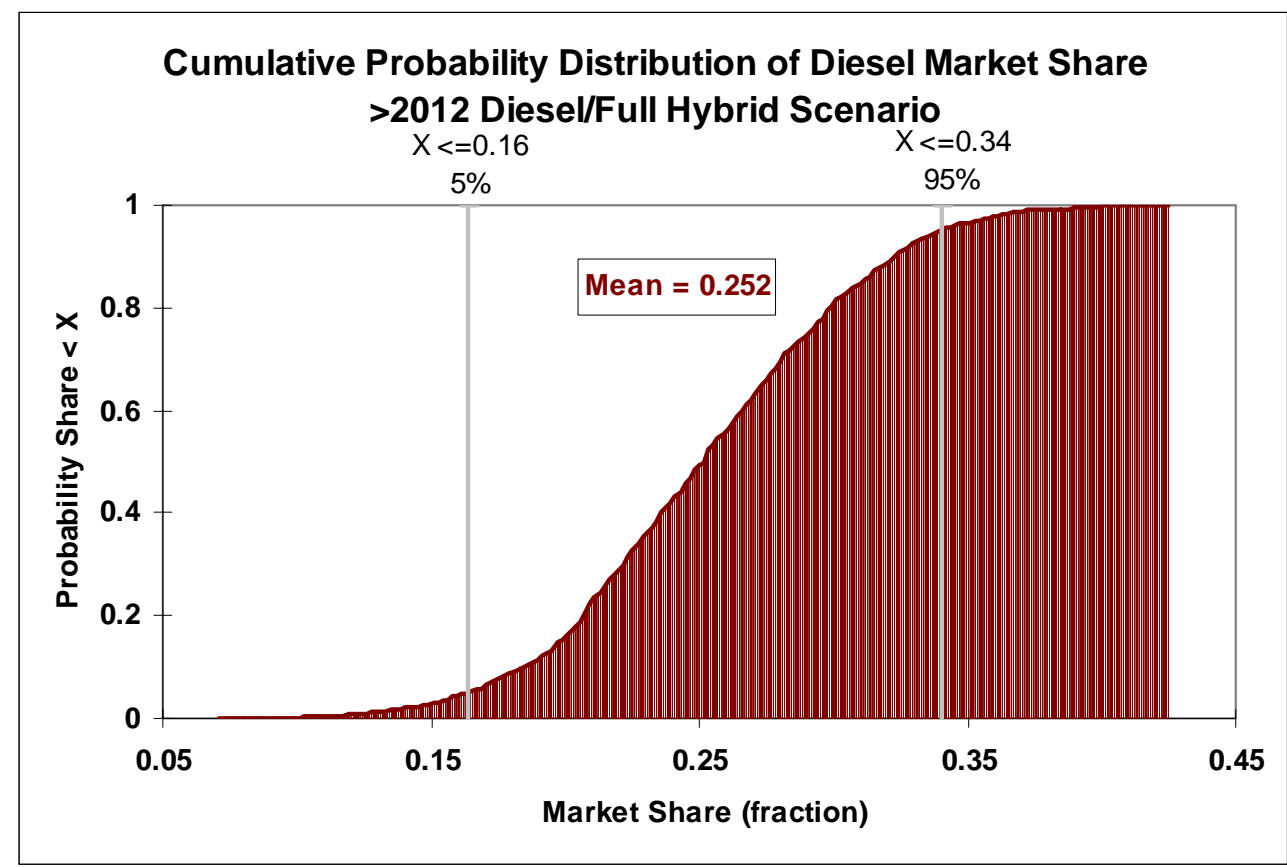

Figure 29. Sensitivity Analysis of Diesel Market Share, >2012 Diesel/Full Hybrid Scenario

The tornado chart (Figure 30) shows which variables have the greatest influence on diesel's market share. Not surprisingly, the incremental price of the diesel vehicle is the single most important factor, with a standardized regression coefficient (similar to a partial correlation) of -0.9: the higher the diesel's price, the lower its market share. Next in importance are the prices of gasoline and diesel fuel: higher gasoline prices boost diesel sales, higher diesel prices lower sales. Gasoline and diesel prices are assumed to be highly correlated; a correlation coefficient of 0.95 , which is based on historical data, is used. Thus, the two prices will generally increase or decrease together. The tornado chart, however, shows the independent effects of these prices (i.e., the effect of an increase in the price of diesel fuel) assuming the price of gasoline stays constant. The positive effect of higher gasoline prices on diesel's market share is greater than the negative effect of higher diesel prices, so the overall effect of an increase in petroleum prices would be to boost diesel market share. The price of hybrid vehicles is next in importance, followed by diesel fuel availability. Diesel and hybrid power trains compete to a limited degree, so that as the price of hybrids increases, sales of diesels increase somewhat. The greater the price elasticity of vehicle choice the smaller the diesel share will be. Since the price elasticity is an assumed parameter, it is comforting that its influence is not great despite varying $-50 \% /+100 \%$ from its average value. The final two variables show that the higher the minimum production volume the lower diesel sales will be due to a reduction in diversity of choice. 


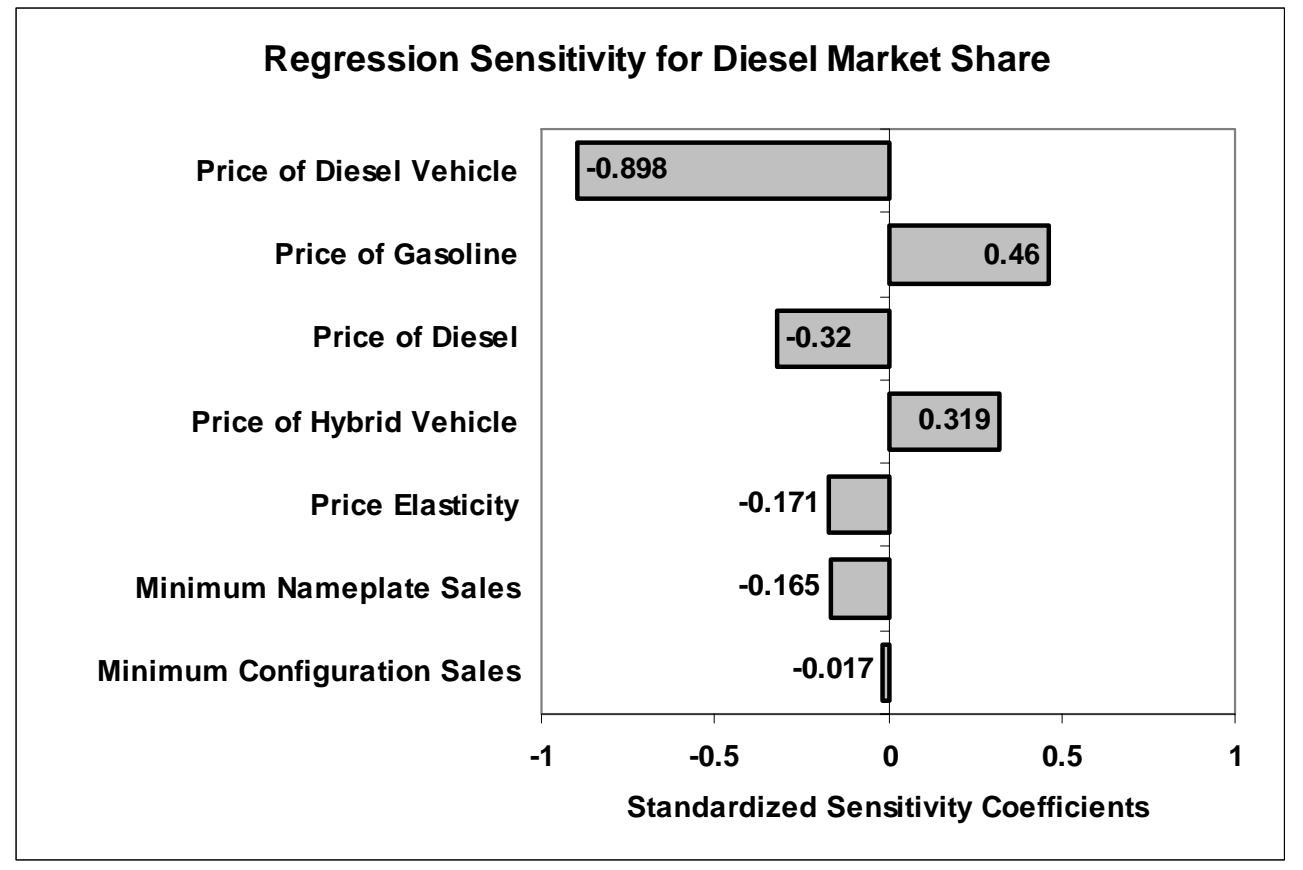

Figure 30. Tornado Chart Showing Influence of Inputs on Diesel Market Share

Hybrid market shares have a similarly wide $90 \%$ confidence interval from $18 \%$ to $29 \%$, with a mean of 19\% (Figure 31). Again, the chief determinant of the hybrid's market share is its own incremental price (Figure 32). The second most important determinant, however, is the assumed price elasticity of choice, indicating that the hybrid forecasts are much more sensitive to this assumption than those for diesels. The minimum production volume is about equally important for hybrids as for diesels. The fact that the predicted hybrid market share is more sensitive to the assumed price sensitivity suggests that the hybrid forecasts should be considered somewhat more uncertain than the diesel forecasts. The hybrid share will increase when diesel prices increase, but it may be a surprise that the hybrid share decreases when gasoline prices increase. This indicates that in the Diesel/Full Hybrid scenario, hybrids compete more directly with diesel vehicles than with conventional gasoline vehicles. In addition, because gasoline and diesel prices are highly correlated, in most cases they will rise together and the net effect will be an increase in hybrid's market share. 


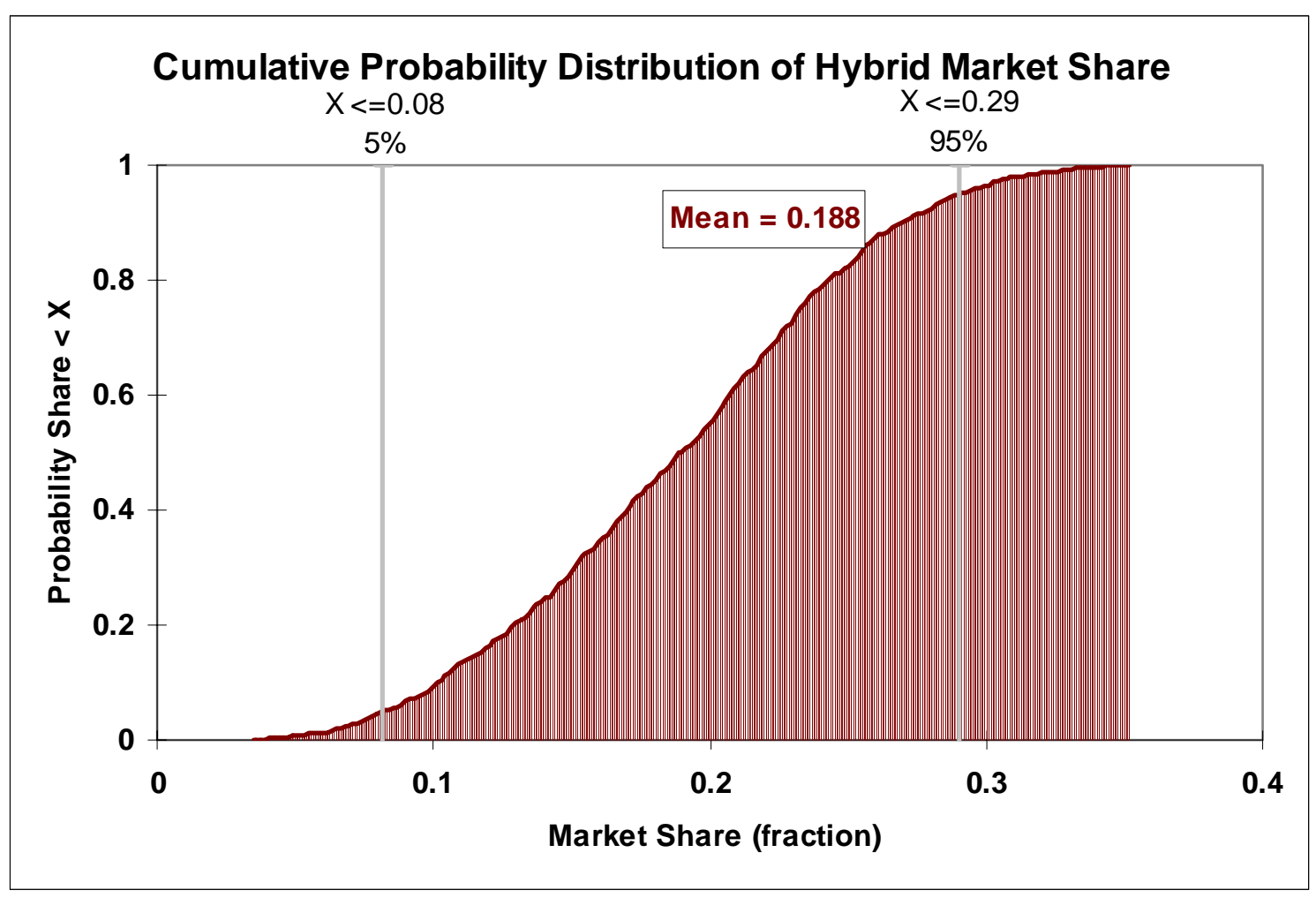

Figure 31. Sensitivity Analysis of Hybrid Market Share, >2012 Diesel/Full Hybrid Scenario

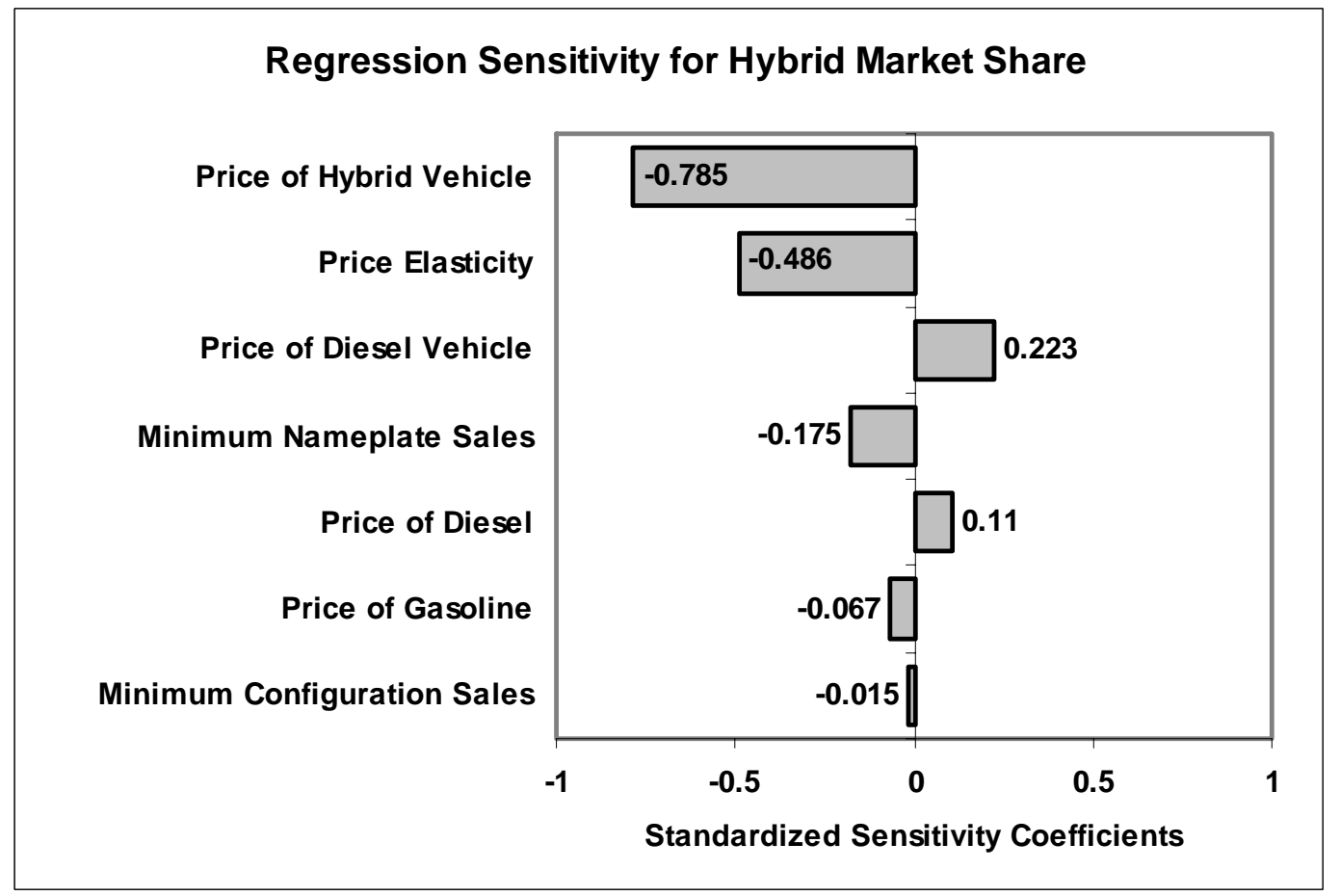

Figure 32. Tornado Chart Showing Influence of Inputs on Hybrid Market Share 
The average fuel economy of new light-duty vehicles has a confidence interval ranging from 26.1 to $27.8 \mathrm{MPG}$, with a mean value of 27 (Figure 33). This is higher than the mean value of 26.6 for the original $>2012$ Diesel/Full Hybrid scenario partly because the mean minimum production value of the sensitivity analysis is 15,000 rather than 25,000 .

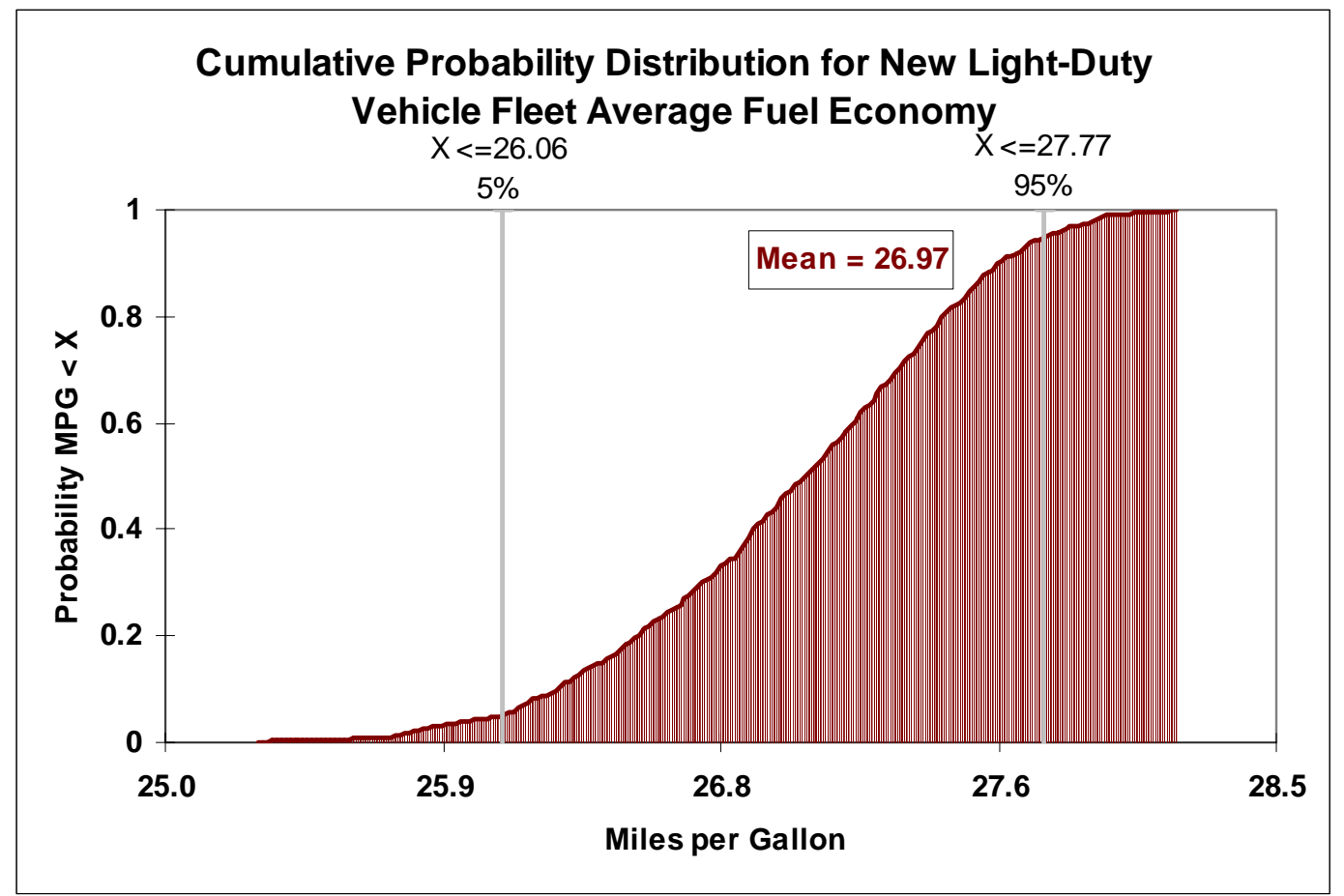

Figure 33. Sensitivity Analysis of LDV Fuel Economy, >2012 Diesel/Full Hybrid Scenario

The most important determinants of the average MPG of new light-duty vehicles are the assumed price elasticities of vehicle choice and the incremental prices of hybrid and diesel vehicles (Figure 34). If consumers are much more sensitivity to price than assumed in this analysis, the MPG impacts of diesels and hybrids could be considerably lower. Next in importance are the incremental prices of diesels and hybrids, hardly a surprise. Also, if the range of choices available to consumers as influenced by the minimum nameplate sales requirement are much more limited, again the MPG impact will be reduced. Finally, an increase in the price of gasoline will tend to raise MPG as consumers shift to hybrids and to conventional gasoline vehicles with higher fuel economy. An increase in diesel price, the price of gasoline held constant, tends to discourage diesels sales which have a net negative impact on fleet average fuel economy. Greater diesel fuel availability has no significant impact. 


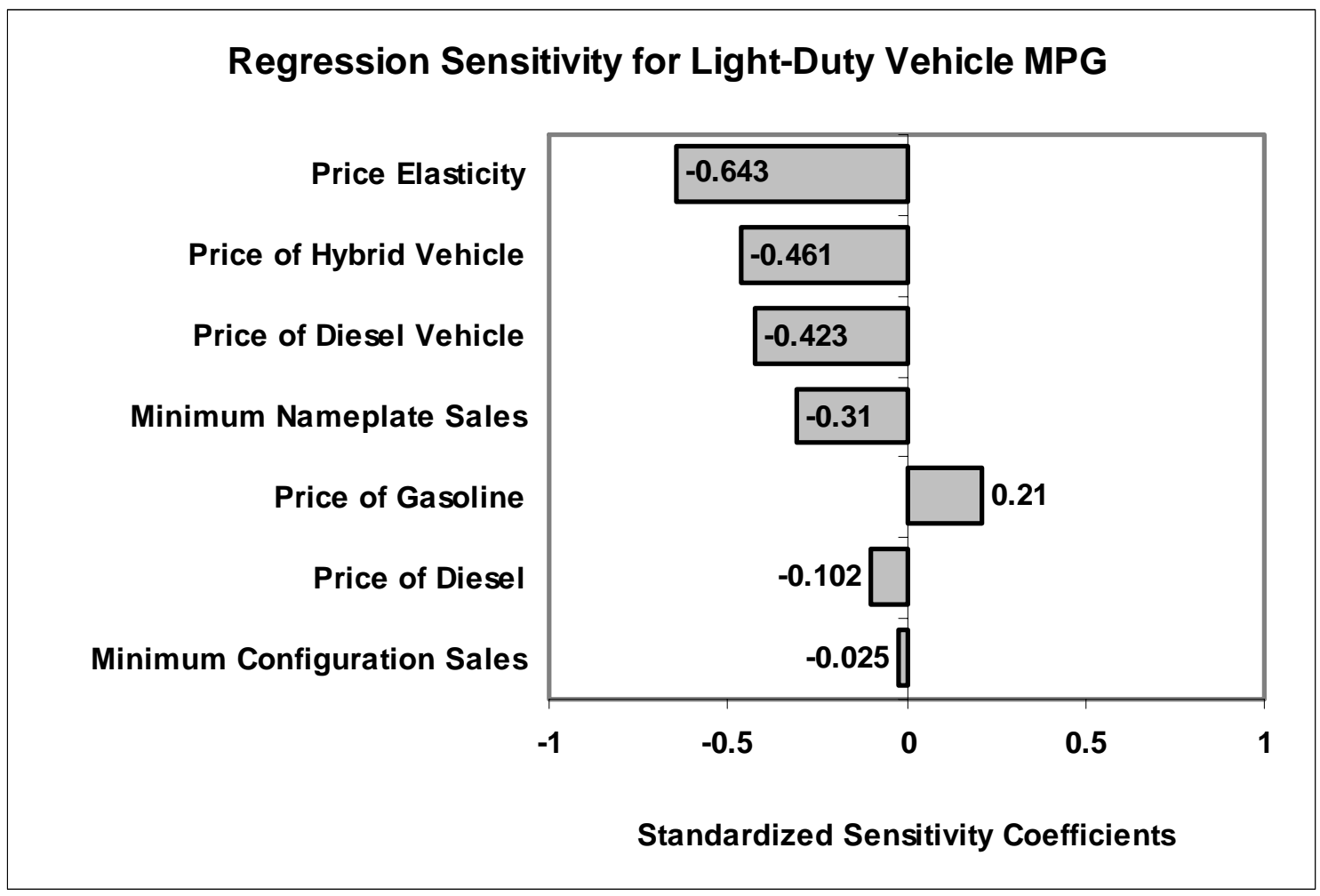

Figure 34. Tornado Chart Showing Influence of Inputs on LDV Fuel Economy 



\section{CONCLUSIONS}

This analysis indicates that if diesels and hybrids can achieve the technology goals we expect they will, they will have a future as mainstream drivetrain technologies for light-duty vehicles in the United States. Diesels must meet Tier 2 bin 5 emissions standards, an achievement that is almost but not quite within reach at the present. Hybrids must reduce costs to roughly half the cost increment of the first generation hybrids, a goal they are well on their way to reaching. If they can achieve these goals, diesels and hybrids should be able to capture $7-10 \%$ of the U.S. light-duty vehicle market by 2008 , and $15-20 \%$ by 2012 (Figure 35 ).

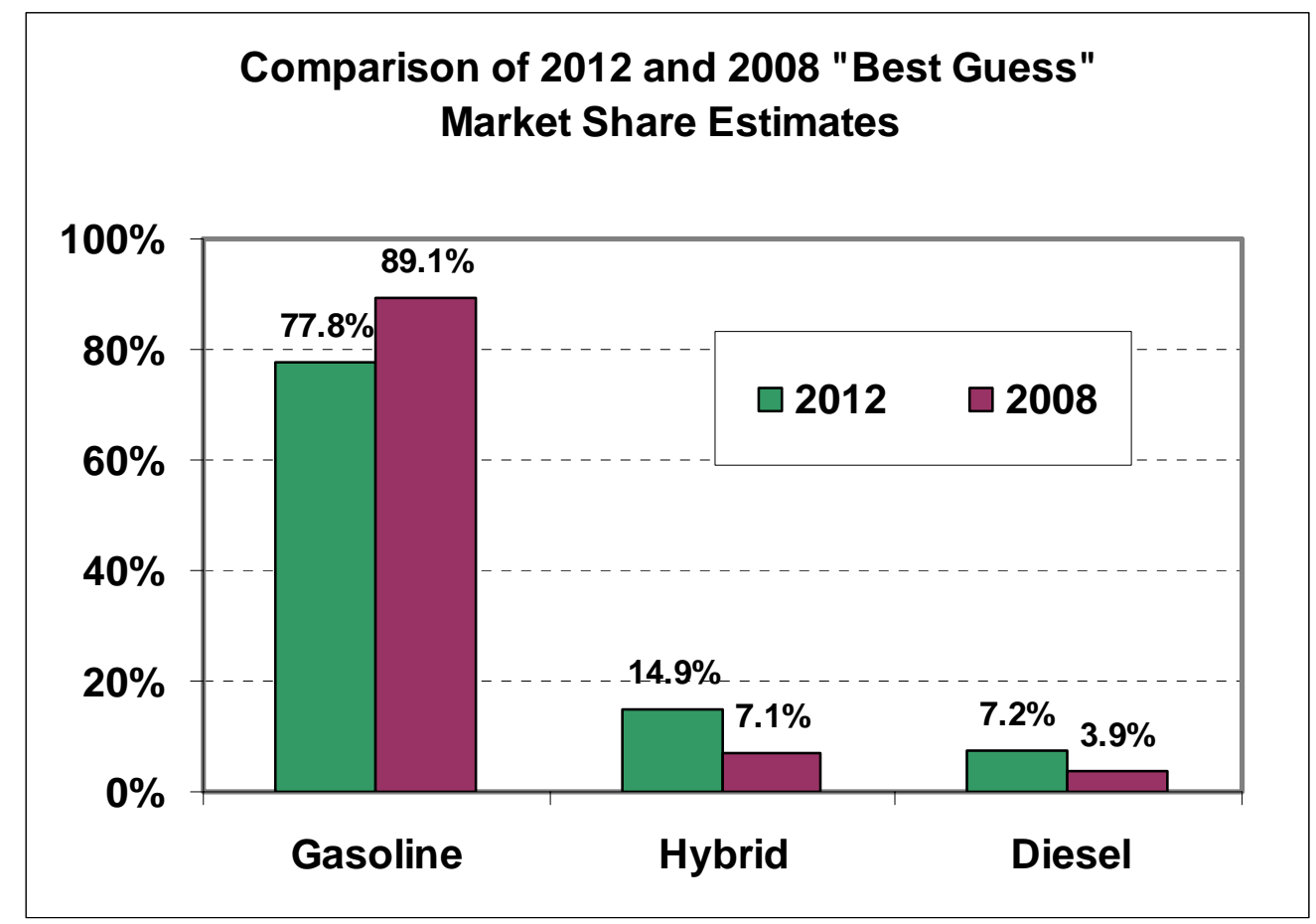

Figure 35. Comparison of Market Success in 2008 and 2012 under "Best Guess" Scenarios

Because of their higher costs, the combined market share of diesels and hybrids is likely to be limited to half or less than half of all light-duty vehicles even in the long-run, unless policy and market conditions change significantly in their favor. Such changes are not unlikely, given continuing concerns about energy security and global climate change. The long-run impact of these technologies on fuel economy is likely to be about a $10 \%$ increase in the absence of additional policy initiatives to boost fuel economy or further technological advances. It is certainly possible, and indeed likely that increased sales of diesels and hybrids could raise new light duty vehicle fleet fuel economy by $1 \%$ to $3 \%$ by 2008 , and by $3 \%$ to $5 \%$ by 2012 , without new policies, assuming no reduction in the fuel economy of conventional gasoline vehicles.

The market success of diesels and hybrids is highly dependent on manufacturers' decisions to introduce a diverse array of makes and models in different vehicle classes. In 2008, when diesel and hybrid offerings are assumed to be very limited, diesels capture only $2-4 \%$ and hybrids only $4-7 \%$ of the light-duty market. In $>2012$, when the number of diesel configurations is much 
greater either can claim $15-30 \%$ of the market. Manufacturers face considerable risk in introducing diesel and hybrid vehicles due to their higher costs and the possibility that diesels may be unable to meet Tier 2, bin 5 standards. Thus, the timing of diesel and hybrid introductions and therefore their market success is uncertain, despite announced product plans. 


\section{REFERENCES}

Adler, T., L. Wargelin, L. Kostyniuk, C. Kalavec and G. Occhiuzzo. 2004. "Experimental Assessment of Incentives for Alternate Fuel Vehicles," presented at the 83rd Meeting of the Transportation Research Board, Washington, DC, January 11-15.

Berry, S., J. Levinson and A. Pakes. 1995. "Automobile Prices in Market Equilibrium," Econometrica, vol. 64, no. 4, pp. 841-890.

Birch, S. 2003. "Ricardo's Diesel Future," Automotive Engineering International, vol. 111, no. 2, pp. 78-79.

Bordley, R. 1994. "An Overlapping Choice Set Model of Automotive Price Elasticities," Transportation Research B, vol. 28B, no. 6, pp. 401-408.

Burke, A. and E. Abeles. 2004. "Feasible CAFE Standard Increases Using Emerging Diesel and Hybrid-Electric Technologies for Light-Duty Vehicles in the United States," UCD-ITS-RR-04-9, Institute of Transportation Studies, University of California at Davis, Davis, CA, April.

CARAVAN. 2004. “ORC Study \#713228," conducted for the National Renewable Energy Laboratory by Opinion Research Corporation, Princeton, NJ, May 27, 2004.

CNN.com. 2004. "Hybrid vehicles electrify 2003 sales,"

http://www.cnn.com/2004/TECH/science/04/22/hybrid.popular.ap/, April 22.

Davis, S.C. and S.W. Diegel. 2003. Transportation Energy Data Book, Edition 23, ORNL6970, Oak Ridge National Laboratory, Oak Ridge, Tennessee, October.

Donndenlinger, J.A. and H.E. Cook. 1997. Methods for Analyzing the Value of Automobiles, SAE Technical Paper 970762, Society of Automotive Engineers, Warrendale, PA.

Duleep, K.G. 2004. "Diesel Technology and Product Plan Review," presentation to the U.S. Department of Energy, Office of Policy, prepared by Energy and Environmental Analysis, Inc., Arlington, Virginia, April.

Duleep, K.G. 2003. “Analysis of Hybrid Technology," presentation to the U.S. Department of Energy, Office of Policy, prepared by Energy and Environmental Analysis, Inc., Arlington, Virginia, November.

Energy Information Administration. 2004. Annual Energy Outlook 2004, DOE/EIA-0383-04, U.S. Department of Energy, Washington, DC, January.

Greene, D.L. 2001. TAFV Alternative Fuels and Vehicles Choice Model Documentation, ORNL/TM-2001/134, Oak Ridge National Laboratory, Oak Ridge, Tennessee, July.

Greene, D.L. 1998. "Fuel Availability and Alternative Fuel Vehicles," Energy Studies Review, vol. 8, no. 3, pp. 215-231. 
Greene, D.L. 1994. Alternative Fuels and Vehicles Choice Model, ORNL/TM-12738, Center for Transportation Analysis, Oak Ridge National Laboratory, Oak Ridge, Tennessee, October. Greene, D.L. 1986. "The Market Share of Diesel Cars in the U.S.A., 1979-83," Energy Economics, vol. 8, no. 1, pp. 13-21.

Greene, D.L. and J.T. Liu. 1988. "Automotive Fuel Economy and Consumers' Surplus," Transportation Research A, vol. 22A, no. 3, pp. 203-218.

Hadder, G.R. 2004. "High Quality Diesel Fuel Production, Logistics and Consumer Costs," Engineering Science and Technology Division, Oak Ridge National Laboratory, Oak Ridge, TN, May.

Irvine, F.O. 1993. "Demand Equations for Individual New Car Models Estimated Using Transaction Prices with Implications for Regulatory Issues," Southern Economic Journal, vol. 49, no. 3, pp. 764-782.

J.D. Power and Associates. 2003. "Hybrid Electric Vehicle Sales Expected to Increase Dramatically over Next Decade," news release, Westlake Village, CA, May 28.

Kleit, A.N. 1990. "The Effect of Annual Changes in Automobile Fuel Economy Standards," Journal of Regulatory Economics, vol. 2, pp. 515-172.

McCarthy, P.S. 1996. "Market Price and Income Elasticities of New Vehicle Demands," The Review of Economics and Statistics, vol. LXXVII, no. 3, pp. 543-547.

McManus, W. 2004. "Hybrids and Clean Diesels: If you Build It, Will They Come?” J.D. Power and Associates, Detroit, Michigan.

McManus, W. 2003. “Consumer Demand for Alternative Powertrain Vehicles,” J.D. Power and Associates, Detroit, Michigan.

Miller, J.B. 2004. "Higher Gas Prices May Fuel Hybrid Sales," Norwich Bulletin, www.norwichbulletin.com/news/stories/20040609/localnews/603888.html, June 9, 2004.

(NRC) National Research Council. 2002. Effectiveness and Impact of Corporate Average Fuel Economy (CAFE) Standards, National Academy Press, Washington, DC.

Nicholas, M.A., S.L. Handy and D. Sperling. 2004. "Siting and Network Analysis Methods for Hydrogen Stations Using Geographical Information Systems," presented at the $83^{\text {rd }}$ Annual Meeting of the Transportation Research Board, January 11-15, 2004, Washington, DC.

Opinion Research Corporation. 2004. ORC Study \#713218, Caravan Fuel Efficient Vehicles, Question V14A, May 20, 2004, Princeton, New Jersey.

Patterson, P. 2004. Personal communication, U.S. Department of Energy, Office of Energy Efficiency and Renewable Energy, Washington, DC, July 16. 
Qualters, C. 2004. "Diesel Market Discussion," private briefing, Bosch, GmbH, Farmington Hills, MI, February 5.

Santini, D. 2004. "Customer Benefits and Attributes of Diesels and Hybrids: Market Competitors or Complements?" presentation slides dated April 14, 2004, Center for Transportation Research, Argonne National Laboratory, Argonne, IL.

Schmidt's Auto Publications. 2004. "Diesel Still Sizzling," AID Newsletter no. 0401, Warwick, England.

Schmidt's Auto Publications. 2003. "Diesels at 40\% and Climbing," AID Newsletter, no. 0302, Warwick, England, and on-line update, "Diesel Car Prospects to 2009," May 17, 2003, www.eagleaid.com/dsltxt.htm.

Toyota Motor Sales, U.S.A., Inc. 2004. "The 2004 Prius - A Wildly Successful Launch!” PRIUS View, Issue 5, Spring 2004, p. 1.

Toyota Motor Sales, U.S.A., Inc. 2003. "Toyota Prius Hybrid Production Increased by 31 Percent for U.S. Market," www.toyota.com/about/news/product/2003/12/08-1-PriusProduction.html, December 10. 

APPENDIX A

CALCULATION OF CONFIGURATION AND CLASS CONSTANTS 



\section{APPENDIX A}

\section{CALCULATION OF CONFIGURATION AND CLASS CONSTANTS}

Given the base year market shares for every configuration, the measured attributes of configurations, and the calculated attribute weights, an intercept term can be estimated for each configuration that causes the NMNL model predictions to exactly match base year sales. These intercept terms reflect the average value of all unmeasured attributes. The same can be done to insure that the NMNL model exactly predicts base year vehicle class shares.

Let $p_{o}$ be the base year sales share of an arbitrarily chosen reference configuration. The logarithm of the ratio of any configuration's market share to the reference market share is equal to the difference in the utility indices of the two vehicles.

$$
\ln \left(\frac{p_{i}}{p_{o}}\right)=\ln \left(\frac{e^{U_{i}}}{e^{U_{o}}}\right)=U_{i}-U_{o}=A_{i}-A_{o}+\Delta U_{i}
$$

Equation A-1

In equation $\mathrm{A}-2, \Delta \mathrm{U}_{\mathrm{i}}$ is the difference of the measured utility indices of configuration $\mathrm{i}$ and the reference configuration. Solving for $A_{i}$, and summing over all configurations, $i=1, n$, and imposing the additional condition that $\sum A_{i}=0$, gives an equation that can be solved for $A_{0}$.

$$
A_{o}=\frac{1}{n}\left(\sum_{i=1}^{n}\left(\Delta U_{i}-\ln \left(\frac{p_{i}}{p_{o}}\right)\right)\right)
$$

Equation A-2

Inserting this value for $A_{o}$ back into equation $A-1$ yields the equation for estimating all remaining $\mathrm{A}_{\mathrm{i}}$ 's.

$$
A_{i}=A_{o}+\ln \left(\frac{p_{i}}{p_{o}}\right)-\Delta U_{i}
$$

Equation A-3

Estimation of vehicle class constants follows the same method; the difference of the expected class utilities are used in place of $\Delta \mathrm{U}_{\mathrm{i}}$.

\section{CALCULATION OF AVERAGE CONSTANT TERMS}

The average configuration is intended to be a vehicle that is typical of (or the average of) all the configurations of a make and model with respect to all attributes not explicitly included in the vehicle choice model (i.e., other than price, fuel economy, range, fuel availability and torque). 
The average nameplate constant was defined as follows. Let the average share for the $i=1, n_{i}$ configurations of nameplate i be $\boldsymbol{S}_{\mathrm{i}}$.

$$
\boldsymbol{S}_{i}=\frac{1}{n_{i}} \sum_{i=1}^{n_{i}} \frac{e^{U_{i}}}{\sum_{j=1}^{n_{i}} e^{U_{j}}} \quad \text { and } \quad U_{i}=A_{i}+\sum_{k=1}^{K} b_{k} x_{i k}=A_{i}+Y_{i}
$$

Equation A-4

We wish to find an average constant term, A, such that if every configuration of nameplate $\mathrm{i}$ had a constant term equal to $\mathbf{A}$, nameplate i would have exactly the same average share, $\boldsymbol{S}_{\mathrm{i}}$.

$$
\begin{gathered}
\sum_{i=1}^{n_{i}} e^{A_{i}+Y_{i}}=\sum_{i=1}^{n_{i}} e^{A} e^{Y_{i}} \\
A=\ln \left[\frac{\sum_{i=1}^{n_{i}} e^{A_{i}+Y_{i}}}{\sum_{i=1}^{n_{i}} e^{Y_{i}}}\right]
\end{gathered}
$$

Equation A-5

A is the average unobserved value of the configurations of nameplate $i$. It is not the constant term that would give a vehicle with the average observed characteristics of the configurations of nameplate $i$ the average market share of those configurations. 


\section{APPENDIX B}

\section{ASSUMED PRODUCT INTRODUCTIONS}





\title{
APPENDIX B
}

\section{ASSUMED PRODUCT INTRODUCTIONS}

\author{
Makes, Models, Configurations of Hybrid and Diesel Light-Duty Vehicles \\ Assumed to Be Available in 2008 "Best Guess Scenario"
}

2008 Hybrid Cars

\begin{tabular}{|c|c|c|c|c|c|}
\hline Manufacturer & Division & Name & $\begin{array}{l}2002 \\
\text { Sales }\end{array}$ & $\begin{array}{l}2002 \\
\text { Price }\end{array}$ & $\begin{array}{c}\text { Hybrid } \\
\text { Type }\end{array}$ \\
\hline DCC & Mer-Benz & A-Class & 24,000 & $\$ 22,500$ & ISAD \\
\hline GMC & Chevy & Cavalier & 210,244 & $\$ 15,890$ & SS \\
\hline Honda & Honda & Civic FIT & 20,000 & $\$ 14,860$ & IMA \\
\hline Honda & Honda & Civic FIT & 10,000 & $\$ 13,860$ & IMA \\
\hline Toyota & Toyota & Echo & 9,229 & $\$ 11,780$ & SS \\
\hline Toyota & Toyota & Echo & 23,266 & $\$ 11,385$ & SS \\
\hline VWA & VWA & Jetta & 47,846 & $\$ 18,775$ & ISAD \\
\hline VWA & VWA & Jetta Wagon & 5,605 & $\$ 19,575$ & ISAD \\
\hline GMC & Pontiac & Grand Am & 2,059 & $\$ 18,465$ & SS \\
\hline GMC & Pontiac & Grand Am & 67,168 & $\$ 19,290$ & SS \\
\hline GMC & Saturn & L100/200 & 63,071 & $\$ 19,065$ & SS \\
\hline GMC & Saturn & LW200 & 5,552 & $\$ 20,130$ & SS \\
\hline GMC & Saturn & LW200 & 364 & $\$ 19,270$ & SS \\
\hline Honda & Acura & Acura $3.2 \mathrm{TL}$ & 60,860 & $\$ 28,880$ & IMA \\
\hline Honda & Honda & Civic $d x$ 4Dr & 107,863 & $\$ 14,060$ & IMA \\
\hline Toyota & Lexus & ES 300 & 70,517 & $\$ 33,065$ & FULL \\
\hline Toyota & Toyota & Prius & 22,737 & $\$ 19,995$ & FULL \\
\hline FMC & Ford & Taurus & 54,537 & $\$ 22,445$ & FULL \\
\hline FMC & Ford & Taurus Wagon & 9,942 & $\$ 21,495$ & FULL \\
\hline FMC & Mazda & 626 & 35,363 & $\$ 19,525$ & FULL \\
\hline FMC & Mazda & 626 & 12,787 & $\$ 22,425$ & FULL \\
\hline FMC & Mercury & Sable & 59,858 & $\$ 20,020$ & FULL \\
\hline FMC & Mercury & Sable Wagon & 4,201 & $\$ 23,560$ & FULL \\
\hline GMC & Chevy & Malibu & 144,946 & $\$ 19,855$ & SS \\
\hline Honda & Honda & Accord & 122,800 & $\$ 25,300$ & IMA \\
\hline Nissan & Nissan & Altima & 146,503 & $\$ 18,849$ & FULL \\
\hline Toyota & Toyota & Camry & 93,460 & $\$ 23,700$ & FULL \\
\hline
\end{tabular}

2008 Hybrid Trucks

\begin{tabular}{lllrrl}
\hline Manufacturer & Division & \multicolumn{1}{c}{ Name } & $\begin{array}{c}\text { 2002 } \\
\text { Sales }\end{array}$ & $\begin{array}{c}\text { 2002 } \\
\text { Price }\end{array}$ & $\begin{array}{c}\text { Hybrid } \\
\text { Type }\end{array}$ \\
\hline Honda & Honda & Odyssey & 148,857 & $\$ 26,750$ & IMA \\
Toyota & Toyota & Sienna & 85,417 & $\$ 28,012$ & FULL \\
FMC & Ford & Escape 4x2 & 67,376 & $\$ 22,075$ & FULL \\
GMC & Chevrolet & Blazer 2WD & 1,394 & $\$ 25,005$ & SS \\
GMC & Chevrolet & Blazer 2WD & 36,159 & $\$ 26,005$ & SS \\
GMC & Chevrolet & Blazer 4WD & 437 & $\$ 27,005$ & SS \\
GMC & Chevrolet & Blazer 4WD & 65,351 & $\$ 28,005$ & SS \\
GMC & Saturn & Vue AWD & 1,052 & $\$ 18,860$ & SS \\
GMC & Saturn & Vue FWD & 717 & $\$ 17,265$ & SS \\
\hline
\end{tabular}




\begin{tabular}{lllrrl}
\hline Manufacturer & Division & \multicolumn{1}{c}{ Name } & Sales & Price & $\begin{array}{c}\text { Hybrid } \\
\text { Type }\end{array}$ \\
\hline Honda & Honda & CR-V & 29,053 & $\$ 19,050$ & IMA \\
Honda & Honda & CR-V & 99,884 & $\$ 20,250$ & IMA \\
TKM & Mazda & Tribute 4x2 & 22,249 & $\$ 21,485$ & FULL \\
TKM & Mazda & Tribute 4x4 & 24,854 & $\$ 22,685$ & FULL \\
Toyota & Toyota & Highlander 2WD & 42,567 & $\$ 25,460$ & FULL \\
Toyota & Toyota & Rav4 2WD & 48,231 & $\$ 17,575$ & FULL \\
Toyota & Toyota & Rav4 4WD & 39,291 & $\$ 18,975$ & FULL \\
GMC & Chevrolet & C1500 Tahoe 2WD & 61,519 & $\$ 33,409$ & FULL \\
GMC & GMC & C1500 Yukon 2WD & 7,193 & $\$ 33,596$ & FULL \\
GMC & GMC & K1500 Yukon 4WD & 1,746 & $\$ 34,996$ & FULL \\
GMC & Chevrolet & C1500 Suburban 2WD & 49,314 & $\$ 36,143$ & FULL \\
GMC & Chevrolet & K1500 Suburban 4WD & 71,668 & $\$ 38,209$ & FULL \\
GMC & Chevrolet & K1500 Tahoe 4WD & 5,017 & $\$ 35,475$ & FULL \\
GMC & GMC & C1500 Yukon XL 2WD & 16,472 & $\$ 36,501$ & FULL \\
GMC & GMC & K1500 Yukon XL 4WD & 22,731 & $\$ 39,034$ & FULL \\
\hline
\end{tabular}

\section{Diesel Cars}

\begin{tabular}{|c|c|c|c|c|}
\hline Manufacturer & Division & Name & $\begin{array}{l}2002 \\
\text { Sales }\end{array}$ & $\begin{array}{l}2002 \\
\text { Price }\end{array}$ \\
\hline DCC & Mer-Benz & A-Class & 24,000 & $\$ 22,500$ \\
\hline VWA & VWA & Golf & 3,255 & $\$ 15,250$ \\
\hline VWA & VWA & Golf TDI & 1,655 & $\$ 17,420$ \\
\hline VWA & VWA & Golf TDI & 6,025 & $\$ 16,545$ \\
\hline VWA & VWA & Jetta & 7,133 & $\$ 18,950$ \\
\hline VWA & VWA & Jetta & 11,326 & $\$ 20,135$ \\
\hline VWA & VWA & Jetta & 1,102 & $\$ 24,700$ \\
\hline VWA & VWA & Jetta Wagon & 340 & $\$ 21,000$ \\
\hline VWA & VWA & New Beetle & 4,766 & $\$ 18,775$ \\
\hline VWA & Audi & Audi A4 & 1,174 & $\$ 33,190$ \\
\hline VWA & VWA & Passat & 8,167 & $\$ 21,750$ \\
\hline VWA & VWA & Passat Wagon & 8,379 & $\$ 23,625$ \\
\hline VWA & VWA & Passat Wagon & 695 & $\$ 25,050$ \\
\hline BMW & BMW & $525 i$ & 12,579 & $\$ 38,275$ \\
\hline DCC & Mer-Benz & C320 & 12,483 & $\$ 38,135$ \\
\hline DCC & Mer-Benz & E 320 & 14,749 & $\$ 48,450$ \\
\hline DCC & Mer-Benz & S 430 & 14,919 & $\$ 71,850$ \\
\hline VWA & Audi & Audi A6 & 2,529 & $\$ 36,400$ \\
\hline VWA & Audi & Audi A6 & 1,412 & $\$ 50,650$ \\
\hline VWA & Audi & Audi A6 Avant & 2,148 & $\$ 39,350$ \\
\hline
\end{tabular}

2008 Diesel Trucks

\begin{tabular}{lllrr}
\hline & & & $\mathbf{2 0 0 2}$ & $\mathbf{2 0 0 2}$ \\
Manufacturer & \multicolumn{1}{c}{ Division } & \multicolumn{1}{c}{ Name } & Sales & Price \\
\hline DCC & Jeep & Liberty 2WD & 46,124 & $\$ 22,994$ \\
DCC & Jeep & Liberty 4WD & 157,615 & $\$ 24,479$ \\
DCC & Jeep & Wrangler & 25,831 & $\$ 19,860$ \\
Isuzu & Isuzu & Trooper & 7,917 & $\$ 29,405$ \\
FMC & Ford & Expedition 4x2 & 32,851 & $\$ 30,430$ \\
\hline
\end{tabular}




\begin{tabular}{lllrr}
\hline Manufacturer & \multicolumn{1}{c}{ Division } & \multicolumn{1}{c}{ Name } & $\begin{array}{r}\mathbf{2 0 0 2} \\
\text { Sales }\end{array}$ & $\begin{array}{r}\mathbf{2 0 0 2} \\
\text { Price }\end{array}$ \\
\hline FMC & Ford & Expedition 4x4 & 4,096 & $\$ 33,300$ \\
GMC & Chevrolet & C1500 Tahoe 2WD & 14,214 & $\$ 32,709$ \\
GMC & Chevrolet & K1500 Tahoe 4WD & 97,036 & $\$ 27,857$ \\
GMC & GMC & C1500 Yukon 2WD & 16,240 & $\$ 34,296$ \\
GMC & GMC & K1500 Yukon 4WD & 24,313 & $\$ 34,996$ \\
DCC & Dodge & Dakota 2WD & 43,412 & $\$ 19,625$ \\
DCC & Dodge & Dakota 4WD & 16,789 & $\$ 22,835$ \\
FMC & Ford & F150 4x2 & 108,687 & $\$ 22,520$ \\
FMC & Ford & F150 4x4 & 35,368 & $\$ 25,935$ \\
GMC & Chevrolet & C1500 Silverado 2WD & 72,250 & $\$ 24,184$ \\
GMC & Chevrolet & K1500 Silverado 4WD & 150,295 & $\$ 27,134$ \\
GMC & GMC & C1500 Sierra 2WD & 22,782 & $\$ 21,868$ \\
GMC & GMC & K1500 Sierra 4WD & 44,469 & $\$ 26,435$ \\
Nissan & Nissan & Titan 4x2 & 40,000 & $\$ 24,000$ \\
Nissan & Nissan & Titan 4x4 & 22,000 & $\$ 26,500$ \\
Toyota & Toyota & Toyota Tundra 2WD & 42,344 & $\$ 22,975$ \\
DCC & Mer-Benz & ML 320 & 30,686 & $\$ 37,595$ \\
Toyota & Toyota & Land Cruiser Wagon 4 & 6,331 & $\$ 52,595$ \\
VWA & Audi & Allroad Quattro & 4,463 & $\$ 40,950$ \\
\hline
\end{tabular}

\section{Makes, Models, Configurations of Hybrid and Diesel Light-Duty Vehicles Assumed to be Available in 2012 "Best Guess" Scenario}

\section{Hybrid Cars and Trucks}

\begin{tabular}{|c|c|c|c|c|c|}
\hline Manufacturer & Division & Name & $\begin{array}{l}2002 \\
\text { Sales }\end{array}$ & $\begin{array}{l}2002 \\
\text { Price }\end{array}$ & $\begin{array}{c}\text { Hybrid } \\
\text { Type }\end{array}$ \\
\hline DCC & Mer-Benz & A-Class & 24,000 & $\$ 22,500$ & ISAD \\
\hline FMC & Ford & Escort & 40,921 & $\$ 15,015$ & SS \\
\hline GMC & Chevy & Cavalier & 210,244 & $\$ 15,890$ & SS \\
\hline Honda & Acura & RSX & 16,507 & $\$ 21,850$ & IMA \\
\hline Honda & Honda & Civic ex & 540 & $\$ 14,860$ & IMA \\
\hline Honda & Honda & Civic ex & 960 & $\$ 13,860$ & IMA \\
\hline Nissan & Nissan & New Model & 12,000 & $\$ 11,750$ & SS \\
\hline Nissan & Nissan & New Model & 28,000 & $\$ 12,650$ & SS \\
\hline Toyota & Toyota & Echo & 9,229 & $\$ 11,780$ & SS \\
\hline Toyota & Toyota & Echo & 23,266 & $\$ 11,385$ & SS \\
\hline VWA & VWA & Jetta & 47,846 & $\$ 18,775$ & ISAD \\
\hline VWA & VWA & Jetta Wagon & 5,605 & $\$ 19,575$ & ISAD \\
\hline BMW & BMW & $325 i$ & 30,738 & $\$ 29,425$ & ISAD \\
\hline DCC & Dodge & Neon & 103,205 & $\$ 15,090$ & ISAD \\
\hline DCC & Dodge & Neon & 16,048 & $\$ 15,915$ & ISAD \\
\hline FMC & Ford & Focus & 83,424 & $\$ 16,050$ & SS \\
\hline FMC & Ford & Focus & 95,367 & $\$ 16,050$ & SS \\
\hline FMC & Ford & Focus Wagon & 33,265 & $\$ 17,565$ & SS \\
\hline FMC & Volvo & S60 & 20,570 & $\$ 27,125$ & FULL \\
\hline GMC & Pontiac & Grand Am & 2,059 & $\$ 18,465$ & SS \\
\hline GMC & Pontiac & Grand Am & 67,168 & $\$ 19,290$ & SS \\
\hline GMC & Saturn & L100/200 & 63,071 & $\$ 19,065$ & SS \\
\hline GMC & Saturn & LW200 & 5,552 & $\$ 20,130$ & SS \\
\hline GMC & Saturn & LW200 & 364 & $\$ 19,270$ & SS \\
\hline Honda & Acura & Acura 3.2TL & 60,860 & $\$ 28,880$ & IMA \\
\hline
\end{tabular}




\begin{tabular}{|c|c|c|c|c|c|}
\hline Manufacturer & Division & Name & Sales & Price & $\begin{array}{c}\text { Hybrid } \\
\text { Type }\end{array}$ \\
\hline Honda & Honda & Civic $d x 4 D r$ & 107,863 & $\$ 14,060$ & IMA \\
\hline Suzuki & Suzuki & Aerio & 7,529 & $\$ 14,491$ & SS \\
\hline Suzuki & Suzuki & Aerio & 1,652 & $\$ 13,571$ & SS \\
\hline Suzuki & Suzuki & Aerio SX & 1,229 & $\$ 13,847$ & SS \\
\hline Suzuki & Suzuki & Aerio SX & 3,256 & $\$ 14,767$ & SS \\
\hline Toyota & Lexus & ES 300 & 70,517 & $\$ 33,055$ & FULL \\
\hline Toyota & Toyota & Camry Solara & 12,719 & $\$ 22,485$ & FULL \\
\hline Toyota & Toyota & Prius & 22,737 & $\$ 19,995$ & FULL \\
\hline VWA & Audi & Audi A4 & 1,174 & $\$ 33,190$ & ISAD \\
\hline DCC & Chrysler & $300 \mathrm{M}$ & 36,663 & $\$ 28,415$ & FULL \\
\hline DCC & Chrysler & Concorde & 14,548 & $\$ 22,510$ & FULL \\
\hline DCC & Dodge & Intrepid & 91,428 & $\$ 20,520$ & FULL \\
\hline FMC & Ford & Taurus & 54,537 & $\$ 22,445$ & FULL \\
\hline FMC & Ford & Taurus Wagon & 9,942 & $\$ 21,495$ & FULL \\
\hline FMC & Lincoln & Lincoln LS & 12,363 & $\$ 33,220$ & FULL \\
\hline FMC & Mazda & 626 & 35,363 & $\$ 19,525$ & FULL \\
\hline FMC & Mazda & 626 & 12,787 & $\$ 22,425$ & FULL \\
\hline FMC & Mercury & Sable & 59,858 & $\$ 20,020$ & FULL \\
\hline FMC & Mercury & Sable Wagon & 4,201 & $\$ 23,560$ & FULL \\
\hline GMC & Buick & LaSabre & 137,737 & $\$ 24,495$ & FULL \\
\hline GMC & Chevy & Impala & 118,204 & $\$ 20,540$ & FULL \\
\hline GMC & Chevy & Malibu & 144,946 & $\$ 19,855$ & SS \\
\hline GMC & Pontiac & Bonneville & 37,343 & $\$ 28,890$ & FULL \\
\hline Honda & Honda & Accord & 122,800 & $\$ 25,300$ & IMA \\
\hline Hyundai & Hyundai & Sonata & 49,666 & $\$ 18,824$ & FULL \\
\hline Mitsubishi & Mitsubishi & Galant & 80,656 & $\$ 18,517$ & $\mathrm{Y}$ \\
\hline Nissan & Nissan & Altima & 146,503 & $\$ 18,849$ & FULL \\
\hline Nissan & Nissan & Maxima & 79,206 & $\$ 25,449$ & FULL \\
\hline Toyota & Toyota & Camry & 93,460 & $\$ 23,700$ & FULL \\
\hline VWA & VWA & Passat & 8,167 & $\$ 21,750$ & ISAD \\
\hline VWA & VWA & Passat & 14,544 & $\$ 25,325$ & ISAD \\
\hline VWA & VWA & Passat Wagon & 8,379 & $\$ 23,625$ & ISAD \\
\hline BMW & BMW & $525 i$ & 12,579 & $\$ 38,275$ & ISAD \\
\hline $\mathrm{DCC}$ & Mer-Benz & C320 & 12,483 & $\$ 38,135$ & FULL \\
\hline DCC & Mer-Benz & E 320 & 14,749 & $\$ 48,450$ & FULL \\
\hline DCC & Mer-Benz & S 430 & 14,919 & $\$ 71,850$ & FULL \\
\hline FMC & Volvo & $\mathrm{S} 80$ & 10,790 & $\$ 38,450$ & FULL \\
\hline GMC & Cadillac & Seville & 25,128 & $\$ 44,039$ & FULL \\
\hline Toyota & Lexus & LS 430 & 27,162 & $\$ 54,405$ & FULL \\
\hline VWA & Audi & Audi A6 & 2,529 & $\$ 36,400$ & ISAD \\
\hline VWA & Audi & Audi A6 Avant & 2,148 & $\$ 39,350$ & ISAD \\
\hline DCC & Chrysler & Town \& Country 2WD & 69,325 & $\$ 26,240$ & FULL \\
\hline DCC & Dodge & Grand Caravan 2WD & 23,583 & $\$ 24,950$ & FULL \\
\hline FMC & Ford & Windstar Van & 18,364 & $\$ 20,250$ & FULL \\
\hline FMC & Ford & Windstar Wagon & 4,232 & $\$ 28,625$ & FULL \\
\hline FMC & Mercury & Villager Wagon & 142,042 & $\$ 24,340$ & FULL \\
\hline Honda & Honda & Odyssey & 148,857 & $\$ 26,750$ & IMA \\
\hline Nissan & Nissan & Quest & 21,099 & $\$ 27,194$ & FULL \\
\hline Toyota & Toyota & Sienna & 85,417 & $\$ 28,012$ & FULL \\
\hline DCC & Chrysler & PT Cruiser & 22,197 & $\$ 17,990$ & SS \\
\hline DCC & Chrysler & PT Cruiser & 147,362 & $\$ 18,815$ & SS \\
\hline DCC & Chrysler & Pacifica & 40,000 & $\$ 28,845$ & FULL \\
\hline DCC & Chrysler & Pacifica & 20,000 & $\$ 32,300$ & FULL \\
\hline DCC & Jeep & Grand Cherokee 2WD & 39,048 & $\$ 25,425$ & FULL \\
\hline DCC & Jeep & Grand Cherokee 4WD & 91,965 & $\$ 27,395$ & FULL \\
\hline FMC & Ford & Escape $4 \times 2$ & 67,376 & $\$ 22,075$ & FULL \\
\hline
\end{tabular}




\begin{tabular}{|c|c|c|c|c|c|}
\hline Manufacturer & Division & Name & $\begin{array}{l}2002 \\
\text { Sales }\end{array}$ & $\begin{array}{l}2002 \\
\text { Price }\end{array}$ & $\begin{array}{c}\text { Hybrid } \\
\text { Type }\end{array}$ \\
\hline GMC & Chevrolet & Blazer 2WD & 1,394 & $\$ 25,005$ & SS \\
\hline GMC & Chevrolet & Blazer 2WD & 36,159 & $\$ 26,005$ & SS \\
\hline GMC & Chevrolet & Blazer 4WD & 437 & $\$ 27,005$ & SS \\
\hline GMC & Chevrolet & Blazer 4WD & 65,351 & $\$ 28,005$ & SS \\
\hline GMC & Chevrolet & Trailblazer 2WD & 87,430 & $\$ 28,840$ & FULL \\
\hline GMC & Chevrolet & Trailblazer 4WD & 165,819 & $\$ 31,065$ & FULL \\
\hline GMC & GMC & Envoy 2WD & 30,715 & $\$ 31,935$ & FULL \\
\hline GMC & GMC & Envoy 4WD & 77,935 & $\$ 34,160$ & FULL \\
\hline GMC & Saturn & Vue AWD & 1,052 & $\$ 18,860$ & SS \\
\hline GMC & Saturn & Vue FWD & 717 & $\$ 17,265$ & SS \\
\hline Honda & Honda & Pilot & 80,000 & $\$ 29,470$ & IMA \\
\hline Honda & Honda & CR-V & 29,053 & $\$ 19,050$ & IMA \\
\hline Honda & Honda & CR-V & 99,884 & $\$ 20,250$ & IMA \\
\hline TKM & Mazda & Tribute $4 \times 2$ & 22,249 & $\$ 21,485$ & FULL \\
\hline TKM & Mazda & Tribute $4 \times 4$ & 24,854 & $\$ 22,685$ & FULL \\
\hline Toyota & Toyota & Highlander 2WD & 42,567 & $\$ 25,460$ & FULL \\
\hline Toyota & Toyota & Rav4 2WD & 48,231 & $\$ 17,575$ & FULL \\
\hline Toyota & Toyota & Rav4 4WD & 39,291 & $\$ 18,975$ & FULL \\
\hline GMC & Chevrolet & C1500 Tahoe 2WD & 61,519 & $\$ 33,409$ & FULL \\
\hline GMC & GMC & C1500 Yukon 2WD & 7,193 & $\$ 33,596$ & FULL \\
\hline GMC & GMC & K1500 Yukon 4WD & 1,746 & $\$ 34,996$ & FULL \\
\hline TKM & Mazda & Mazda B3000 4x2 & 7,231 & $\$ 18,070$ & FULL \\
\hline FMC & Ford & EX SP Trac 4x2 & 40,864 & $\$ 23,880$ & FULL \\
\hline FMC & Ford & EX SP Trac $4 \times 4$ & 30,725 & $\$ 26,650$ & FULL \\
\hline GMC & Chevrolet & C1500 Silverado 2WD & 85,182 & $\$ 22,689$ & FULL \\
\hline GMC & Chevrolet & K1500 Silverado 4WD & 35,847 & $\$ 25,639$ & FULL \\
\hline GMC & GMC & C1500 Sierra 2WD & 27,113 & $\$ 21,068$ & FULL \\
\hline GMC & GMC & K1500 Sierra 4WD & 9,917 & $\$ 25,635$ & FULL \\
\hline BMW & BMW & X5 3.0 & 30,564 & $\$ 41,225$ & FULL \\
\hline Honda & Acura & MDX & 48,998 & $\$ 37,300$ & IMA \\
\hline GMC & Cadillac & Escalade 2WD & 10,692 & $\$ 48,735$ & FULL \\
\hline GMC & Cadillac & Escalade AWD & 43,311 & $\$ 52,230$ & FULL \\
\hline GMC & Chevrolet & C1500Suburban 2WD & 49,314 & $\$ 36,143$ & FULL \\
\hline GMC & Chevrolet & K1500 Suburban 4WD & 71,668 & $\$ 38,209$ & FULL \\
\hline GMC & Chevrolet & K1500 Tahoe 4WD & 5,017 & $\$ 35,475$ & FULL \\
\hline GMC & GMC & C1500 Yukon XL 2WD & 16,472 & $\$ 36,501$ & FULL \\
\hline GMC & GMC & K1500 Yukon XL 4WD & 22,731 & $\$ 39,034$ & FULL \\
\hline
\end{tabular}

\section{Diesel Cars and Trucks}

\begin{tabular}{|c|c|c|c|c|}
\hline Manufacturer & Division & Name & $\begin{array}{l}2002 \\
\text { Sales }\end{array}$ & $\begin{array}{l}2002 \\
\text { Price }\end{array}$ \\
\hline DCC & Mer-Benz & A-Class & 24,000 & $\$ 22,500$ \\
\hline VWA & VWA & Golf & 3,255 & $\$ 15,250$ \\
\hline VWA & VWA & Golf TDI & 1,655 & $\$ 17,420$ \\
\hline VWA & VWA & Golf TDI & 6,025 & $\$ 16,545$ \\
\hline VWA & VWA & Jetta & 7,133 & $\$ 18,950$ \\
\hline VWA & VWA & Jetta & 11,326 & $\$ 20,135$ \\
\hline VWA & VWA & Jetta & 1,102 & $\$ 24,700$ \\
\hline VWA & VWA & Jetta Wagon & 340 & $\$ 21,000$ \\
\hline VWA & VWA & New Beetle & 4,766 & $\$ 18,775$ \\
\hline DCC & Mer-Benz & C240 & 33,611 & $\$ 31,735$ \\
\hline VWA & Audi & Audi A4 & 1,174 & $\$ 33,190$ \\
\hline
\end{tabular}




\begin{tabular}{|c|c|c|c|c|}
\hline Manufacturer & Division & Name & $\begin{array}{l}2002 \\
\text { Sales }\end{array}$ & $\begin{array}{l}2002 \\
\text { Price }\end{array}$ \\
\hline VWA & VWA & Passat & 8,167 & $\$ 21,750$ \\
\hline VWA & VWA & Passat Wagon & 8,379 & $\$ 23,625$ \\
\hline VWA & VWA & Passat Wagon & 695 & $\$ 25,050$ \\
\hline BMW & BMW & $525 i$ & 12,579 & $\$ 38,275$ \\
\hline BMW & BMW & $745 i$ & 10,575 & $\$ 67,850$ \\
\hline DCC & Mer-Benz & C320 & 12,483 & $\$ 38,135$ \\
\hline DCC & Mer-Benz & E 320 & 14,749 & $\$ 48,450$ \\
\hline DCC & Mer-Benz & S 430 & 14,919 & $\$ 71,850$ \\
\hline FMC & Jaguar & Jaguar S-Type 6 & 8,033 & $\$ 43,675$ \\
\hline VWA & Audi & Audi A6 & 2,529 & $\$ 36,400$ \\
\hline VWA & Audi & Audi A6 & 1,412 & $\$ 50,650$ \\
\hline VWA & Audi & Audi A6 Avant & 2,148 & $\$ 39,350$ \\
\hline DCC & Dodge & Durango 2WD & 16,800 & $\$ 29,320$ \\
\hline DCC & Dodge & Durango 4WD & 33,133 & $\$ 31,440$ \\
\hline DCC & Jeep & Liberty 2WD & 46,124 & $\$ 22,994$ \\
\hline DCC & Jeep & Liberty 4WD & 157,615 & $\$ 24,479$ \\
\hline DCC & Jeep & Wrangler & 25,831 & $\$ 19,860$ \\
\hline FMC & Ford & Explorer 4x2 & 125,415 & $\$ 29,190$ \\
\hline FMC & Ford & Explorer $4 \times 4$ & 217,575 & $\$ 31,155$ \\
\hline FMC & Mercury & Mountaineer 4x2 & 7,070 & $\$ 29,645$ \\
\hline FMC & Mercury & Mountaineer $4 \times 4$ & 27,422 & $\$ 31,645$ \\
\hline Isuzu & Isuzu & Trooper & 7,917 & $\$ 29,405$ \\
\hline Nissan & Nissan & Pathfinder 2WD & 15,861 & $\$ 28,999$ \\
\hline Nissan & Nissan & Pathfinder 4WD & 38,712 & $\$ 32,499$ \\
\hline Nissan & Nissan & Xterra V6 2WD & 40,628 & $\$ 24,199$ \\
\hline Nissan & Nissan & Xterra V6 4WD & 1,684 & $\$ 26,449$ \\
\hline Nissan & Nissan & Xterra V6 4WD & 34,714 & $\$ 26,199$ \\
\hline FMC & Ford & Expedition $4 \times 2$ & 32,851 & $\$ 30,430$ \\
\hline FMC & Ford & Expedition $4 \times 4$ & 4,096 & $\$ 33,300$ \\
\hline GMC & Chevrolet & C1500 Tahoe 2WD & 14,214 & $\$ 32,709$ \\
\hline GMC & Chevrolet & K1500 Tahoe 4WD & 97,036 & $\$ 27,857$ \\
\hline GMC & GMC & C1500 Yukon 2WD & 16,240 & $\$ 34,296$ \\
\hline GMC & GMC & K1500 Yukon 4WD & 24,313 & $\$ 34,996$ \\
\hline DCC & Dodge & Dakota 2WD & 43,412 & $\$ 19,625$ \\
\hline DCC & Dodge & Dakota 4WD & 16,789 & $\$ 22,835$ \\
\hline DCC & Dodge & Ram 1500 2WD & 114,196 & $\$ 19,990$ \\
\hline DCC & Dodge & Ram 1500 4WD & 55,866 & $\$ 22,730$ \\
\hline FMC & Ford & F150 4x2 & 108,687 & $\$ 22,520$ \\
\hline FMC & Ford & $\mathrm{F} 1504 \times 4$ & 35,368 & $\$ 25,935$ \\
\hline GMC & Chevrolet & C1500 Silverado 2WD & 72,250 & $\$ 24,184$ \\
\hline GMC & Chevrolet & K1500 Silverado 4WD & 150,295 & 27,134 \\
\hline GMC & GMC & C1500 Sierra 2WD & 22,782 & $\$ 21,868$ \\
\hline GMC & GMC & K1500 Sierra 4WD & 44,469 & $\$ 26,435$ \\
\hline Nissan & Nissan & Titan & 40,000 & \\
\hline Nissan & Nissan & Titan & 22,000 & \\
\hline Toyota & Toyota & Toyota Tundra 2WD & 42,344 & $\$ 22,975$ \\
\hline BMW & BMW & $\times 54.4$ & 8,246 & $\$ 50,420$ \\
\hline DCC & Mer-Benz & ML 320 & 30,686 & $\$ 37,595$ \\
\hline FMC & Lincoln & Navigator $4 \times 2$ & 9,367 & $\$ 44,590$ \\
\hline FMC & Lincoln & Navigator $4 \times 4$ & 8,517 & $\$ 48,340$ \\
\hline FMC & Rover & Range Rover 4.6 & 3,927 & $\$ 68,000$ \\
\hline GMC & Chevrolet & C1500 Suburban 2WD & 49,314 & $\$ 36,143$ \\
\hline GMC & Chevrolet & K1500 Suburban 4WD & 71,668 & $\$ 38,209$ \\
\hline GMC & GMC & K1500 Yukon XL 4WD & 22,731 & $\$ 39,034$ \\
\hline Mitsubishi & Mitsubishi & Montero & 17,461 & $\$ 35,897$ \\
\hline Nissan & Infiniti & Infiniti QX4 2WD & 4,018 & $\$ 35,150$ \\
\hline
\end{tabular}




\begin{tabular}{lllrc}
\hline Manufacturer & \multicolumn{1}{c}{ Division } & \multicolumn{1}{c}{ Name } & $\mathbf{2 0 0 2}$ & \multicolumn{1}{c}{$\mathbf{2 0 0 2}$} \\
& Infiniti & Infiniti QX4 4WD & 11,925 & $\$ 36,550$ \\
\hline Nissan & Nissan & Armada & 15,000 & $\$ 36,450$ \\
Nissan & Nissan & Armada & 25,000 & $\$ 39,250$ \\
Nissan & Toyota & Land Cruiser Wagon 4 & 6,331 & $\$ 52,595$ \\
Toyota & Toyota & Sequoia 2WD & 41,737 & $\$ 39,405$ \\
Toyota & Toyota & Sequoia 4WD & 38,158 & $\$ 42,752$ \\
Toyota & Audi & Allroad Quattro & 4,463 & $\$ 40,950$ \\
VWA & Ford & E150 Van & 20,688 & $\$ 21,430$ \\
FMC & & & \\
\hline
\end{tabular}





\section{APPENDIX C}

CHARACTERISTICS OF DIESEL AND HYBRID PRODUCT LINES FOR WHICH THERE IS NO MODEL YEAR 2002 COUNTERPART 

Table C1. Characteristics of Diesel and Hybrid Product Lines for which there is No Model Year 2002 Counterpart

\begin{tabular}{|c|c|c|c|c|c|c|c|c|c|c|c|}
\hline \multirow[b]{2}{*}{ Manufacturer } & \multirow[b]{2}{*}{ Division } & \multirow[b]{2}{*}{ Name } & \multirow[b]{2}{*}{ Class } & \multirow[b]{2}{*}{ Sales } & \multirow[b]{2}{*}{$\begin{array}{c}\text { Price } \\
(2002 \$)\end{array}$} & \multirow[b]{2}{*}{$\begin{array}{c}\text { Composite } \\
\text { MPG }\end{array}$} & \multirow[b]{2}{*}{$\begin{array}{l}\text { Torque } \\
\mathrm{Nm}\end{array}$} & \multirow{2}{*}{$\begin{array}{l}\text { Tank } \\
\text { Size } \\
\text { (gals.) }\end{array}$} & \multirow[b]{2}{*}{$\begin{array}{l}\text { Hybrid } \\
\text { Type }\end{array}$} & \multicolumn{2}{|c|}{$\begin{array}{c}\text { Year of } \\
\text { Introduction }\end{array}$} \\
\hline & & & & & & & & & & Hybrid & Diesel \\
\hline DCC & Mer-Benz & A-Class & Mini \& subcompact & 24,000 & $\$ 22,500$ & 34.8 & 205.0 & 14.0 & & 2008 & 2008 \\
\hline Nissan & Nissan & New & Mini\& subcompact & 12,000 & $\$ 11,750$ & 37.8 & 175.0 & 13.2 & Stop-start & 2012 & \\
\hline Nissan & Nissan & New & Mini \& subcompact & 28,000 & $\$ 12,650$ & 37.0 & 175.0 & 13.2 & Stop-start & 2012 & \\
\hline DCC & Chrysler & Pacifica & Small SUV & 40,000 & $\$ 28,845$ & & 340.0 & 20.0 & Full & 2012 & \\
\hline DCC & Chrysler & Pacifica & Small SUV & 20,000 & $\$ 32,300$ & & 340.0 & 20.0 & Full & 2012 & \\
\hline Honda & Honda & Pilot & Small SUV & 80,000 & $\$ 29,470$ & 22.5 & 332.2 & 19.2 & IMA & 2012 & \\
\hline Nissan & Nissan & Titan $4 \times 2$ & Large Pickup & 40,000 & $\$ 24,000$ & 18.4 & 500.0 & 24.0 & & & 2008 \\
\hline Nissan & Nissan & Titan $4 \times 4$ & Large Pickup & 22,000 & $\$ 26,500$ & 18.0 & 500.0 & 24.0 & & & 2008 \\
\hline Nissan & Nissan & Armada & Luxury Truck & 15,000 & $\$ 36,450$ & 18.4 & 500.0 & 24.0 & & & 2012 \\
\hline Nissan & Nissan & Armada & Luxury Truck & 25,000 & $\$ 39,250$ & 18.0 & 500.0 & 24.0 & & & 2012 \\
\hline
\end{tabular}

